LBL -32500

DE93 000627

\title{
Chemistry of Radiation Damage to Wire Chambers
}

\author{
Jonathan Wise \\ (Ph.D. Thesis) \\ Lawrence Berkeley Laboratory \\ University of California \\ One Cyclotron Road \\ Berkeley, CA 94720
}

August 1992

This work was supported by the Director, Office of Energy Research, Office of High Energy and Nuclear Physics, Division of High Energy Physics, of the U.5. Department of Energy under Contract No. DE-AC03-76SF00098.

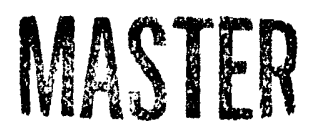




\title{
Chemistry of Radiation Damage to Wire Chambers \\ Jonathan Wise \\ (Ph.D. Thesis)
}

August 1992

\begin{abstract}
Proportional counters are used to study aspects of radiation damage to wire chambers (wire aging). Principles of low-pressure, rf plasma chemistry are used to predict the plasma chemistry in electron avalanches ( $1 \mathrm{~atm}, \mathrm{dc})$.

1. Aging is studied in $\mathrm{CF}_{4} / \mathrm{iC}_{4} \mathrm{H}_{10}$ gas mixtures. Wire deposits are analyzed by Auger electron spectroscopy. An apparent cathode aging process resulting in

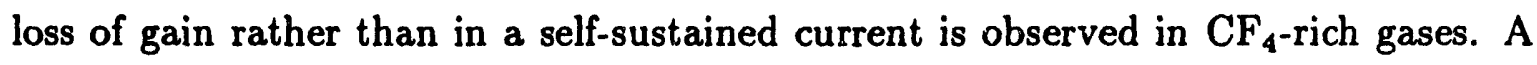
four-part model considering 1) plasma polymerization of the hydrocarbon, 2) etching of wire deposits by $\left.\mathrm{CF}_{4}, 3\right)$ acceleration of deposition processes in strongly etching environments, and 4) reactivity of the wire surface is developed to understand anode wire aging in $\mathrm{CF}_{4} / \mathrm{iC}_{4} \mathrm{H}_{10}$ gases. Practical guidelines suggested by the model are discussed.

2. Data are presented to suggest that trace amounts of Freons do not affect aging rates in either dimethyl ether or $\mathrm{Ar} / \mathrm{C}_{2} \mathrm{H}_{6}$. Apparent loss of gain is explained by attachment of primary electrons to a continuously increasing concentration of Freon 11 $\left(\mathrm{CCl}_{3} \mathrm{~F}\right)$ in the counter gas. An increase in the concentration of Freon 11 in dimethyl ether is caused by a distillation process in the gas supply bottle and is a natural consequence of the unequal volatilities of the two compounds.
\end{abstract}




\section{Acknowledgements}

Of the many people who contributed to my graduate experience, it is my thesis advisers, John Kadyk and Dennis Hess, to whom I owe the most. I am deeply indebted to them for their enthusiastic interest in my work, advice, encouragement, and patience as this thesis developed. It has been an honor to work under their guidance.

I gratefully acknowledge David Graves and Robert Ely for serving on my dissertation committee.

It is a pleasure to thank Doug Shigley for his superb management of the many mechanical needs of this project; it could not have been completed without him. Thanks go to Ron Jones for meeting all of my often-unreasonable demands for electronic equipment. Thanks also to Walt Johansen and Jeff Hull for valuable discussions.

Finally, I lay the blame for this work with my high school science teachers Dick Gray and Phil Perry. They got me started. 


\section{Contents}

Abstract

Acknowledgements $\quad$ v

1 Introduction. 1

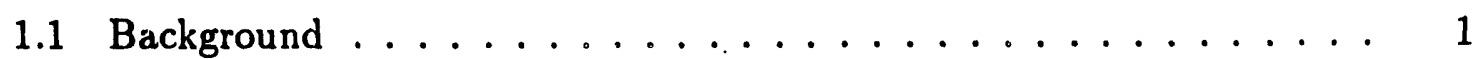

1.2 Wire Chamber Operation ................. 2

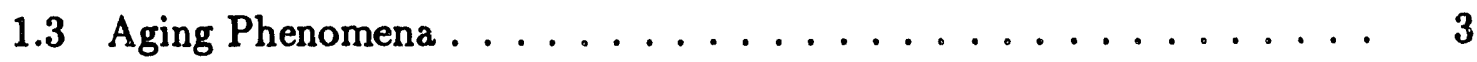

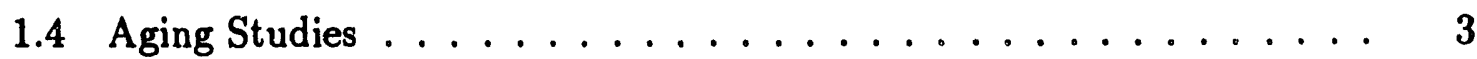

1.5 Experimental Overview ..................... 5

1.6 Thesis Organization . . . . . . . . . . . . . . 6

References ........................ 7

2 A Model for Wire Aging in CF $_{4}$-Based Gases 9

2.1 Introduction . . . . . . . . . . . . . . . . . 10

2.2 Experimental ........................ 11

2.2.1 Accelerated Aging Tests ............... 12

2.2 .2 Pulse Height . . . . . . . . . . . . . . 13

2.2.3 Analysis of Deposits .................. 13

2.3 Aging in $\mathrm{CF}_{4} \ldots \ldots \ldots \ldots \ldots \ldots$

2.3.1 Au/W Wires ............................. 18

2.3.2 Non-gold Wires ................... 21

2.3.3 Cathode Effects .................. 25

2.3.4 Etching in $\mathrm{CF}_{4} \ldots \ldots \ldots 29$ 
2.4 Deposition and Etching in $\mathrm{CF}_{4}$ /isobutane Mixtures . . . . . . 30

2.5 Chemistry of Wire Aging . . . . . . . . . . . . . . . 37

2.5.1 Chemical Model for Aging ............... 38

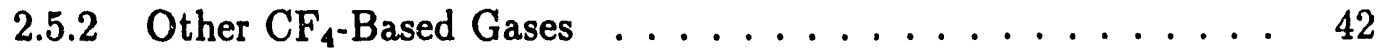

2.5.3 Other Models for Aging in $\mathrm{CF}_{4} / \mathrm{iC}_{4} \mathrm{H}_{10} \ldots \ldots \ldots$

2.5.4 Practical Guidelines ................ . 45

2.6 Copper Fluoride Film Growth . . . . . . . . . . . . . . . 46

2.7 Summary and Conclusions . . . . . . . . . . . . . . 48

References ........................ 49

3 Effects of Freons on Wire Chamber Aging 53

3.1 Introduction . . . . . . . . . . . . . . 53

3.2 Experimental ............................. 54

3.3 Aging Tests with Freons in Argon/Ethane . . . . . . . . . . 55

3.4 Dimethyl Ether ....................... 56

3.5 Rayleigh Distillation .................. 57

3.6 Simulation of Rayleigh Distillation . . . . . . . . . . 59

3.7 Aging Tests with Freon 11 in Dimethyl Ether . . . . . . . . . 60

3.8 Discussion ............................. 69

3.8 .1 Aging Results ........................ 69

3.8.2 Degradation of Energy Resolution ............ 70

3.8.3 Rayleigh Distillation ............... 71

3.9 Conclusions . . . . . . . . . . . . . . . . . 72

Acknowledgements ........................ 72

References ........................ 73

4 Summary and Conclusions $\quad 75$

4.1 Summary ......................... 75

4.2 Conclusions . . . . . . . . . . . . . . . . 75

$4.2 .1 \quad \mathrm{CF}_{4} / \mathrm{iC}_{4} \mathrm{H}_{10}$ Gases ..................... 75

4.2 .2 Dimethyl Ether . . . . . . . . . . . . 76

4.2 .3 Heating Effects .................. 76 


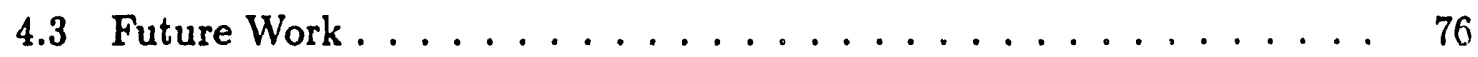

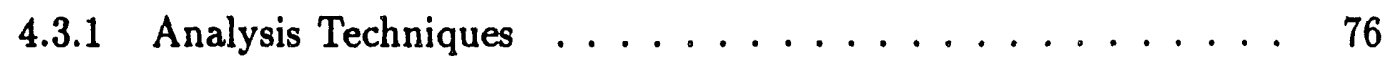

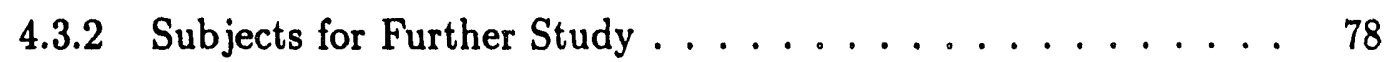

References . . . . . . . . . . . . . . . . . 80

A Heating Effects in Straw Tubes $\quad 81$

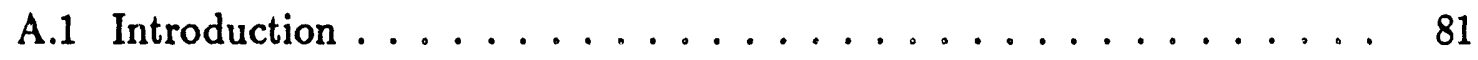

A.2 Heating Effects $\ldots \ldots \ldots \ldots \ldots \ldots \ldots \ldots \ldots$

A.3 Conclusions $\ldots \ldots \ldots \ldots \ldots \ldots \ldots \ldots$

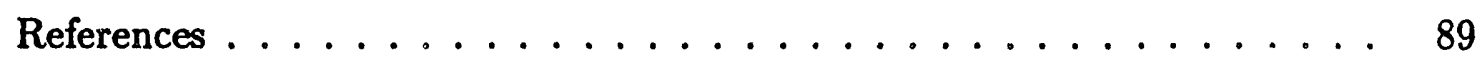

B Appearance of the Plasma in Aging Tests 91

C Wire Pretreatment Processes

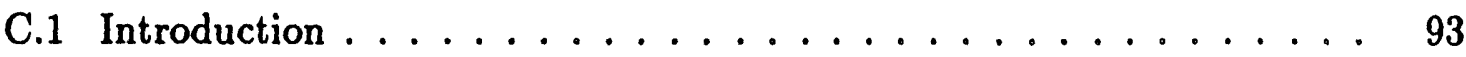

C.2 Operational Procedure . . . . . . . . . . . . . . 93

C.3 Fluorocarbon Deposition by $\mathrm{CHF}_{3} \ldots \ldots \ldots \ldots \ldots$

C.4 Fluorination by $\mathrm{SF}_{6} / \mathrm{O}_{2}(96 / 4) \ldots \ldots \ldots \ldots \ldots$

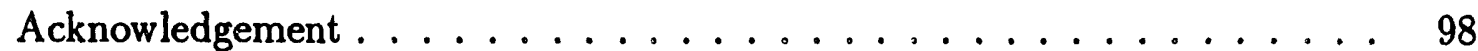

References . . . . . . . . . . . . . . . . . . . . . 102

D Procedures for Aging Tests 103

D.1 Introduction . . . . . . . . . . . . . . . . . . 103

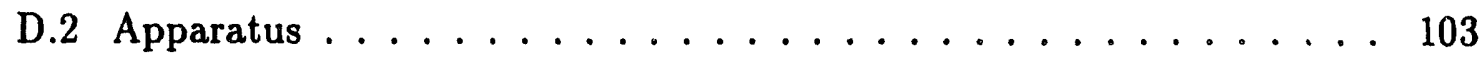

D.3 Wire Chamber . . . . . . . . . . . . . . . . . . . 109

D.4 Gas Plumbing and Safety Shutoff System . . . . . . . . . 110

D.5 Test Startup Procedures . . . . . . . . . . . . . . . . . 112

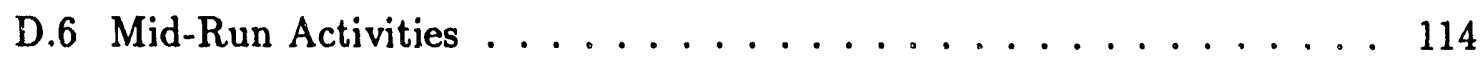

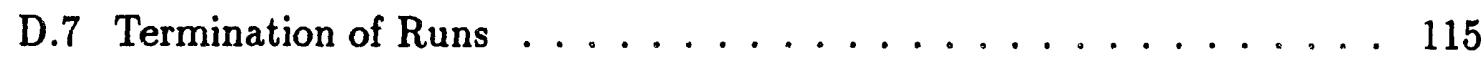

D.8 Addresses of Suppliers $\ldots \ldots \ldots \ldots \ldots \ldots \ldots$

References . . . . . . . . . . . . . . . . . 117 


\section{List of Tables}

2.1 Interruptions of aging tests with $\mathrm{CF}_{4} \ldots \ldots \ldots \ldots \ldots$

2.2 Aging transients in $\mathrm{CF}_{4}$ with $\mathrm{Al}$ cathodes $\ldots \ldots \ldots \ldots \ldots 28$

2.3 Recovery results for $\mathrm{Au} / \mathrm{W}$ wires in $\mathrm{CF}_{4} / \mathrm{iC}_{4} \mathrm{H}_{10}$ gases $\ldots \ldots \ldots . . .36$

2.4 Recovery results for $\mathrm{Au} / \mathrm{W}$ wires in fluorine-containing gases . . . . 43

2.5 Aging properties and atomic composition ratios . . . . . . . . 44

3.1 Aging results with halogenated additives in $\mathrm{Ar} / \mathrm{C}_{2} \mathrm{H}_{6} \ldots \ldots \ldots$

3.2 Predicted relative volatility of DME/Freon $11 \ldots \ldots$

3.3 Numerical solution to Rayleigh distillation equation . . . . . . . . 61

A.1 Measurements of heating effects in straw tube . . . . . . . 86

A.2 Aging in straw tube as function of gas flow rate $\ldots \ldots \ldots . \ldots 88$

C.1 Thickness measurements on $\mathrm{Si}$ wafers treated in $\mathrm{SF}_{6} / \mathrm{O}_{2} \ldots \ldots .98$ 


\section{List of Figures}

2.1 Typical aging curves in $\mathrm{CF}_{4}$ and $\mathrm{CF}_{4} / \mathrm{iC}_{4} \mathrm{H}_{10} \ldots \ldots \ldots \ldots$

2.2 Decay constants and gain changes for various anode materials $\ldots .17$

2.3 Current, pulse height, and energy resolution of $\mathrm{Au} / \mathrm{W}$ wire $\ldots \ldots 19$

2.4 AES spectrum and depth profile of $\mathrm{Au} / \mathrm{W}$ wire $\ldots \ldots \ldots 20$

2.5 Photos of $\mathrm{Au} / \mathrm{W}$ wires aged in $\mathrm{CF}_{4} \ldots \ldots \ldots \ldots \ldots \ldots \ldots \ldots$

2.6 Current, pulse height, and energy resolution of $\mathrm{Cu}$ wire . . . . . 23

2.7 AES depth profiles of $\mathrm{Cu}$ and $\mathrm{Al}$ wires aged in $\mathrm{CF}_{4} \ldots \ldots \ldots 24$

2.8 Photos of Ni wires $\ldots \ldots \ldots \ldots \ldots \ldots \ldots \ldots \ldots$

2.9 Effect of new anode wires in aged cathode shell $\ldots \ldots \ldots \ldots 27$

2.10 Photos of $\mathrm{Au} / \mathrm{W}$ wires aged in $\mathrm{CF}_{4} / \mathrm{iC}_{4} \mathrm{H}_{10}$ mixtures $\ldots \ldots \ldots 31$

2.11 AES spectrum of $\mathrm{Au} / \mathrm{W}$ wire aged in $\mathrm{CF}_{4} / \mathrm{iC}_{4} \mathrm{H}_{10}(95 / 5) \ldots \ldots 32$

2.12 Photos of non-gold wires aged in $\mathrm{CF}_{4} / \mathrm{iC}_{4} \mathrm{H}_{10}$ mixtures $\ldots \ldots \ldots 33$

2.13 AES depth profile of $\mathrm{Ni}$ wire aged in $\mathrm{CF}_{4} / \mathrm{iC}_{4} \mathrm{H}_{10}(95 / 5) \ldots \ldots$

2.14 Aging (recovery) rates as a function of gas composition . . . . . 36

2.15 Model of anode aging in $\mathrm{CF}_{4} /$ hydrocarbon gases . . . . . . 41

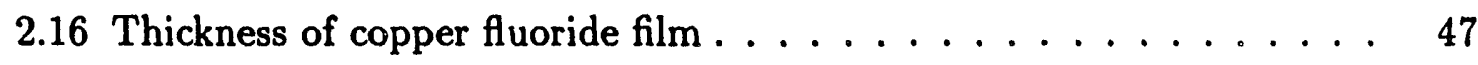

3.1 Aging test with Freon 11 at varying levels $\ldots \ldots \ldots \ldots 56$

3.2 Aging test with 5 ppm Freon 11 in DME . . . . . . . . 62

$3.3{ }^{55} \mathrm{Fe}$ pulse height spectra after DME aging with Freon $11 \ldots \ldots 3$

$3.4{ }^{55} \mathrm{Fe}$ pulse height spectrum after DME aging without Freon $11 \ldots 64$

3.5 Aging test in which all liquid DME was used . . . . . . . . 64

$3.6{ }^{55} \mathrm{Fe}$ pulse height spectrum after two tests using all liquid DME . . 65

3.7 Enrichment multiples of Freon 11 in DME . . . . . . . . . . 67

A.1 Estimate of carbon-wire anode temperature $\ldots \ldots \ldots \ldots$ 
A.2 Cross-sectional view of the feedthrough pin . . . . . . . . 87

A.3 Gain in straw tube as function of gas flow rate . . . . . . . . . . 88

C.1 Three-view drawing of wire support device . . . . . . . . . . . . . 94

C.2 Film thicknesses deposited from $\mathrm{CHF}_{3} \ldots \ldots \ldots$

C.3 Surface roughness profiles of $\mathrm{Si}$ wafers treated in $\mathrm{SF}_{6} / \mathrm{O}_{2} \ldots \ldots$

C.4 AES depth profiles of fluorinated Ni wires . . . . . . . . . 100

C.5 AES depth profiles of oxidized $\mathrm{Cu}$ wires . . . . . . . . . . . 101

D.1 Schematic of wire aging test system . . . . . . . . . . . . . 104

D.2 Test proportional counters . . . . . . . . . . . . . 105

D.3 Schematic of HV distribution box . . . . . . . . . . . . 110 


\section{Chemistry of Radiation Damage to Wire Chambers}




\section{Chapter 1}

\section{Introduction}

\subsection{Background}

Wire chambers are detectors that were developed for charged-particle detection and tracking. An important application of these devices is in modern high-energy physics experiments, where very large (on the order of $10^{5}$ wires), and consequently very expensive, wire chambers are normally a component of the experimental detector. Wire chamber technology is also used in other fields, including astrophysics, biological diagnostics, and medical imaging.

A wire chamber is essentially a matrix of wires in an enclosure filled with a gas, usually at atmospheric pressure. Electrons created by ionizing events within the gas volume can be detected on the wires. For particle tracking applications, the times at which electrons are detected on different wires and knowledge of the locations of the wires are used to reconstruct the path followed by the particle.

During the course of experiments using wire chambers, it is common to encounter problems that limit their useful lifetime. Although there are several manifestations of these problems, including loss of gain, loss of gain uniformity, loss of energy resolution, excessive and self-sustained currents, sparking, etc., the generic term "aging" is used to describe all forms of performance degradation.

Wire chambers are radiation detectors and $i \hat{t}$ is ironic that they can be damaged in their normal mode of operation. Although aging problems are widespread, the 
degree of aging experienced by different chambers has varied widely. The fact that there are some cases in which little aging has occurred has given hope that solutions to the aging problem might be found and encouraged searches for conditions under which little aging would occur.

\subsection{Wire Chamber Operation}

It is useful to have a qualitative understanding of the electron avalanche to understand wire aging phenomena. Most other details of the theory and physics of wire chambers are not relevant to this work and the interested reader is referred elsewhere [1].

The electron avalanche is the mechanism for the process of gas gain, wherein a single electron is converted to a pulse of, typically, $10^{4}-10^{5}$ electrons. Briefly, an avalanche is initiated when an electron drifting in a gas enters a region of sufficiently high electric field $\left(\sim 10^{5} \mathrm{~V} / \mathrm{cm}\right.$ at atmospheric pressure) near an anode wire that it gains enough energy to undergo ionizing collisions with gas molecules, thereby freeing more electrons. These electrons move closer to the anode wire, where the electric field is even stronger $(E \sim 1 / r)$, and ionize more molecules, releasing still more electrons. This process repeats until all of the electrons are collected at the anode, producing a detectable pulse of electric charge. The gain is simply the amplification factor of the avalanche.

In very simplified terms, a wire chamber is a gas-filled three-dimensional array of thin anode wires and cathodes (either wires or continuous surfaces). The anode/cathode array establishes an electric field appropriate to the desired detection task. When a sufficiently energetic charged particle passes through the chamber, it ionizes some of the gas molecules along its path, leaving a thin ionization trail (particle track). The electrons freed by this ionization drift towards an anode where they initiate avalanches and are thus detected. Since the velocity of drifting electrons is known, the measured time of drift determines the position of the track relative to the wire. From such measurements on many wires, the track of the detected particle can be completely reconstructed. 


\subsection{Aging Phenomena}

In addition to the free electrons, the avalanche also creates reactive species, primarily radicals and ions, that may undergo a large variety of reactions leading to a modification of the wire surface (reaction with the wire surface material, polymerization and deposition onto the wire, etc.). Positive ions, affected by the electric field, drift towards the cathode, and may therefore play a lesser role than neutral radicals in anode aging processes. The positive ions may, however, become involved in aging processes at the cathode. The degradation of the wire surfaces by various types of deposits causes the various aging phenomena. Thus, aging may be considered as a side effect of the process of gas gain.

Aging effects occur on both the anode and the cathode, but with very different results. This work is concerned mainly with anode wire aging effects.

Anode aging results from a change in the nature of the anode surface and usually manifests itself as a loss of gain. Loss of gain can result from an increase in the anode wire radius, such as would result from deposition of a layer, and/or from a reduction in the effective anode potential, such as would result from (negative) charge accumulation on an insulating layer. Both of these effects reduce the field strength at the anode and thus the gain. A related problem, nonuniformity of gain, either along one wire or between several wires, follows directly from nonuniformity of deposits.

Cathode aging results from the presence of an insulating layer on the cathode surface and manifests itself as a self-sustained discharge. The insulating layer prevents positive ions created in the avalanche from reaching the cathode and being neutralized. Instead, these ions accumulate on the layer and create a dipole field which, if it exceeds the threshold for field emission [2], can eject electrons from the cathode. The regenerative effect that results if these electrons enter the drift space and initiate more avalanches ultimately leads to a self-sustained (Malter) discharge.

\subsection{Aging Studies}

Previous studies of wire aging have been largely trial-and-error, aimed at discovering satisfactory sets of operating conditions. This haphazard approach reflects a poor 
understanding of the chemical processes that lead to aging. A pervasive belief among workers in the field is that aging is due to certain types of contamination in the gas [3]. Despite extensive discussions in the literature [4] speculating on the nature and source of possible contaminants in wire chamber gases, however, specific contaminants have only rarely been identified [5]. While trace contaminants in the gas may well have disproportionately large influence on the chemistries responsible for aging, it has rarely been considered that aging effects may be a result of the bulk composition of the gas.

At present, aging mechanisms are only partially understood, and several recent reviews cover much of what is known about wire aging [6-9]. The few results from wire aging studies not covered in these reviews are referred to in Chapter 2.

Clearly, the wire chamber aging problem is very complex, and there are a large number of factors that may potentially affect aging including gas composition, gas flow rate, chamber construction materials, radiation dose rate, etc. Moreover, there is no unique solution to wire aging due to the different demands placed on wire chambers by different applications. With careful and directed analysis, however, it should be possible to describe qualitatively the dominant chemical reactions that cause aging in any specific application.

A sensible approach in this regard is to consider the chemical processes at work. The electron avalanche, which is responsible for wire chamber aging processes, may be thought of as a 1 atm, dc plasma. Although little is known about the plasma chemistry of this regime, the low-pressure (0.1-5 Torr), rf discharge regime has been studied extensively, since such plasmas are frequently used in microelectronics processing and for polymer and inorganic film deposition. While the plasma characteristics of these two regimes are expected to be rather different, estimates of electron energies and $E / p$ suggest that these parameters may be quite similar [7]. Further, studies of atmospheric-pressure plasmas have generally concluded that the reaction mechanisms in the two regimes are similar [10]. For these reasons, principles of low-pressure, rf plasma chemistry may be useful to interpret the chemistry occurring in the electron avalanche. 


\subsection{Experimental Overview}

In this thesis, three general experimental routes were taken to investigate aging: 1) accelerated wire aging tests, 2) gas-phase analysis of the effluent from a proportional counter, and 3) analysis of the surfaces of aged wires.

Accelerated aging tests [11] were perhaps the central part of these investigations. To age wires in a reasonable length of time (1-10 days), initial current densities on the wires are two to three orders of magnitude larger than those encountered in actual wire chamber operation. In these tests, proportional counters $(0.95 \mathrm{~cm}$ ID cathode, $50 \mu \mathrm{m}$ dia anode wire) are irradiated with an ${ }^{55} \mathrm{Fe}$ source $(\sim 1 \mathrm{mCi}) .\left({ }^{55} \mathrm{Fe}\right.$ is a $5.9 \mathrm{keV}$ gamma emitter. Upon absorption in the counter gas, each gamma creates about 200 ion pairs.) The current drawn by the wire is monitored by frequent sampling. Changes in the gain can be inferred from changes in the current because the two are linearly related. For the analysis of each test, the gain (current) is plotted as a function of the total charge transfer, the assumption being that the extent of aging is closely correlated with the charge transferred.

To a certain extent, the use of aging tests continued the trial-and-error pattern of previous studies because these tests are useful both to identify conditions that might be used in full-scale wire chambers and to identify for further study conditions that cause rapid aging.

Gas-phase analysis of the effluent of a proportional counter was undertaken as an approach to allow systematic and detailed study of the plasma reactions occurring in wire chambers. A proportional counter tube similar to those used for aging tests is irradiated by an ${ }^{55} \mathrm{Fe}$ source. Condensible trace species in the proportional tube effluent are concentrated by several orders of magnitude in a cryotrap to provide the sensitivity needed for detection and identification; separation and analysis are subsequently performed on this sample by gas chromatography/mass spectrometry. We hoped that by correlating wire aging rates with the reaction products in the proportional tube effluent, the dominant reactions responsible for wire aging could be identified and appropriate measures to prevent aging in full-scale wire chambers determined. Results of gas-phase analysis of hydrocarbon gases $\left(\mathrm{CH}_{4}, \mathrm{C}_{2} \mathrm{H}_{6}, \mathrm{C}_{3} \mathrm{H}_{8}\right.$, 
$\mathrm{iC}_{4} \mathrm{H}_{10}$ ) have already been described [8], and are not reproduced here.

Analysis of wire surfaces was performed using Auger electron spectroscopy (AES) combined with scanning electron microscopy (SEM). The Auger technique provides definitive identification of elements with $Z<3$ on a surface to a depth of $\sim 1 \mathrm{~nm}$. Auger spectroscopy was often combined with argon ion beam sputtering of the surface to obtain a composition-depth profile. This mode of investigation was motivated by the ideas that the composition of the deposits on a wire could help to identify aging mechanisms and that stratified deposits could indicate sequential aging mechanisms.

\subsection{Thesis Organization}

Chapter 2 describes work performed to understand the aging properties of $\mathrm{CF}_{4}$-based gases. It has recently become clear that $\mathrm{CF}_{4} / \mathrm{iC}_{4} \mathrm{H}_{10}(80 / 20)$ exhibits very little aging in tests, suggesting that it will be of considerable use in future wire chambers. Taken separately, however, the component gases of this mixture do age: $\mathrm{iC}_{4} \mathrm{H}_{10}$ is reported to coat the cathode [12], and the present work revealed rapid aging in $\mathrm{CF}_{4}$ that may be a cathode phenomenon. A nonmonotonic dependence of aging properties on gas composition was observed, with extensive deposition occurring in $\mathrm{CF}_{4}$-rich gases. A four-part model considering 1) plasma polymerization of the hydrocarbon, 2) etching of wire deposits by $\left.\mathrm{CF}_{4}, 3\right)$ acceleration of deposition processes in strongly etching environments, and 4) reactivity of the wire surface was developed to understand anode aging in $\mathrm{CF}_{4} / \mathrm{iC}_{4} \mathrm{H}_{10}$ gases. This model suggests practical guidelines for use of $\mathrm{CF}_{4} / \mathrm{iC}_{4} \mathrm{H}_{10}$ gases and may be generally applicable to $\mathrm{CF}_{4} /$ hydrocarbon gases.

Chapter 3 describes an investigation into the effects of Freons in general and Freon 11 in particular on the aging observed in dimethyl ether [13]. A key point to this investigation is that it was believed that Freon 11 greatly accelerated aging in dimethyl ether. By making use of controlled addition of Freons to the bulk gas, this study showed that the aging was not nearly as severe as believed and that a physical phenomenon (distillation in the dimethyl ether supply cylinder) could cause the apparent aging reported in the literature.

Appendix A describes a study of heating effects in straw tubes [14]. The results 
of this study indicated that heat transfer in the tubes was predominantly by radial conduction through the gas rather than by removal through the combined effects of the gas volumetric flow rate and the gas heat capacity, which had been generally accepted as the dominant mechanism. The realization that gas flow rates are not a critical issue may simplify considerably the design of straw-tube wire chambers.

The other appendices describe experimental details and issues not directly related to the main discussion. Appendix $B$ describes an approach used to observe the plasma around an operating wire during an aging test. Appendix $\mathrm{C}$ describes the plasma processes used to pretreat some wires before using them in aging tests. Appendix D describes the instrumentation and procedures used for wire aging tests.

\section{References}

[1] (a) F. Sauli, CERN 77-09 (1977); (b) B. Sadoulet, Physica Scripta, 23 (1981) 434.

[2] L. Malter, Phys. Rev., 50 (1936) 48.

[3] See, for example: (a) A. Dwurazny, K. Jelen, and E.R. Zarebska, Nucl. Instr. and Meth., 217 (1983) 301; (b) M. Danilov, V. Nagovitsin, V. Shibaev, I. Tichomirov, E. Michel, and W. Schmidt-Parzefall, Nucl. Instr. and Meth., A274 (1989) 189.

[4] See, for example: (a) A.J.F. den Boggende, A.C. Brinkman, and W. de Graaff, J. Sci. Instr. (J. Phys. E), 2 (1969) 701; (b) G. Bari, M. Basile, G. Bonvinci et al., Nucl. Instr. and Meth., A251 (1986) 292.

[5] (a) M. Jibaly, P. Chrusch, G. Hilgenberg, S. Majewski, R. Wojcik, R. Weintraub, and F. Sauli, Nucl. Instr. and Meth., A273 (1988) 161; (b) M. Jibaly, P. Chrusch, G. Hilgenberg, S. Majewski, R. Wojcik, F. Sauli, and J. Gaudaen, IEEE Trans. Nucl. Sci., NS-36 (1989) 552; (c) M. Jibaly, S. Majewski, P. Chrusch, R. Wojcik, F. Sauli, and J. Gaudaen, Nucl. Instr. and Meth., A283 (1989) 692.

[6] J. Kadyk, ed., Proceedings of the Workshop on Radiation Damage to Wire Chambers, LBL-21170 (1986).

[7] J. Va'vra, Nucl. Instr. and Meth., A252 (1986) 547.

[8] J. Wise, MS Thesis, LBL-29033 (1990).

[9] J.A. Kadyk, Nucl. Instr. and Meth., A300 (1991) 436. 
[10] (a) M.E. Fraser, D.A. Fee, and R.S. Sheinson, Plasma Chem. Plasma Process, 5 (1985) 163; (b) S. Kanazawa, M. Kogoma, T. Moriwaki, and S. Okazaki, J. Phys. D: Appl. Phys., 21 (1988) 838.

[11] J. Kadyk, J. Wise, D. Hess, and M. Williams, IEEE Trans. Nucl. Sci., NS-37 (1990) 478.

[12] Aging in $\mathrm{iC}_{4} \mathrm{H}_{10}$ : S. Majewski, ref. [6], p. 239.

Aging in $\mathrm{Ar} / \mathrm{iC}_{4} \mathrm{H}_{10}$ : G. Charpak, H.G. Fisher, C.R. Gruhn, A. Minten, F. Sauli, G. Plch, and G. Flugge, Nucl. Instr, and Meth., 99 (1972) 279.

Aging in $\mathrm{CO}_{2} / \mathrm{iC}_{4} \mathrm{H}_{10}$ : (a) I. Juricic and J. Kadyk, IEEE Trans. Nucl. Sci., NS-34 (1987) 481; (b) P. Drell, ref. [6], pp. 314,315.

[13] J. Wise, J.A. Kadyk, D.W. Hess, and M.C. Williams, "Effects of Freons on Wire Chamber Aging," Nucl. Instr, and Meth., A297 (1990) 169.

[14] J.A. Kadyk, J. Va'vra, and J. Wise, "Use of Straw Tubes in High-Radiation Environments," Nucl. Instr. and Meth., A300 (1991) 511. 


\section{Chapter 2}

\section{A Chemical Model for Wire Chamber Aging in $\mathrm{CF}_{4} / \mathrm{iC}_{4} \mathrm{H}_{10}$ Gases}

\section{Abstract}

Aging of proportional counters in $\mathrm{CF}_{4} / \mathrm{iC}_{4} \mathrm{H}_{10}$ gases is studied as a function of gas composition. Wire deposits are analyzed by Auger electron spectroscopy. An apparent cathode aging process resulting in loss of gain rather than in a self-sustained current is observed in $\mathrm{CF}_{4}$-rich gases. For tests with such gases, the current drawn is not a reliable measure of the extent of anode aging. Anode wire deposits are formed by the $95 / 5$ and $90 / 10$ mixtures of $\mathrm{CF}_{4} / \mathrm{iC}_{4} \mathrm{H}_{10}$; etching of deposits is observed in the 50/50 and 80/20 mixtures and in pure $\mathrm{CF}_{4}$. A four-part model considering 1) plasma polymerization of the hydrocarbon, 2) etching of wire deposits by $\left.\mathrm{CF}_{4}, 3\right)$ acceleration of deposition processes in strongly etching environments, and 4) reactivity of the wire surface is developed to understand anode aging in $\mathrm{CF}_{4} / \mathrm{iC}_{4} \mathrm{H}_{10}$ gases. Goldplated wires are resistant to aging while non-gold-plated wires are unacceptable for use in these gases. Application of the model to other fluorine-containing gases is discussed. Principles of low-pressure, rf plasma chemistry are used to predict the plasma chemistry in avalanches $(1 \mathrm{~atm}, \mathrm{dc})$. 


\subsection{Introduction}

Wire chambers are commonly used in high-energy physics experiments for particle detection and tracking. Although wire chambers represent a mature technology, wire aging studies have been largely empirical, and the causes of wire aging are still poorly understood. Wire aging studjes have become more chemically oriented in recent years, however, and it has been suggested thai plasma chemistry, in particular, may be a useful tool for understanding the chemical reactions that lead to wire aging [1]. This work models wire aging using principles of plasma chemistry.

Plasma chemistry finds extensive application in microelectronics processing, which typically makes use of low-pressure (<1 Torr), rf (13.6 MHz) plasmas. While the plasma characteristics of this regime are expected to differ from those of wire chambers ( $1 \mathrm{~atm}, \mathrm{dc}$ ), estimates of electron energies and $E / p$ suggest that these parameters may be quite similar [2]. In previous work, we observed that the gaseous products formed in the avalanches in a proportional counter are, qualitatively, those expected if the chemical mechanisms in the avalanche are similar to the mechanisms in low-pressure discharges [3]. Moreover, other studies of atmospheric pressure plasmas have noted similarities to the low pressure regime and have generally concluded that reaction mechanisms in these two pressure regimes are similar [4-6]. For these reasons, we will draw on knowledge of the low-pressure, rf plasma regime to interpret results in wire chamber aging.

In plasma processing, $\mathrm{CF}_{4}$-based gases are used for both etching and deposition processes, the distinction being made by the gas with which the $\mathrm{CF}_{4}$ is mixed. In general, addition of oxygenated species shifts the chemistry of the plasma towards etching while addition of hydrogenated species shifts the plasma towards polymerization. Because a predominantly etching environment can be created from $\mathrm{CF}_{4}$, it was reasonable to assume that this gas could be used to make a wire chamber gas more resistant to aging.

There is considerable interest in the use of $\mathrm{CF}_{4}$-based gases for wire chamber applications in high-radiation environments. The $80 / 20$ mixture of $\mathrm{CF}_{4} / \mathrm{iC}_{4} \mathrm{H}_{10}$ was originally used because of its high drift velocity [7-9], high primary ionization [7], and 
low electron diffusion [10]. This mixture was subsequently found to have very good aging properties [11-13], and also to etch silicon-based deposits $[14,15]$ and hydrocarbon deposits [15] from gold-plated wires. Although a complete understanding of the chemical mechanisms responsible for this etching is not necessary to use this gas mixture, some understanding is necessary to predict the aging properties of $\mathrm{CF}_{4}$ with other than $20 \% \mathrm{iC}_{4} \mathrm{H}_{10}$ or in mixtures with other hydrocarbons. A mechanistic understanding is also necessary to predict the consequences of trace-level contaminants or intentional additives in the gas.

This work confirms the etching of anode deposits on gold-plated wires with $\mathrm{CF}_{4}$ / $\mathrm{iC}_{4} \mathrm{H}_{10}(80 / 20)$ and shows that etching occurs over a range of $\mathrm{CF}_{4} / \mathrm{iC}_{4} \mathrm{H}_{10}$ mixtures. Deposition is shown to occur for some $\mathrm{CF}_{4} / \mathrm{iC}_{4} \mathrm{H}_{10}$ mixtures and for non-gold anode materials. A chemical model to explain the observed deposition or etching in these gases is developed and practical guidelines suggested by the model are discussed.

We have previously reported that extensive and rapid anode aging occurs in $\mathrm{CF}_{4}$ and that aging transients occur for $\mathrm{CF}_{4} / \mathrm{iC}_{4} \mathrm{H}_{10}$ mixtures [16,17]. As a consequence of further experimentation, we believe that that interpretation of results reflects an incomplete understanding of the chemical processes and aging mechanisms.

\subsection{Experimental}

The parameters varied in this work were primarily gas composition and wire material. Gases used were $\mathrm{CF}_{4}$ and $\mathrm{iC}_{4} \mathrm{H}_{10}$, encompassing the full range of mixtures from pure $\mathrm{CF}_{4}$ to pure $\mathrm{iC}_{4} \mathrm{H}_{10}$. Wire materials were most often $\mathrm{Au}$ (plated on $\mathrm{W}$ ), $\mathrm{Ni}$, and $\mathrm{Cu}$. Stablohm (an alloy consisting of $75 \% \mathrm{Ni}, 20 \% \mathrm{Cr}$, balance $\mathrm{Al}$ and $\mathrm{Cu}$ ), $\mathrm{Al}, \mathrm{W}$, and $\mathrm{C}$ wires were used to a lesser extent.

All gases were purchased from Matheson Gas Co. (Newrark, CA). Unless otherwise noted, gas mixtures were premixed by Matheson and were used as received. Pure $\mathrm{CF}_{4}$ (semiconductor grade, minimum purity $99.999 \%$ ) was normally filtered with a model L-60 Nanochem filter (Semi-Gas Systems, San Jose, CA). Au/W wire was purchased from Luma Metall (Kalmar, Sweden). Stablohm, $\mathrm{Al}, \mathrm{Cu}$, and $\mathrm{Ni}$ wires were purchased from California Fine Wire (Grover City, CA). W wire was purchased 
from The Rembar Company (Dobbs Ferry, NY).

\subsubsection{Accelerated Aging Tests}

To age wires in a reasonable length of time (1-10 days), accelerated aging tests were performed in which the current densities on the wires were two to shree orders of magnitude higher than those encountered in actual wire chamber operation. Briefly, proportional counters $(0.95 \mathrm{~cm}$ ID copper cathode, $50 \mu \mathrm{m}$ dia anodie wire, $\sim 10 \mathrm{sccm}$ gas flow rate) were irradiated with an ${ }^{55} \mathrm{Fe}$ point source $(1 \mathrm{mCi}, 3 \mathrm{~mm}$ dia). The irradiated length of wire was $\sim 3.5 \mathrm{~mm}$. Initial wire currents were typically $400 \mathrm{nA}$, corresponding to a current density of about $1.1 \mu \mathrm{A} / \mathrm{cm}$. The current drawn by the wire was monitored by frequent sampling. Changes in the gain can be inferred from changes in the current because the two are linearly related. Barometric pressure and gas temperature were also monitored so that corrections for variations in the gain caused by changes in the gas density could be made. For the analysis of each test, the gain (current) was plotted as a function of the total charge transfer, the assumption being that the extent of aging is closely correlated with the charge transferred. Aging rates are parameterized as the normalized rate of loss of gain, $R$ :

$$
R=-\frac{1}{G_{0}} \frac{d G}{d Q}=-\frac{1}{I_{0}} \frac{d I}{d Q}
$$

where $R$ has units of $\% / \mathrm{C} / \mathrm{cm}$. The apparatus used to collect aging data has been described elsewhere [13].

A fundamental assumption used to justify accelerated aging tests is that the aging rate is independent of the radiation dose rate. The validity of this assumption was not addressed in this work, but since the dose rates used in the accelerated tests are so much higher than those occurring in a wire chamber in normal operation, caution is warranted when attempting to draw parallels between the two operating regimes. In the case of $\mathrm{CF}_{4} / \mathrm{iC}_{4} \mathrm{H}_{10}(80 / 20)$, however, there is some evidence to suggest that aging is independent of dose rate [12]. 


\subsubsection{Pulse Height}

Aging was also characterized using the ${ }^{55} \mathrm{Fe}$ pulse height and energy resolution. Because the ${ }^{55} \mathrm{Fe}$ pulse height spectrum does not exhibit a narrow peak in $\mathrm{CF}_{4} / \mathrm{iC}_{4} \mathrm{H}_{10}$ gases [18], the counter gas was alternated between $\mathrm{CF}_{4}$-based test gases, for the aging segments, and $\mathrm{Ar} / \mathrm{C}_{2} \mathrm{H}_{6}(50 / 50)$, for the pulse height measurements. The ${ }^{55} \mathrm{Fe}$ spectrum in $\mathrm{Ar} / \mathrm{C}_{2} \mathrm{H}_{6}$ has characteristic peaks that are useful for monitoring gain and gain uniformity and also a well-characterized degradation pattern resulting from aging [19].

To collect pulse height data, the counter gas was changed to $\mathrm{Ar} / \mathrm{C}_{2} \mathrm{H}_{6}(50 / 50)$, the $1 \mathrm{mCi}, 3-\mathrm{mm}$-dia ${ }^{55} \mathrm{Fe}$ point source used for aging was replaced with a $500 \mu \mathrm{Ci}{ }^{55} \mathrm{Fe}$ line source (collimated width $\sim 1 \mathrm{~mm}$ ), and the anode potential was set to $2080 \mathrm{~V}$. The collimated ${ }^{55} \mathrm{Fe}$ source was oriented perpendicularly to the wire axis so that pulse height spectra could be collected at distinct positions along the wire. The acquisition time for each spectrum was $5 \mathrm{~min}$; the current during acquisition was normally $0.35 \mathrm{nA}$.

\subsubsection{Analysis of Deposits}

Surface analysis of wires was performed with scanning electron microscopy (SEM) and Auger electron spectroscopy (AES). SEM photographs shown in this work were taken with a beam voltage of $10 \mathrm{kV}$ and are at $\times 1400$ magnification. AES analysis provides definitive identification of elements on a surface to a depth of $\sim 1 \mathrm{~nm}$. AES was combined with argon ion beam sputtering of the surface to obtain a composition-depth profile [20]. It should be noted that no simple relationship between sputter time and depth exists due to the composition dependence of the sputtering rate. Because AES is insensitive to elements with $Z<3$, it cannot be used to detect hydrogen. Therefore, hydrocarbons could not be distinguished from purely carbonaceous deposits by this technique. 


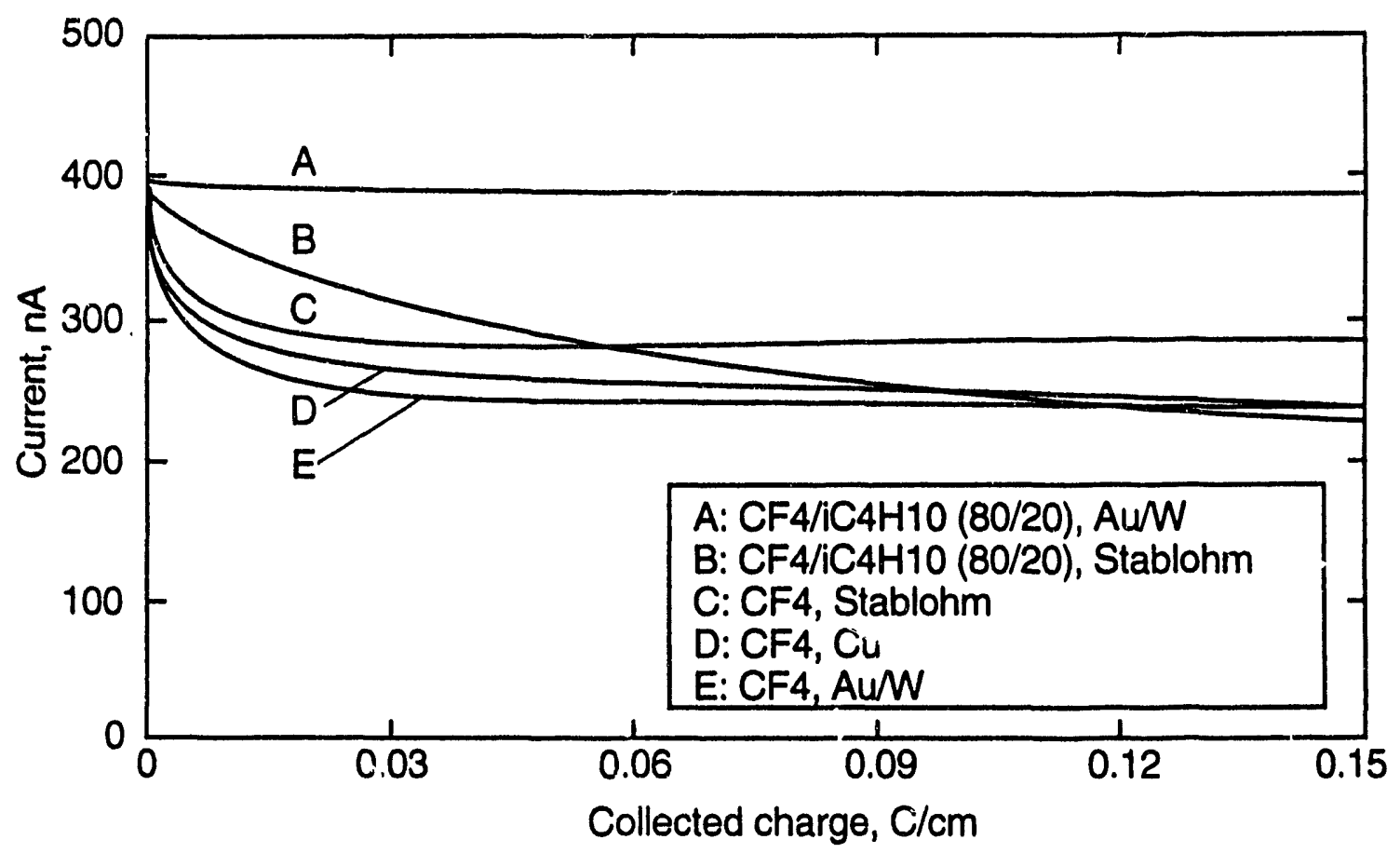

XBL 927-5284

Figure 2.1: Typical aging curves (current as a function of collected charge) for $\mathrm{CF}_{4}$ and $\mathrm{CF}_{4} / \mathrm{iC}_{4} \mathrm{H}_{10}$ gases.

\subsection{Aging in $\mathrm{CF}_{4}$}

A simple model to explain the aging properties of $\mathrm{CF}_{4} / \mathrm{iC}_{4} \mathrm{H}_{10}(80 / 20)$ relates these properties to the presence of $\mathrm{CF}_{4}$ in the gas. Because $\mathrm{CF}_{4} / \mathrm{iC}_{4} \mathrm{H}_{10}(80 / 20)$ did not age appreciably, we believed that a steady-state etching/deposition balance occurred, possibly resulting in a thin fluorohydrocarbon film on the wire surface. We further expected that because $\mathrm{CF}_{4}$ is the parent for the reactive species responsible for the etching processes, the resistance to aging and the ability to etch anode deposits would correlate directly to the $\mathrm{CF}_{4}$ content of the gas. It was therefore surprising to discover that pure $\mathrm{CF}_{4}$ and $\mathrm{CF}_{4}$-rich gases appeared to age rapidly.

Aging tests with $\mathrm{CF}_{4}$ typically resemble the curves shown in Fig. 2.1, exhibiting a nonlinear transient behavior. To determine whether the transient was real or was an artifact, possibly related to the startup procedure of the aging tests, the transient was 
Table 2.1: Summary of results for interruptions of aging tests with $\mathrm{CF}_{4}$. Except where otherwise noted, $\mathrm{CF}_{4}$ flow through the counter was maintained. The current after the interruption was corrected for gas density fluctuations with $\alpha_{\rho}=6$.

\begin{tabular}{|c|c|c|c|c|c|l|}
\hline Wire & $\begin{array}{c}\text { Wire } \\
\text { material }\end{array}$ & $\begin{array}{c}I_{\text {before }} \\
{[\mathrm{nA}]}\end{array}$ & $\begin{array}{c}I_{\text {after }} \\
{[\mathrm{nA}]}\end{array}$ & $\begin{array}{c}\Delta I \\
{[\%]}\end{array}$ & $\begin{array}{c}\Delta t \\
{[\mathrm{hr}]}\end{array}$ & Comments \\
\hline 1 & $\mathrm{Au} / \mathrm{W}$ & 286.4 & 285.9 & -0.18 & 0.17 & \\
1 & $\mathrm{Au} / \mathrm{W}$ & 271.3 & 280.4 & +3.35 & 0.53 & open to air $0.28 \mathrm{hr}$ \\
1 & $\mathrm{Au} / \mathrm{W}$ & 192.7 & 195.3 & +1.35 & 1.22 & $\begin{array}{l}\text { open to air } 1.05 \mathrm{hr}, \\
\text { forced convection }\end{array}$ \\
& & & & & & \\
1 & $\mathrm{Au} / \mathrm{W}$ & 193.9 & 195.3 & +0.72 & 1.17 & \\
2 & $\mathrm{Au} / \mathrm{W}$ & 244.8 & 247.4 & +1.06 & 18.02 & \\
2 & $\mathrm{Au} / \mathrm{W}$ & 231.6 & 232.4 & +0.35 & 1.68 & \\
2 & $\mathrm{Au} / \mathrm{W}$ & 232.7 & 232.7 & +0.00 & 3.47 & \\
3 & $\mathrm{~W}$ & 233.4 & 232.5 & -0.39 & 0.20 & \\
3 & $\mathrm{~W}$ & 170.4 & 170.5 & +0.06 & 0.28 & apply $+2080 \mathrm{~V}$ to shell, \\
& & & & & & \\
ground anode wire
\end{tabular}

interrupted. If the transient was an artifact, it might occur again when the test was restarted. Aging tests were interrupted first by turning off the anode voltage and then by stopping the gas flow and opening the counter to air. In one test, the anode and cathode potentials were reversed to ensure complete dissipation of any accumulated charge. The ${ }^{55} \mathrm{Fe}$ source was net removed from the counter at any time during these interruptions. In all tests, the current returned to virtually the same value $( \pm 1 \%)$ that it had prior to the interruption, indicating that the decrease in current is real, the result of some aging process. These results are summarized in Table 2.1.

To provide a meaningful basis for comparison of different aging curves, we use the functional form

$$
I=A+B \exp \left(-Q^{1 / 2} / D\right)
$$

to analyze the transients. The exponential dependence was chosen because it is the expected form for changes in gain [21]; the square-root within the exponential was chosen empirically, because of the good fits to this functional dependence. We parameterize the aging transients with a gain change $\left(I / I_{0}=I_{\text {asymptote }} / I_{\text {initial }}=A / A+\right.$ 
$B$ ) and a decay constant, $D$. A chi-squared fit was performed over the interval 0$10 \mathrm{mC}$.

Fig. 2.2 shows decay constants and gain changes for several anode wire materials aged in $\mathrm{CF}_{4}$. There is surprisingly little variation in these parameters considering the variety of different materials $\left(D=1.27 \pm 0.45 \mathrm{mC}^{1 / 2}, I / I_{0}=0.60 \pm 0.1\right.$ for $\mathrm{Au} / \mathrm{W}$ wires only; $D=1.14 \pm 0.38 \mathrm{mC}^{1 / 2}, I / I_{0}=0.57 \pm 0.16$ for all other wires). The approximate independence of the decay constant to anode material suggests that the initial aging in $\mathrm{CF}_{4}$ may be due to a deposition on the wire rather than to a reaction with it. If so, fluorocarbon deposits would be expected on all wires but, as discussed in sections 2.3.1 and 2.3.2, such deposits were not observed. Purifying the $\mathrm{CF}_{4}$ had little effect on the transient for $\mathrm{Au} / \mathrm{W}$ wires $\left(D=1.22 \pm 0.46 \mathrm{mC}^{1 / 2}, I / I_{0}=0.58 \pm 0.15\right.$ without filter; $D=1.31 \pm 0.47 \mathrm{mC}^{1 / 2}, I / I_{0}=0.62 \pm 0.12$ with Nanochem hiter), indicating that the $\mathrm{CF}_{4}$, and not a trace component, is responsible for the aging. The quality of least-squares fits to a straight line of $D$ and $I / I_{0}$ for $\mathrm{Au} / \mathrm{W}$ wires with respect to gas flow rate over the range $1-15 \mathrm{sccm}$ was poor $(r=0.42$ and $r=-0.19$, respectively), suggesting that aging in $\mathrm{CF}_{4}$ is not sensitive to flow rate in that range.

In an at treated to create a film similar to that believed to form during aging. It was expected that by forming the film in advance, steady-state wire operation might be approached more quickly and the magnitude and possibly the duration of the transient reduced. Wires were pretreated in a barrel reactor [22] with a $13.56 \mathrm{MHz}$ plasma of either 1) $\mathrm{CHF}_{3}(200 \mathrm{~W}, 350 \mathrm{mTorr}$, exposure times of 30,60 , or $120 \mathrm{sec})$ to deposit a fluorocarbon film, or 2) $\mathrm{SF}_{6} / \mathrm{O}_{2}(96 / 4)(30 \mathrm{~W}, 200 \mathrm{mT}$ Torr, exposure times of 60 or $180 \mathrm{sec})$ to fluorinate the wire surface. Film thicknesses deposited by the $\mathrm{CHF}_{3}$ plasma were measured by ellipsometry on a silicon wafer used as a control, and ranged from $16 \mathrm{~nm}$ to $50 \mathrm{~nm}$. AES revealed that the surface of $\mathrm{Ni}$ wires treated in the $\mathrm{SF}_{6} / \mathrm{O}_{2}$ plasma was fluorinated to a thickness comparable to that resulting from aging in $\mathrm{CF}_{4}$ with total collected charge of $100 \mathrm{mC} / \mathrm{cm}$ but that the surface of $\mathrm{Cu}$ wires so treated was oxidized rather than fluorinated.

As shown in Fig. 2.2, neither pretreatment process resulted in a significant change in the transient, although the decay constants for one set of wires treated in the 

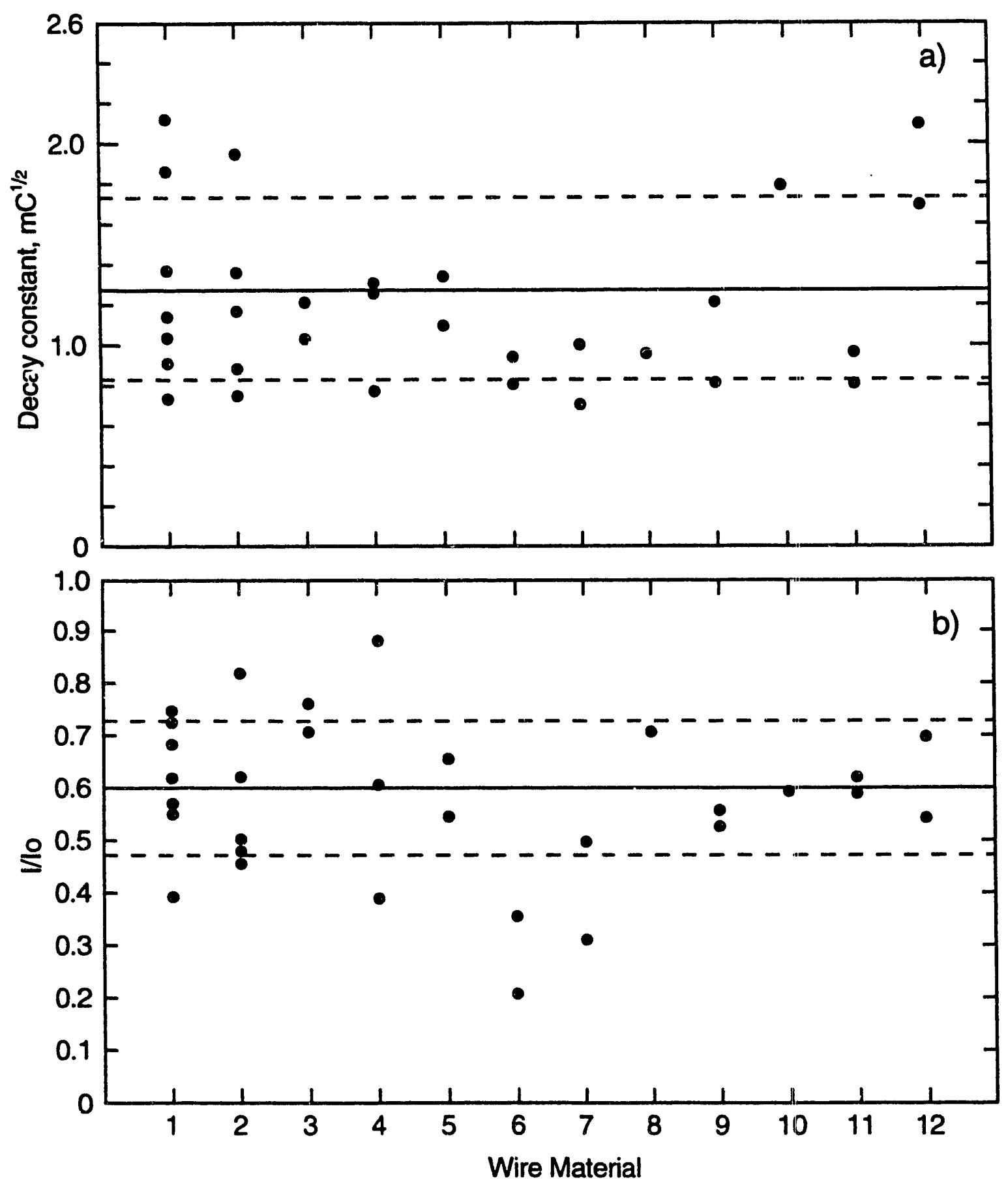

XBL $927-5283$

Figure 2.2: (a) Decay constants and (b) gain changes for various anode materials aged in $\mathrm{CF}_{4}$. The solid line is the average for the $\mathrm{Au} / \mathrm{W}$ wires; the dashed lines indicate the one-standard-deviation limits. Wire materials are: $1, \mathrm{Au} / \mathrm{W} ; 2, \mathrm{Au} / \mathrm{W}$, unfiltered $\mathrm{CF}_{4} ; 3$, Stablohm; 4, Ni; $5, \mathrm{Cu} ; 6, \mathrm{Al} ; 7, \mathrm{~W} ; 8, \mathrm{C} ; 9$, Ni pretreated in $\mathrm{SF}_{6} / \mathrm{O}_{2} ; 10$, $\mathrm{Cu}$ pretreated in $\mathrm{SF}_{6} / \mathrm{O}_{2} ; 11, \mathrm{Au} / \mathrm{W}$ with nominal $50 \mathrm{~nm} \mathrm{CHF}_{3}$ film; $12 \mathrm{Au} / \mathrm{W}$ with nominal $37 \mathrm{~nm} \mathrm{CHF}_{3}$ film. 
$\mathrm{CHF}_{3}$ plasma are marginally larger than those for untreated wires. The lack of effect resulting from pretreatment suggests that the rapid decrease in the current may not reflect anode aging.

\subsection{1 $\mathrm{Au} / \mathrm{W}$ Wires}

Plots of pulse height, energy resolution, and current for aging of an $\mathrm{Au} / \mathrm{W}$ wire in $\mathrm{CF}_{4}$ are shown in Fig. 2.3. (The procedures used to collect these data are described in section 2.2.2.) There is a slight increase in the pulse height; the energy resolution is essentially unchanged. This is surprising in view of the large decrease in current, which is essentially the pulse height integrated over the irradiated region of the wire. The lack of degradation of the pulse height suggests that very little degradation of the wire surface occurs or possibly that degradation of the wire surface occurs but disappears before the pulse height measurement is made. However, potential mechanisms for the disappearance of wire deposits, such as reaction with the ambient gas or evaporation, do not seem plausible for fluorocarbons. It is thus likely that no degradation of the wire surface occurred.

An unexpected occurrence in this measurement was that the post-interruption currents were typically $5-10 \%$ higher than their corresponding pre-interruption values (Fig. 2.3a). This behavior is very different than that observed when the aging tests were interrupted but pulse height measurements were not taken, in which case the preand post-interruption currents were virtually identical (Table 2.1). This difference may be due to a modification of the anode surface resulting from exposure to the $\mathrm{Ar} / \mathrm{C}_{2} \mathrm{H}_{6}$. The magnitude of the overshoot does not appear correlated to the amount charge collected during this exposure, however: after $50 \mathrm{~min}$ at $400 \mathrm{nA}$ in $\mathrm{Ar} / \mathrm{C}_{2} \mathrm{H}_{6}$, the overshoot was still only about $10 \%$. It is possible that the overshoot results from slight changes in the position of the ${ }^{55} \mathrm{Fe}$ source used to age the wire.

A typical AES spectrum of an $\mathrm{Au} / \mathrm{W}$ wire aged in $\mathrm{CF}_{4}$ is shown in Fig. 2.4a. In addition to $A u$, only trace amounts of $C$ and $O$ are present. Such traces of $C$, and frequently $\mathrm{O}$, are normally observed on surfaces exposed to air. Depth profiles (Fig. 2.4b) reveal no deposits in excess of the atmospheric carbon contamination. The appearance of these aged wires is indistinguishable from that of new wires (Fig. 2.5). 

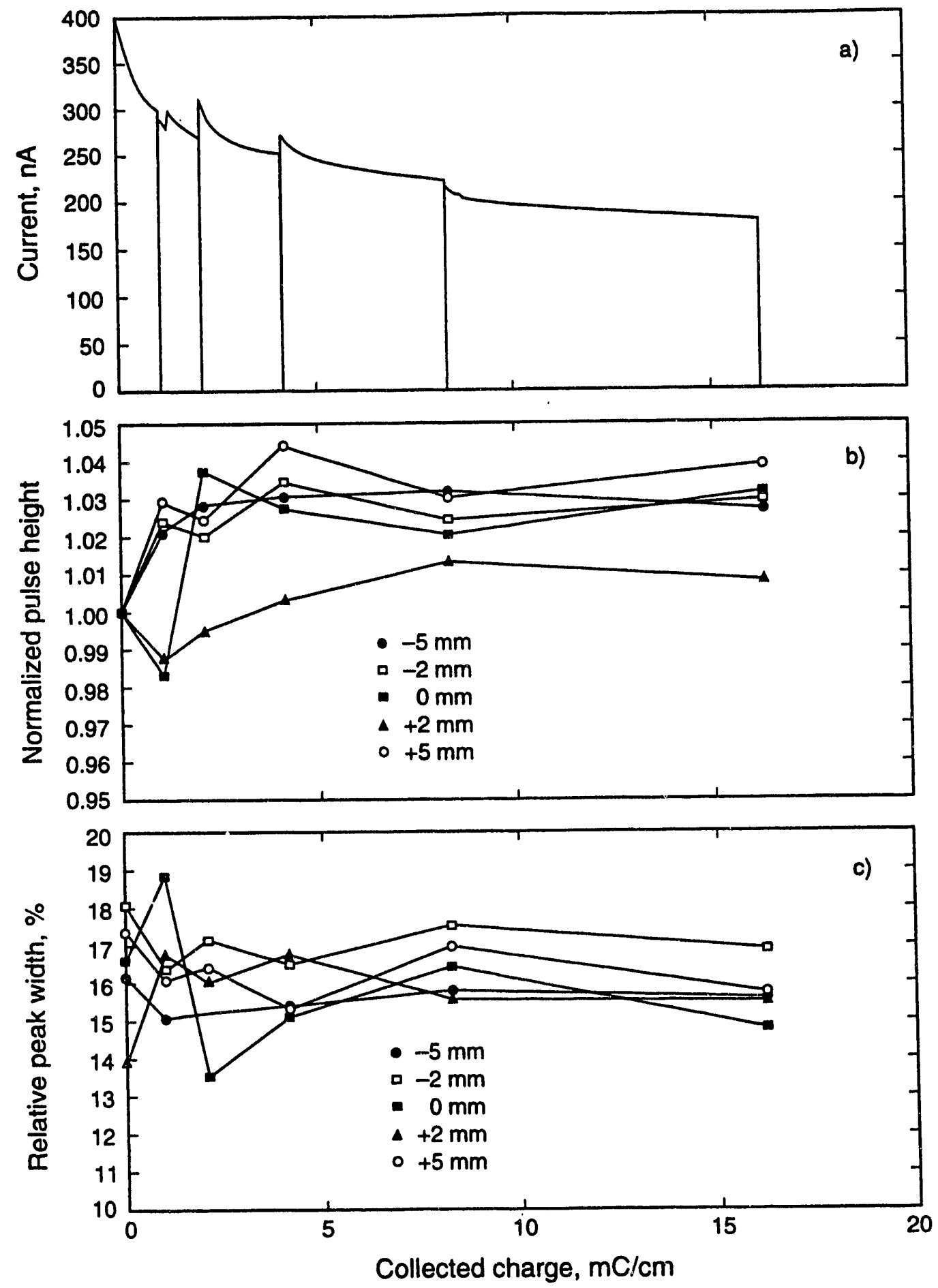

XBL 926-5692

Figure 2.3: Aging parameters as a function of collected charge for an $\mathrm{Au} / \mathrm{W}$ wire aged in $\mathrm{CF}_{4}$ : (a) current, (b) pulse height, (c) energy resolution. Distances are relative to the center of irradiation. The current overshoot in (a) is observed when an aging test with $\mathrm{CF}_{4}$ is interrupted and exposed to $\mathrm{Ar} / \mathrm{C}_{2} \mathrm{H}_{6}$ (see text). 


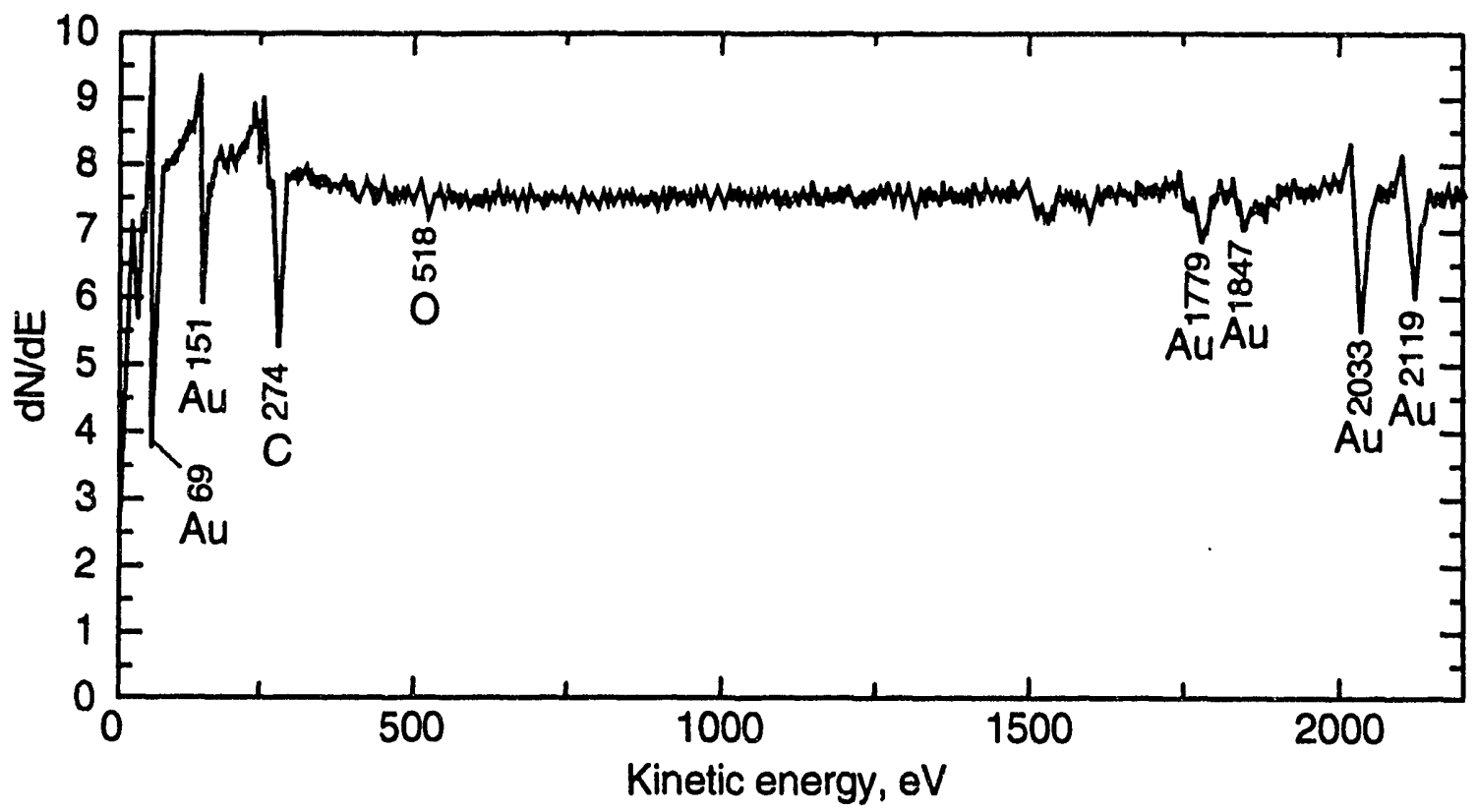

XBL 927.5282

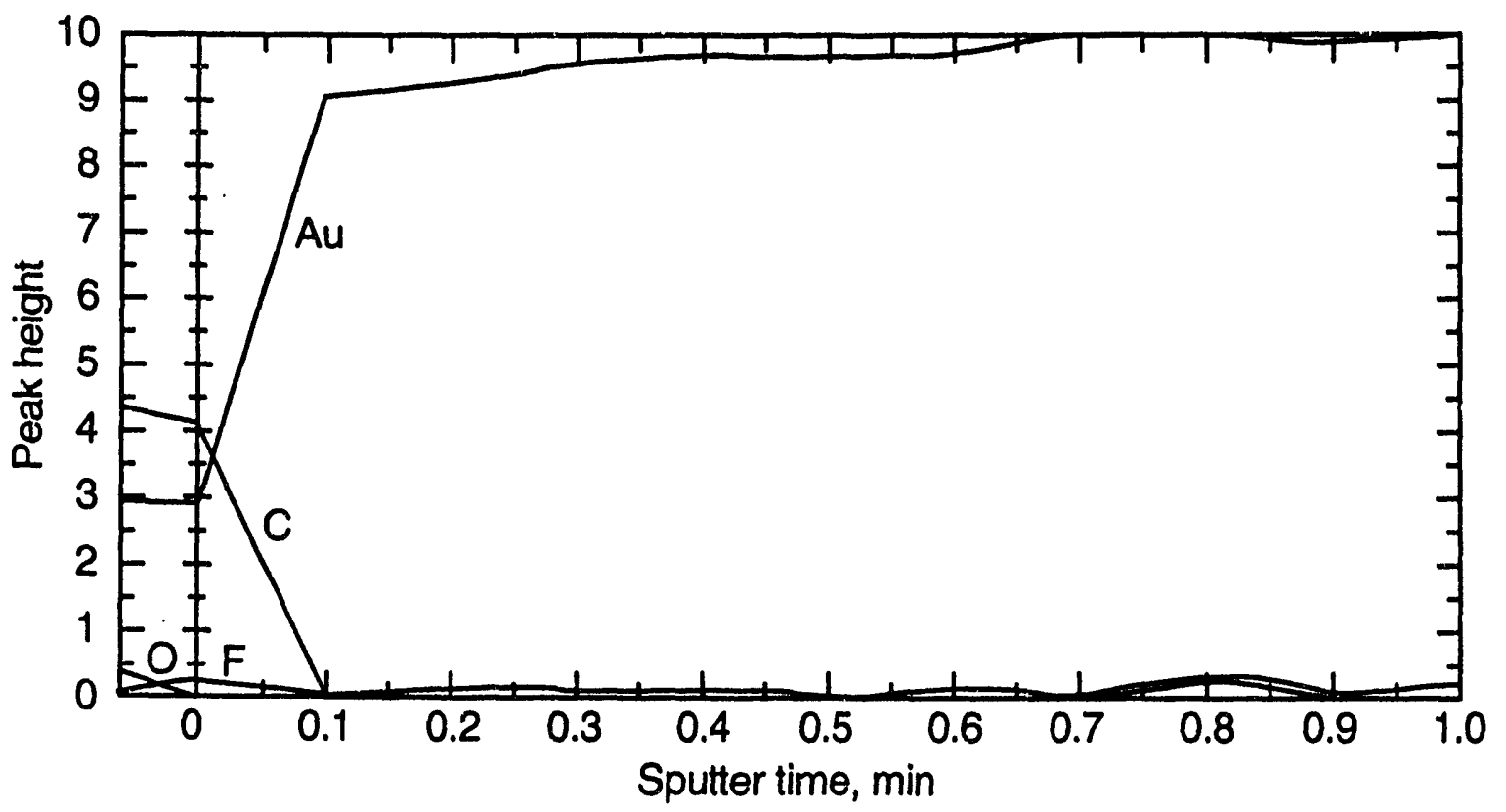

XBL $927-5280$

Figure 2.4: (a) AES spectrum and (b) depth profile of $\mathrm{Au} / \mathrm{W}$ wire aged in $\mathrm{CF}_{4}$. 
The lack of detectable deposits is consistent with the lack of degradation of pulse height or of energy resolution and with a previous study that had reported little aging in $\mathrm{CF}_{4}$ [23].

Although suggested by the rapid decrease in the current, fluorocarbon deposition was not observed on wires aged by our standard procedure (i.e., with an irradiated region of $\sim 3.5 \mathrm{~mm}$ ). Fluorocarbon deposits were observed, however, on an $\mathrm{Au} / \mathrm{W}$ wire aged in $\mathrm{CF}_{4}$ that had been irradiated over a $\sim 3 \mathrm{~cm}$ region with a current density of $0.36 \mu \mathrm{A} / \mathrm{cm}$. No deposition was observed in a similar test in which the current density was reduced to $0.02 \mu \mathrm{A} / \mathrm{cm}$. One possible explanation is that a combination of high current density and long residence time in the irradiated region may promote polymerization and deposition of $\mathrm{CF}_{\mathrm{x}}$ radicals.

\subsubsection{Non-gold Wires}

Plots of pulse height, energy resolution, and current for aging of a $\mathrm{Cu}$ wire in $\mathrm{CF}_{4}$ are shown in Fig. 2.6. Degradation is clearly evident for the $\mathrm{Cu}$ wire but, like the $\mathrm{Au} / \mathrm{W}$ wire, there is still a discrepancy between the various measures of aging, with current dropping much faster than either pulse height or energy resolution. Because the energy resolution is a measure of the uniformity rather than the thickness of the deposits, its degradation pattern will not necessarily be correlated with those of the current or pulse height. The slightly more rapid degradation of both pulse height and energy resolution downstream relative to upstream of the center of irradiation suggests that convection of etching and/or polymerizing species is of some significance under the conditions used in these aging tests. Such convective effects are probably less important in real wire chambers where, unlike the aging tests, the plasma is neither spatially localized nor temporally continuous.

Non-gold wires that we have tested react to form a metal fluoride on the surface when aged in $\mathrm{CF}_{4}$. Fig. 2.7a shows a typical AES depth profile of a $\mathrm{Cu}$ wire aged in $\mathrm{CF}_{4}$. It is clear from the correlation between fluorine and the metal and the absence of carbon that a metal fluoride is present. There is also some carbon, possibly in the form of a fluorocarbon, on top of the fluoride. Bulk deposits clearly identifiable as fluorocarbons were not observed. Similar depth profiles are observed for $\mathrm{Al}$ (Fig. 2.7b), 


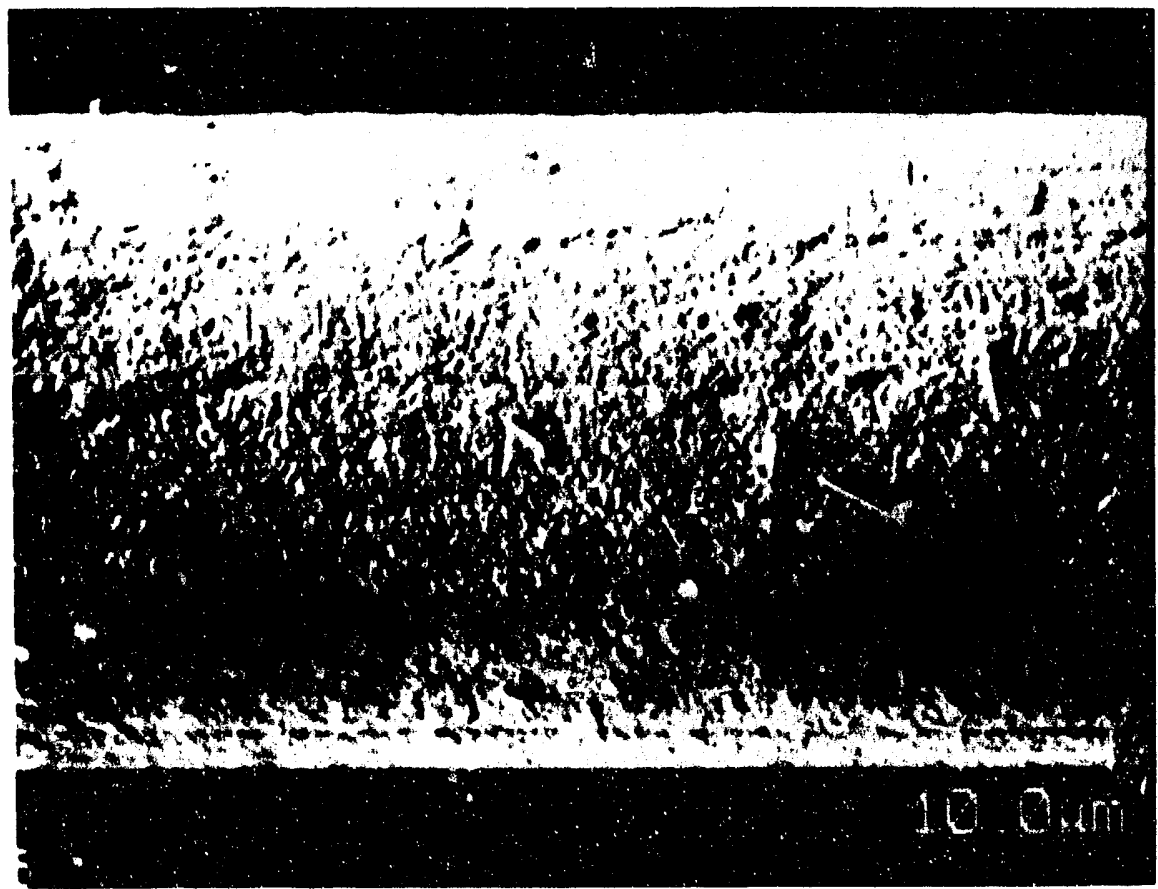

XBB926-4159

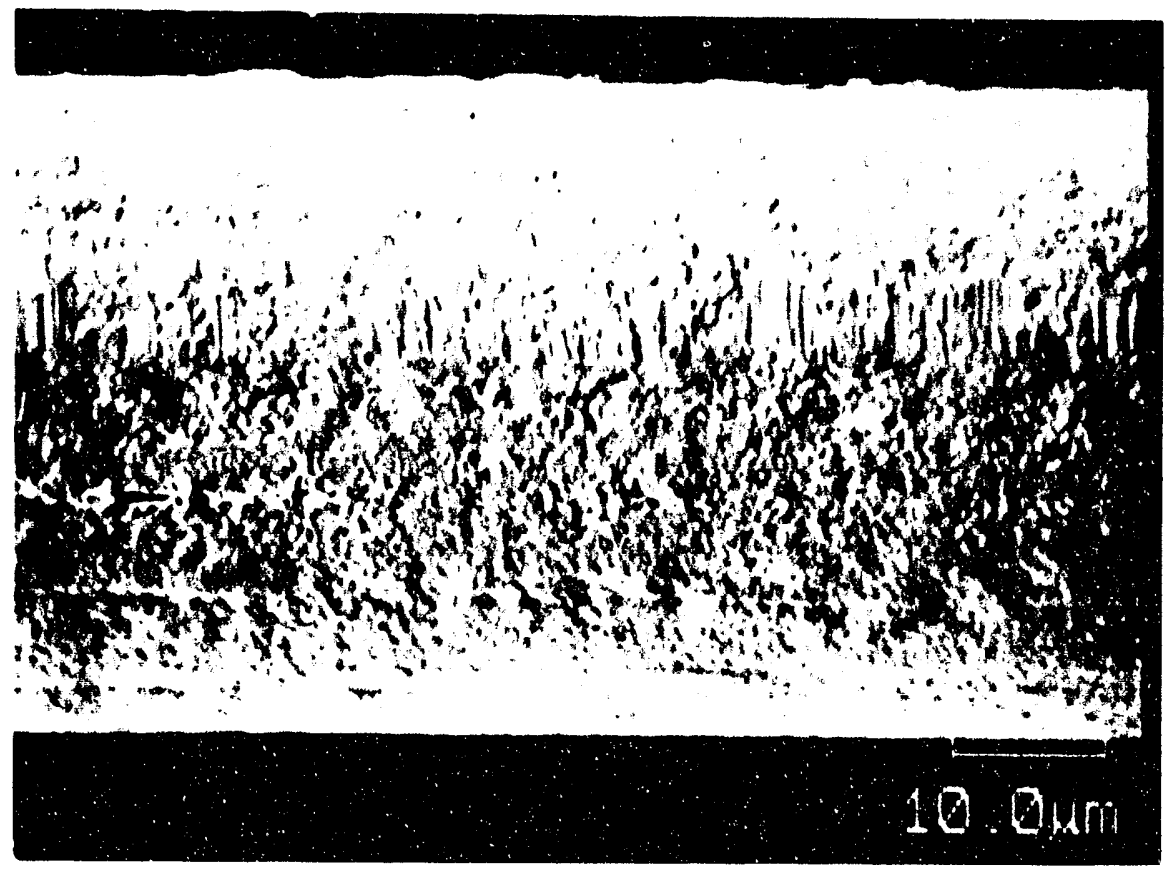

XBB926-4155

Figure 2.5: Photos of $\mathrm{Au} / \mathrm{W}$ wires: (a) new, (b) aged in $\mathrm{CF}_{4}$. 

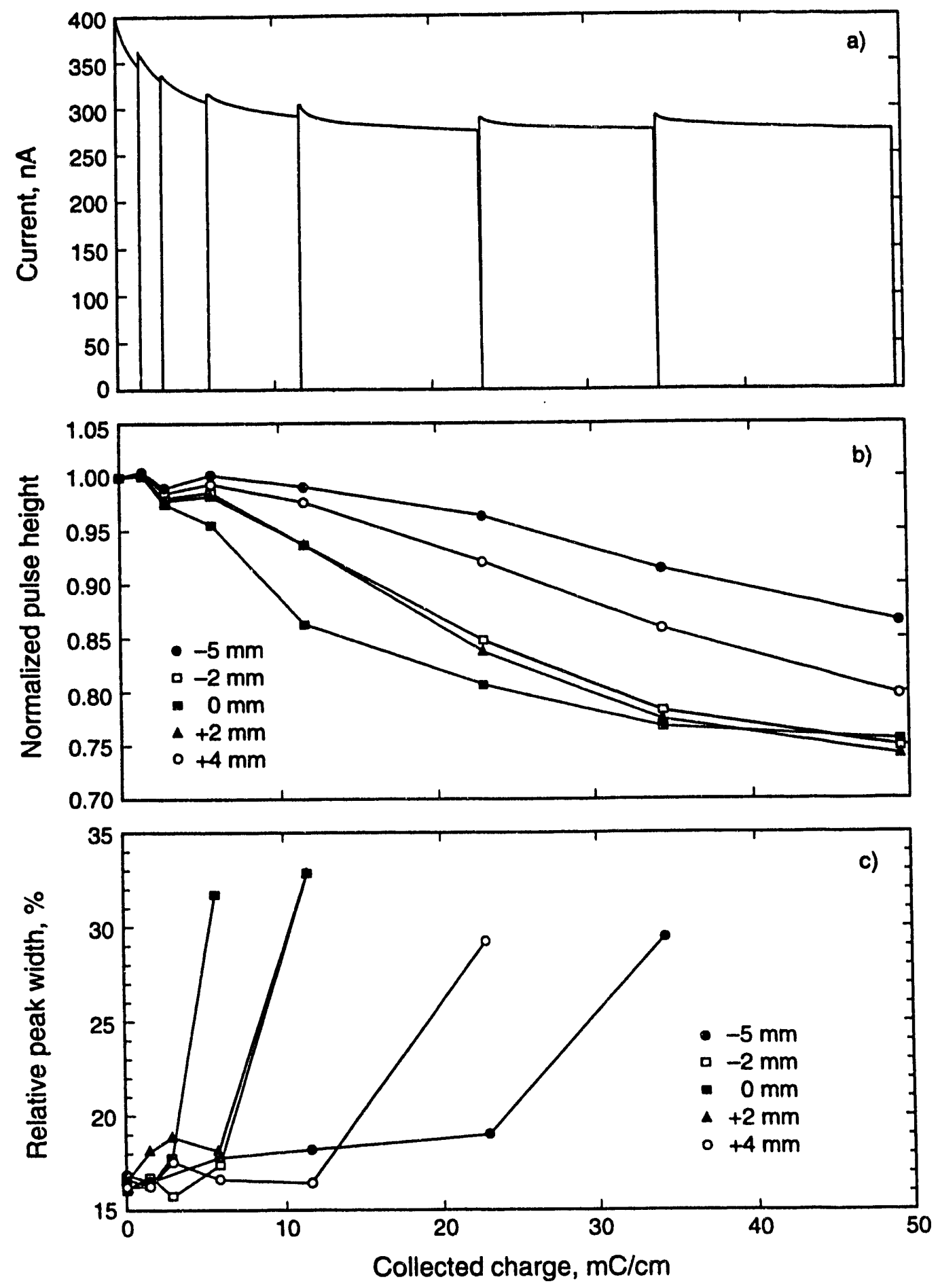

XBL 926-5693

Figure 2.6: Aging parameters as a function of collected charge for a $\mathrm{Cu}$ wire aged in $\mathrm{CF}_{4}$ : (a) current, (b) pulse height, (c) energy resolution. Distances are relative to the center of irradiation. 


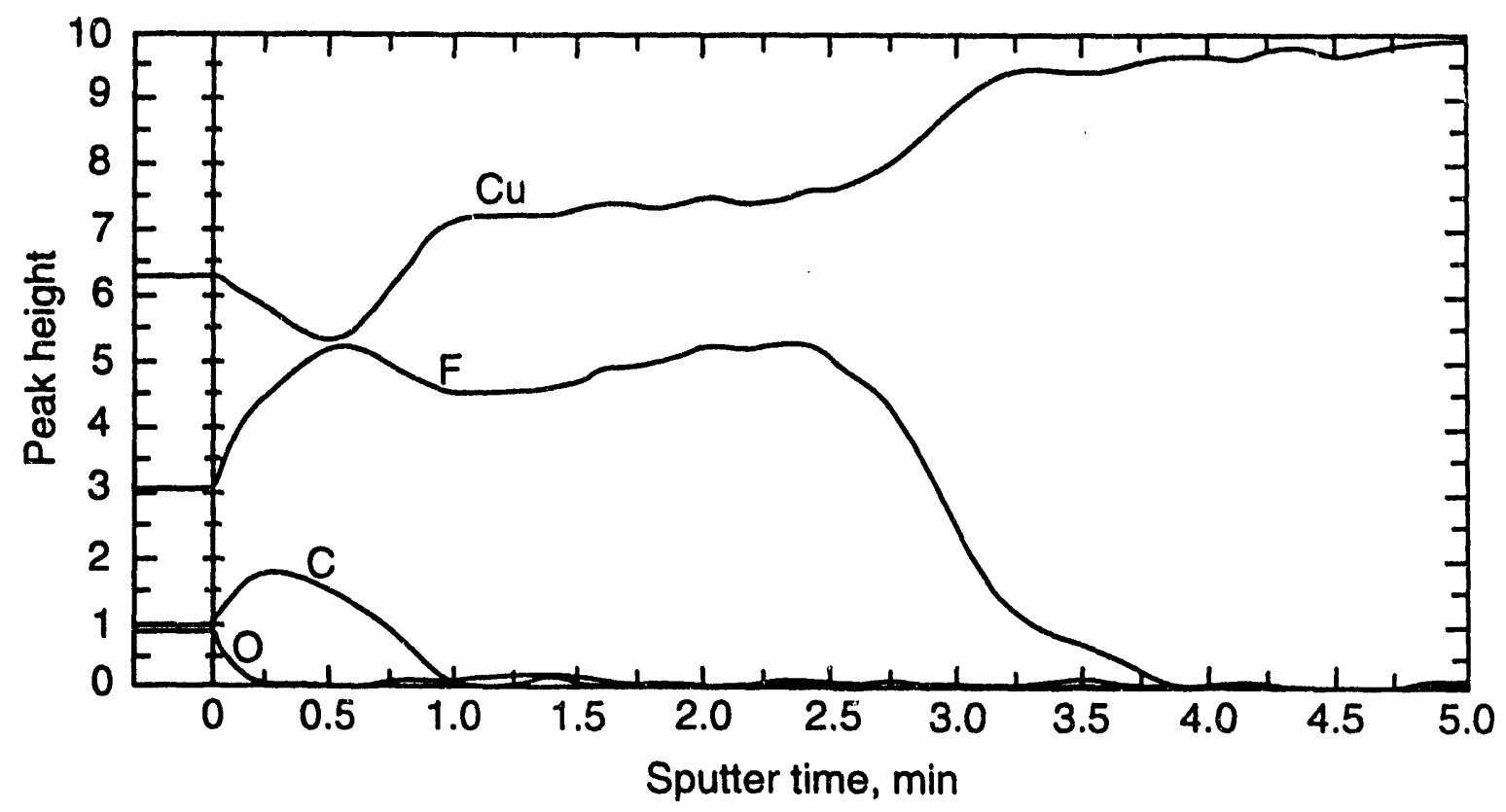

XBL926-6106

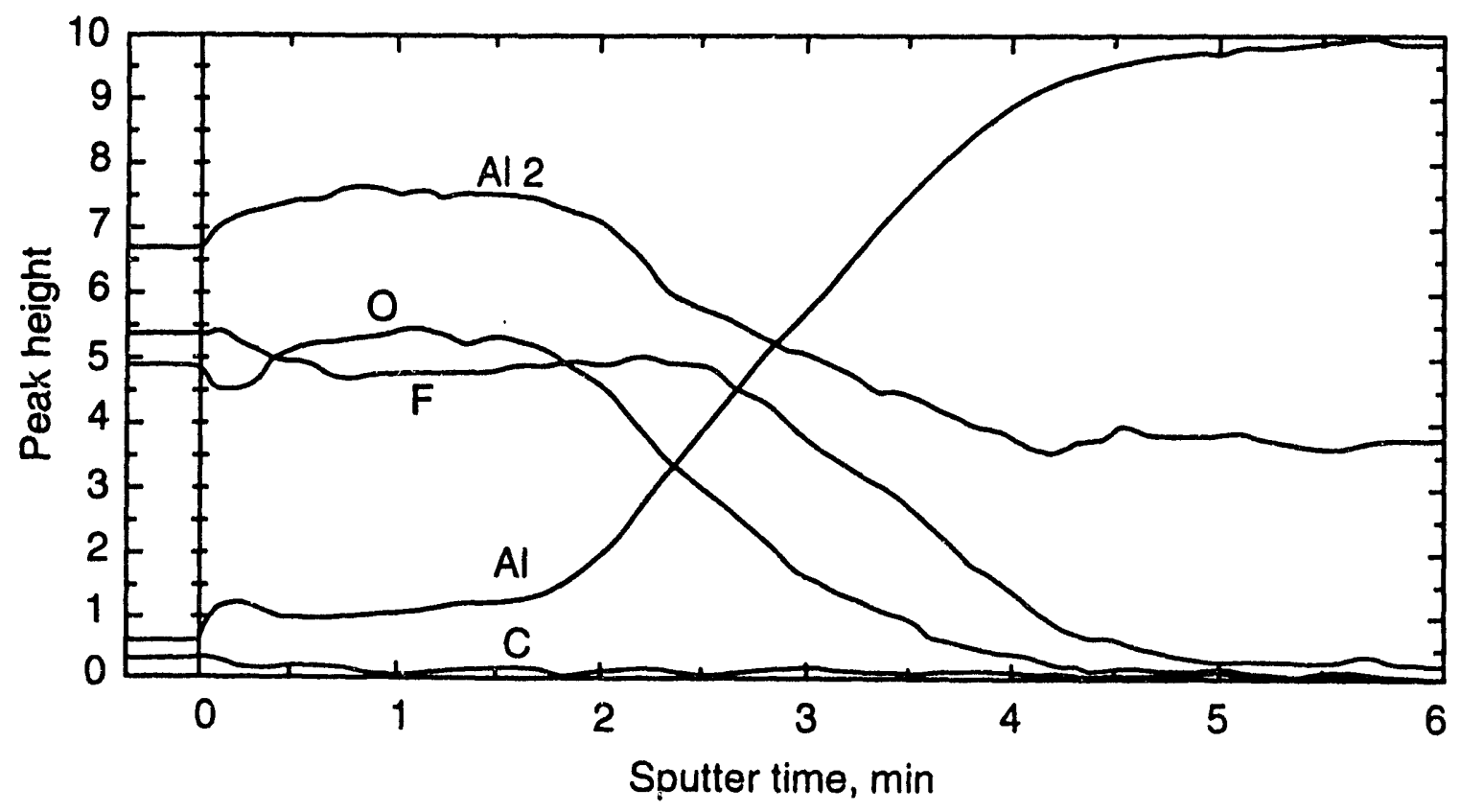

XBL926-6107

Figure 2.7: AES depth profiles of (a) $\mathrm{Cu}$ wire and (b) $\mathrm{Al}$ wire aged in $\mathrm{CF}_{4}$ showing metal fluoride film. For the $\mathrm{Al}$ wire, the drop in intensity of the $\mathrm{Al} 2$ curve is an artifact of the data acquisition process, resulting from the difference in binding energy between $\mathrm{Al}(1396 \mathrm{eV})$ and $\mathrm{Al}_{2} \mathrm{O}_{3}(1378 \mathrm{eV})$. 
$\mathrm{Ni}$, and Stablohm wires. The morphology of the metal fluorides is smooth, resembling that of unused wires (Fig. 2.8). Growth of the copper fluoride is discussed further in section 2.6.

The fluorination of non-gold wires by $\mathrm{CF}_{4}$ provides an additional aging mechanism relative to gold wires, which may explain some of the variation observed in $D$ for different wire materials (Fig. 2.2).

\subsubsection{Cathode Effects}

The lack of degradation of the pulse height spectra and the lack of deposits suggest that $\mathrm{Au} / \mathrm{W}$ anode wires do not age in $\mathrm{CF}_{4}$. If so, the observed decrease in anode current could not be due to anode aging and might therefore be due to cathode aging. Cathode aging would also explain the relative independence of the decay constant for $\mathrm{CF}_{4}$ to anode material because copper cathodes were always used for those tests. In addition, if the observed $\mathrm{CF}_{4}$ aging is a cathode phenomenon, the beneficial effect of the $\mathrm{iC}_{4} \mathrm{H}_{10}$ could be understood by its likely role of scavenging fluorine radicals or charge-exchanging with fluorocarbon ions en route to the cathode.

One means of investigating possible cathode aging was to separate anode and cathode effects by combining new and aged portions of counter tubes [24]. In the present case, cathode shells of counter tubes that had been aged in $\mathrm{CF}_{4}$ were restrung with new anode wires. One such test resulted in a self-sustained breakdown, indicating the presence of cathode deposits. In a second test (Fig. 2.9), replacement of the anode wire did not restore the current to its initial value. The first aging segment shows the expected aging transient in $\mathrm{CF}_{4}$. After an interval of 55 days the anode wire was replaced and the test was continued, with a recovery of the current from $43 \%$ to $70 \%$ of its initial value (point A). This recovery may be due to the length of time during which the tube was idle or to failure to replace the ${ }^{55} \mathrm{Fe}$ source in its original position. At the end of the second aging segment the anode wire was again replaced (point B). The time interval was reduced to $2.15 \mathrm{hr}$ and great care was taken to ensure that the ${ }^{55} \mathrm{Fe}$ source was replaced in its previous position. The wire current was within $\sim 5 \%$ of its previous value. This test was repeated in a different counter tube; the time interval for replacement of the anode wire was $1.3 \mathrm{hr}$, and the before and after 


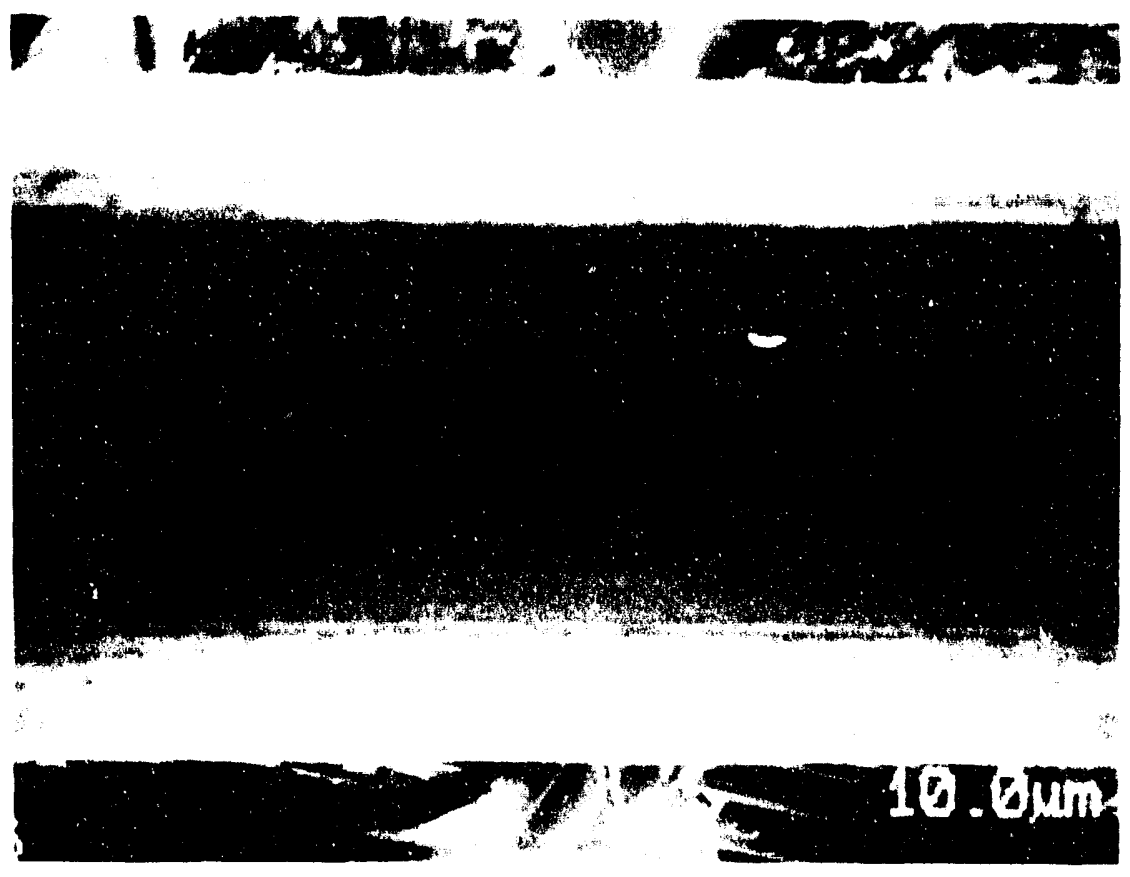

XBB926-4718

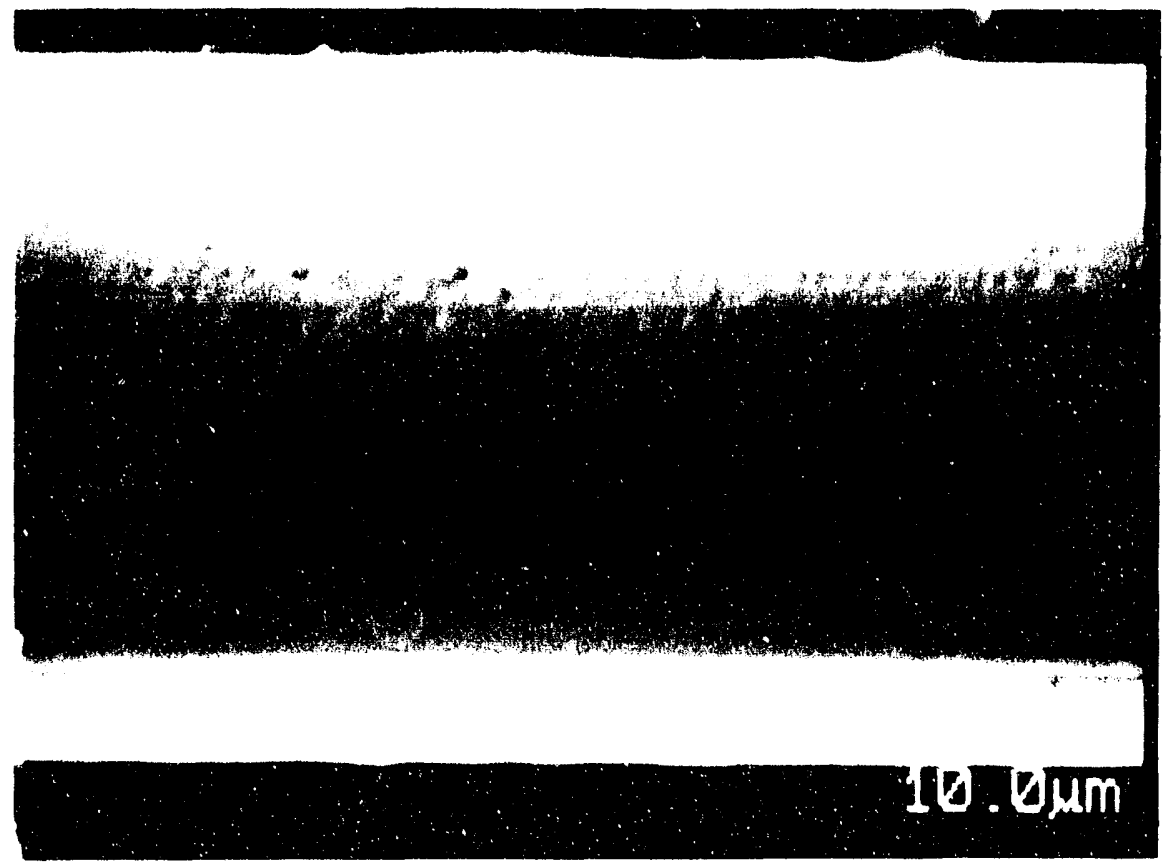

XBB927-5401

Figure 2.8: Photos of $\mathrm{Ni}$ wires: (a) new, (b) aged in $\mathrm{CF}_{4}$. Note the smooth surfaces. The small dark spots on the new wire are native contamination. Other non-gold wires have similar appearances. 


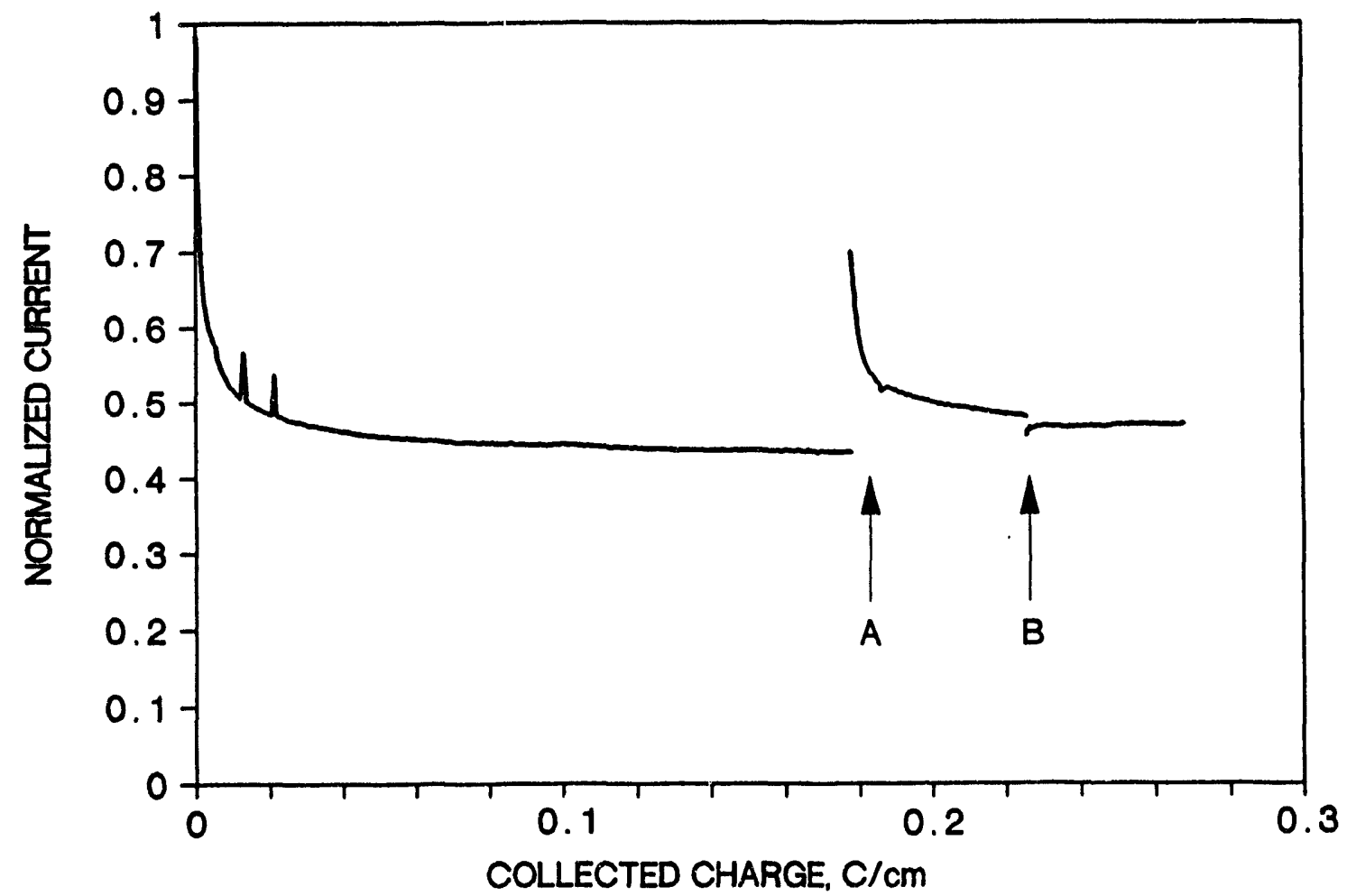

Figure 2.9: Effect of new anode wires in a cathode shell aged with $\mathrm{CF}_{4}$. The initial current was $408 \mathrm{nA}$. New anode wires were installed at points $\mathrm{A}$ and $\mathrm{B}$. The time intervals were 55 days and $2.15 \mathrm{hr}$, respectively. 
values of the wire current agreed to within $\sim 9 \%$. These results indicate that some aging occurs, but not on the anode. Cathode aging is implied, but is not shown conclusively.

Possible effects of cathode material on aging in $\mathrm{CF}_{4}$ were investigated using rectangular aluminum counter tubes with windows $1 \mathrm{~cm}$ dia. The design of these counters has been described previously [25]. Three cathode materials ( $\mathrm{Al}, \mathrm{Au}$, and $\mathrm{Ni}$ ) were used; the latter two materials were plated onto the tube and the window foil. The aging transients were unchanged by using $\mathrm{Au}$ and $\mathrm{Ni}$ instead of $\mathrm{Cu}$ cathodes. In approximately half of the tests using Al cathodes, however, the magnitude of the transient was greatly reduced (Table 2.2 ).

Table 2.2: Summary of aging transients in $\mathrm{CF}_{4}$ with $\mathrm{Al}$ cathodes. With $\mathrm{Cu}$ cathodes, average $R \sim>3 \% / \mathrm{mC}$.

\begin{tabular}{|l|c|c|c|}
\hline $\begin{array}{c}\text { Wire } \\
\text { material }\end{array}$ & $\begin{array}{c}\text { Collected } \\
\text { charge }[\mathrm{mC}]\end{array}$ & $I_{\text {final }} / I_{\max }$ & $\begin{array}{c}\text { Average } R \\
{[\% / \mathrm{mC}]}\end{array}$ \\
\hline $\mathrm{Cu}$ & 9.56 & 0.987 & 0.14 \\
$\mathrm{Cu}$ & 7.67 & 0.979 & 0.27 \\
$\mathrm{Cu}$ & 25.9 & 0.970 & 0.12 \\
$\mathrm{Cu}$ & 5.62 & 0.939 & 1.09 \\
$\mathrm{Cu}$ & 3.05 & 0.926 & 2.43 \\
$\mathrm{Au} / \mathrm{W}$ & 33.5 & 0.910 & 0.27 \\
$\mathrm{Stablohm}$ & 32.2 & 0.887 & 0.35 \\
$\mathrm{Cu}$ & 16.8 & 0.761 & 1.42 \\
$\mathrm{Cu}$ & 1.59 & 0.620 & 23.9 \\
$\mathrm{Cu}$ & 4.59 & 0.570 & 9.4 \\
$\mathrm{Cu}$ & 1.76 & 0.520 & 27.3 \\
\hline
\end{tabular}

Trace amounts of fluorine, most probably in the form of a fluorocarbon, were observed on the cathode window foils from these tests. There was no indication of metal fluorides, nor was there any significant spatial variation in the composition of surface deposits. SEM imaging revealed no distinct deposits; from AES depth profiling the deposit thickness was estimated at $\sim 10 \mathrm{~nm}$.

A cathode aging phenomenon might be understood if charge accumulation on an 
insulating cathode layer accounts for the decrease in current observed in $\mathrm{CF}_{4}$. The (insulating) native aluminum oxide may be of sufficient quality that a steady-state level of charge accumulation is achieved during startup of an aging test with the result that no transient is observed. For conducting cathode materials, charge accumulation cannot occur until a suitable (fluorocarbon) film is formed. Because formation of such a film results from reactions in the avalanche, film growth and the consequent charge accumulation are observable as a function of time after an aging test is started.

It is generally considered unlikely that deposition of a film on the cathode would result in loss of gain, the traditional explanation of cathode aging arguing that an insulating film leads to field emission and a self-sustained (Malter) breakdown [26]. However, if the insulating film on the cathode were thick enough that the field developed would not exceed the field emission threshold, the voltage drop at the cathode would reduce the effective anode potential, and hence the gain. A voltage drop of about $100 \mathrm{~V}$ is needed to cause the $\sim 50 \%$ reduction in gain typically observed for aging in $\mathrm{CF}_{4}$. To remain below the threshold for field emission, measured to be $\sim 1.75 \times 10^{5} \mathrm{~V} / \mathrm{cm}$ in the counters used for these tests, a cathode film therefore needs to be at least $1.75 \mu \mathrm{m}$ thick. An upper limit on the mass of material available for reaction can be made by relating the energy dissipated by the avalanches in the time over which the rapid aging in $\mathrm{CF}_{4}$ occurs and the dissociation energy of the C-F bond. This corresponds to about $7 \times 10^{-4} \mathrm{~g}$ of material which, if evenly distributed on a cathode area of $1 \mathrm{~cm}^{2}$, would form a layer about $7 \mu \mathrm{m}$ thick. While this estimate suggests that cathode aging without self-sustained breakdowns may be a possibility, the cathode deposits observed were only $\sim 10 \mathrm{~nm}$, far thinner than that calculated to prevent field emission. We have been unable to explain the mechanism of cathode aging in $\mathrm{CF}_{4}$.

\subsubsection{Etching in $\mathrm{CF}_{4}$}

In view of the considerable evidence that $\mathrm{Au} / \mathrm{W}$ anode wires do not age in $\mathrm{CF}_{4}$, it was reasonable to ask whether $\mathrm{CF}_{4}$ would etch deposits. Recovery in $\mathrm{CF}_{4}$ was attempted with wires aged in $\mathrm{CF}_{4} / \mathrm{iC}_{4} \mathrm{H}_{10}(95 / 5)$ (see section 2.4), and was observed in the current, the pulse height, and the energy resolution. Recovery rates were 
rapid (typically $>1000 \% / \mathrm{C} / \mathrm{cm}$ ), and full gain was restored after only $0.01 \mathrm{C} / \mathrm{cm}$ of charge. The extraordinary rapidity of this recovery is an indication of the efficacy of the etching reactions in $\mathrm{CF}_{4}$.

Evidence of etching in $\mathrm{CF}_{4}$ is also shown in Fig. 2.3 (a slight increase in the pulse height) and in the third segment of Fig. 2.9 (a slight increase in the current). These results may be due to removal of native contamination from the (new) wires used in these tests.

Deposits on $\mathrm{Au} / \mathrm{W}$ wires that had been damaged by exposure to $\mathrm{Ar} / \mathrm{C}_{2} \mathrm{H}_{6}(50 / 50)$ bubbled through silicone oil [13] were etched by $\mathrm{CF}_{4} / \mathrm{iC}_{4} \mathrm{H}_{10}(80 / 20)$ but not by dimethyl ether or by $\mathrm{Ar} / \mathrm{C}_{2} \mathrm{H}_{6}(50 / 50)$, indicating that the recovery is due to a (chemical) etching process requiring fluorine and not to a (mechanical) ablation process. Due to the low energies of negative ions in an avalanche, ablation was not expected. Bubbling $\mathrm{CF}_{4}$ through the silicone oil caused a change in the aging transient $\left(D \sim 6 \mathrm{mC}^{1 / 2} ; I / I_{0} \sim 0.85\right)$; AES revealed only atmospheric contamination on wires aged in this way.

\subsection{Aging Properties of $\mathrm{CF}_{4} / \mathrm{iC}_{4} \mathrm{H}_{10}$ Mixtures}

As a means of understanding the chemistry that leads to etching in $\mathrm{CF}_{4} / \mathrm{iC}_{4} \mathrm{H}_{10}$ $(80 / 20)$, it was useful to study the aging properties of a wide range of gas mixtures. This was also a useful step in the development of a general model for aging in $\mathrm{CF}_{4} / \mathrm{iC}_{4} \mathrm{H}_{10}$ gases.

$\mathrm{CF}_{4} / \mathrm{iC}_{4} \mathrm{H}_{10}$ (95/5): Heavy carbonaceous deposits are formed on $\mathrm{Au} / \mathrm{W}$ wires aged in this gas mixture (Fig. 2.10a). Some variation in thickness with azimuthal position around the wire is evident. The AES spectrum is dominated by an intense $\mathrm{C}$ peak (Fig. 2.11); the thickness of the deposit masks the underlying metal. It is notable that the deposits are carbonaceous; the absence of fluorine indicates that they are formed primarily from the $\mathrm{iC}_{4} \mathrm{H}_{10}$ and not from the $\mathrm{CF}_{4}$. Depth profiling revealed a uniform composition throughout the deposit.

Heavy, rough deposits are also formed on non-gold wires aged in $\mathrm{CF}_{4} / \mathrm{iC}_{4} \mathrm{H}_{10}$ (95/5); these deposits typically have distinct morphology (Fig. 2.12a). Depth profiling 


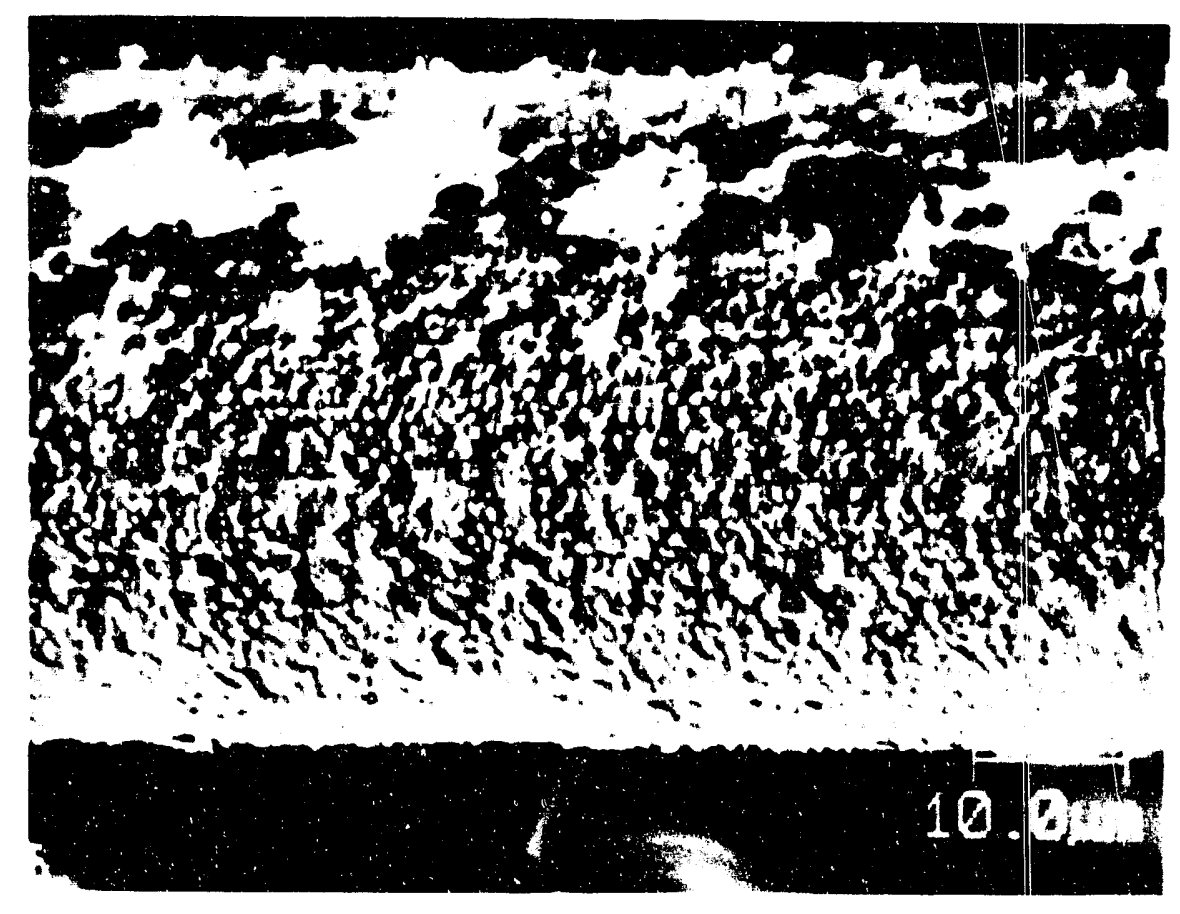

XBB926-4157

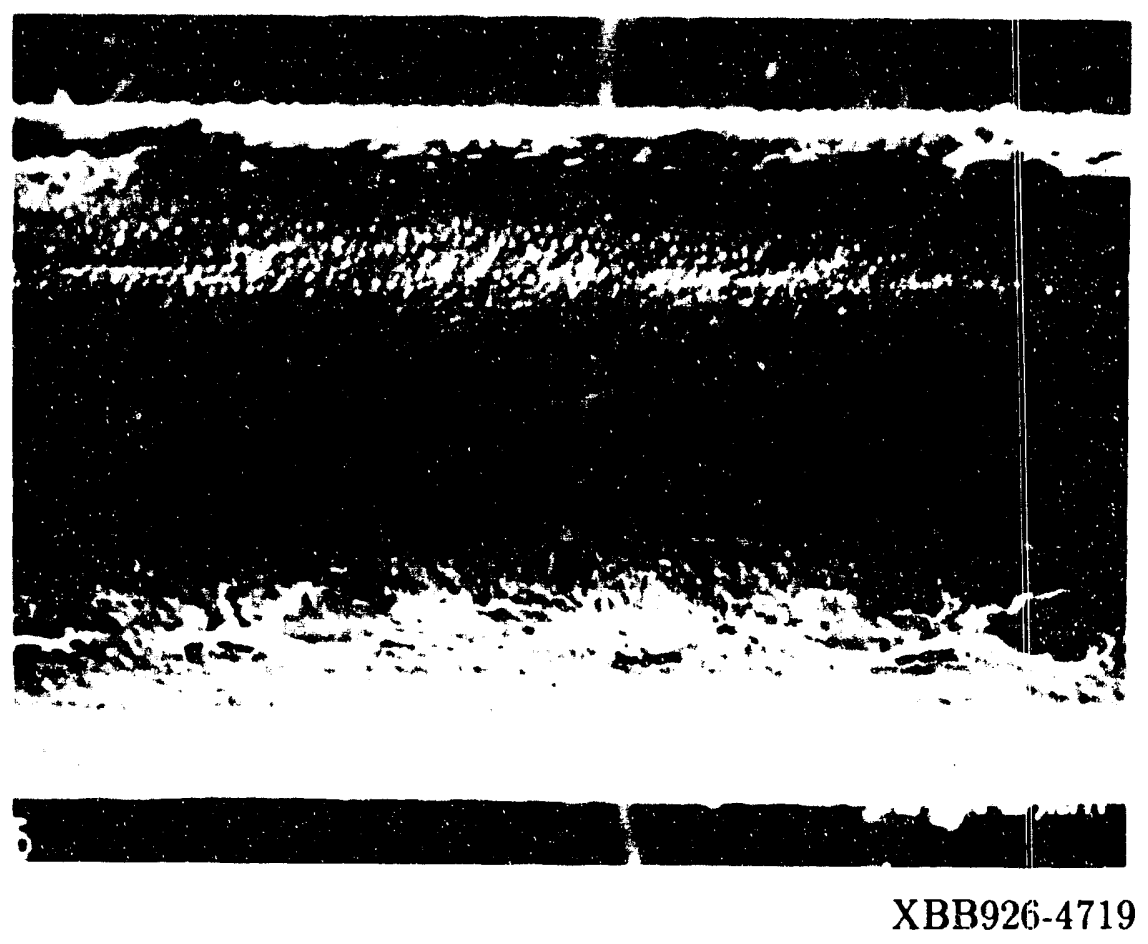

Figure 2.10: Photos of $\mathrm{Au} / \mathrm{W}$ wires aged in $\mathrm{CF}_{4} / \mathrm{iC}_{4} \mathrm{H}_{10}$ mixtures: (a) $(95 / 5)$, (b) $(90 / 10)$. 


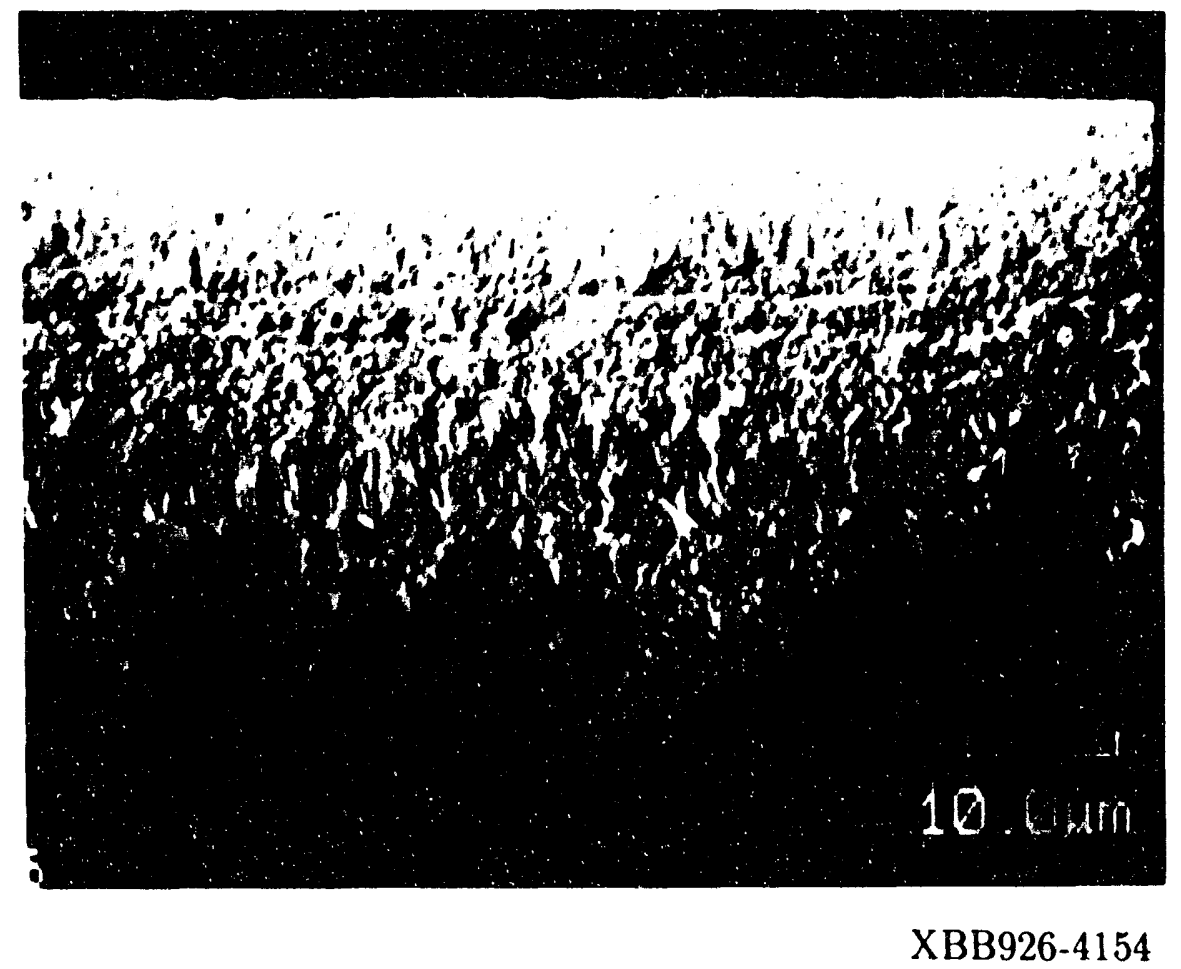

Figure 2.5: (c) $\mathrm{Au} / \mathrm{W}$ wire aged in $\mathrm{CF}_{4} / \mathrm{iC}_{4} \mathrm{H}_{10}(80 / 20)$.

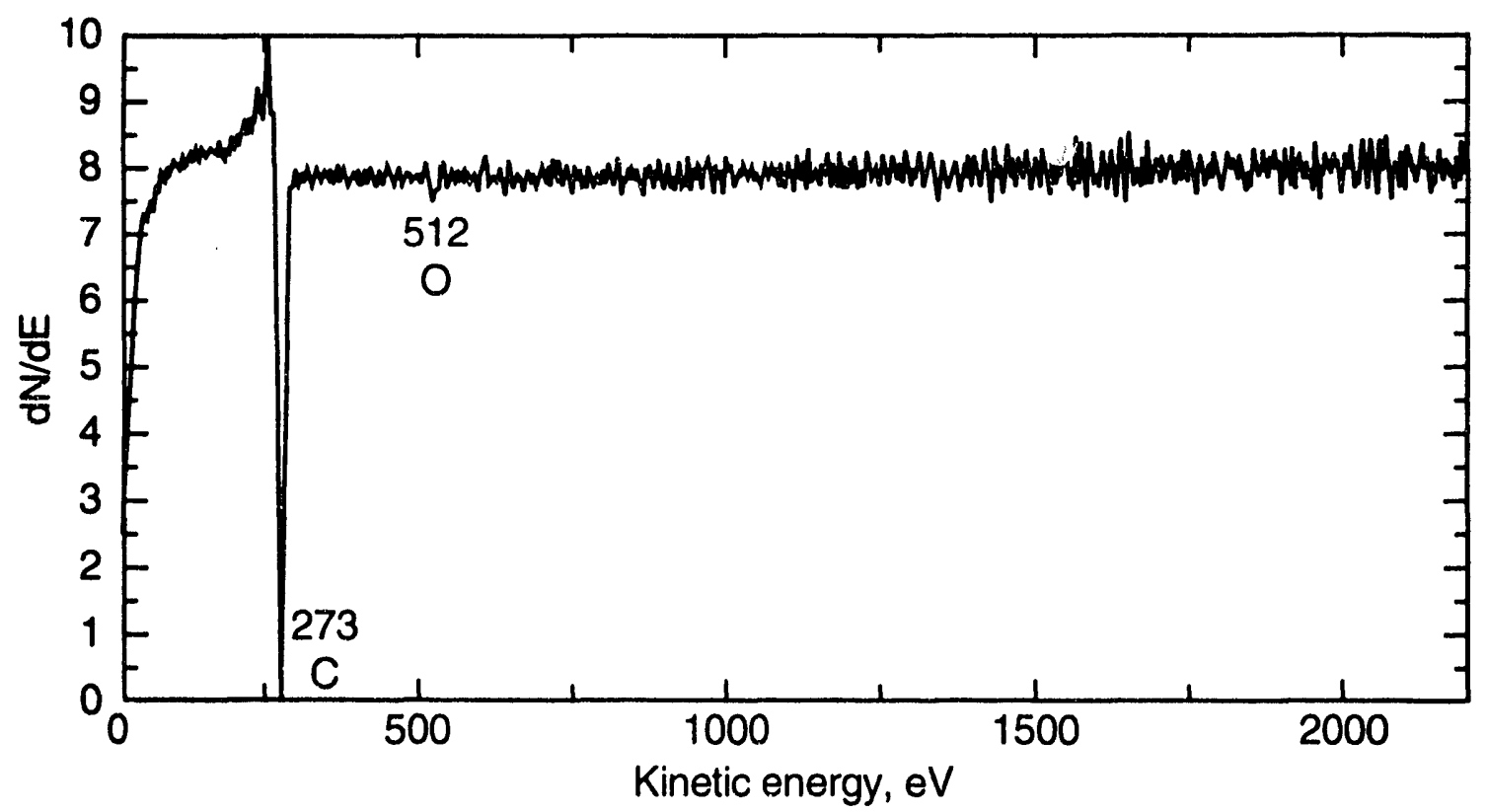

XBL 927-5281

Figure 2.11: AES spectrum of $\mathrm{Au} / \mathrm{W}$ wire aged in $\mathrm{CF}_{4} / \mathrm{iC}_{4} \mathrm{H}_{10}(95 / 5)$. An intense $\mathrm{C}$ peak masks the underlying metal. 


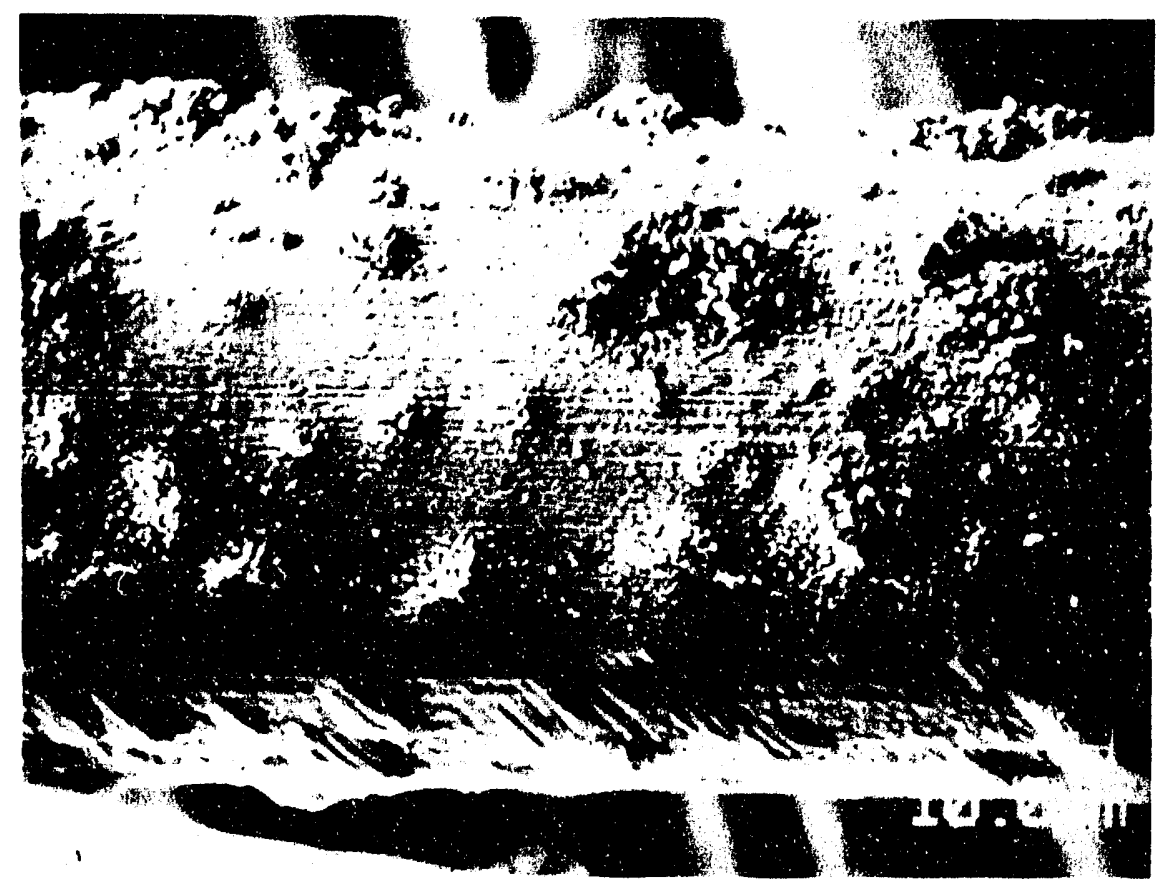

XBB926-4158

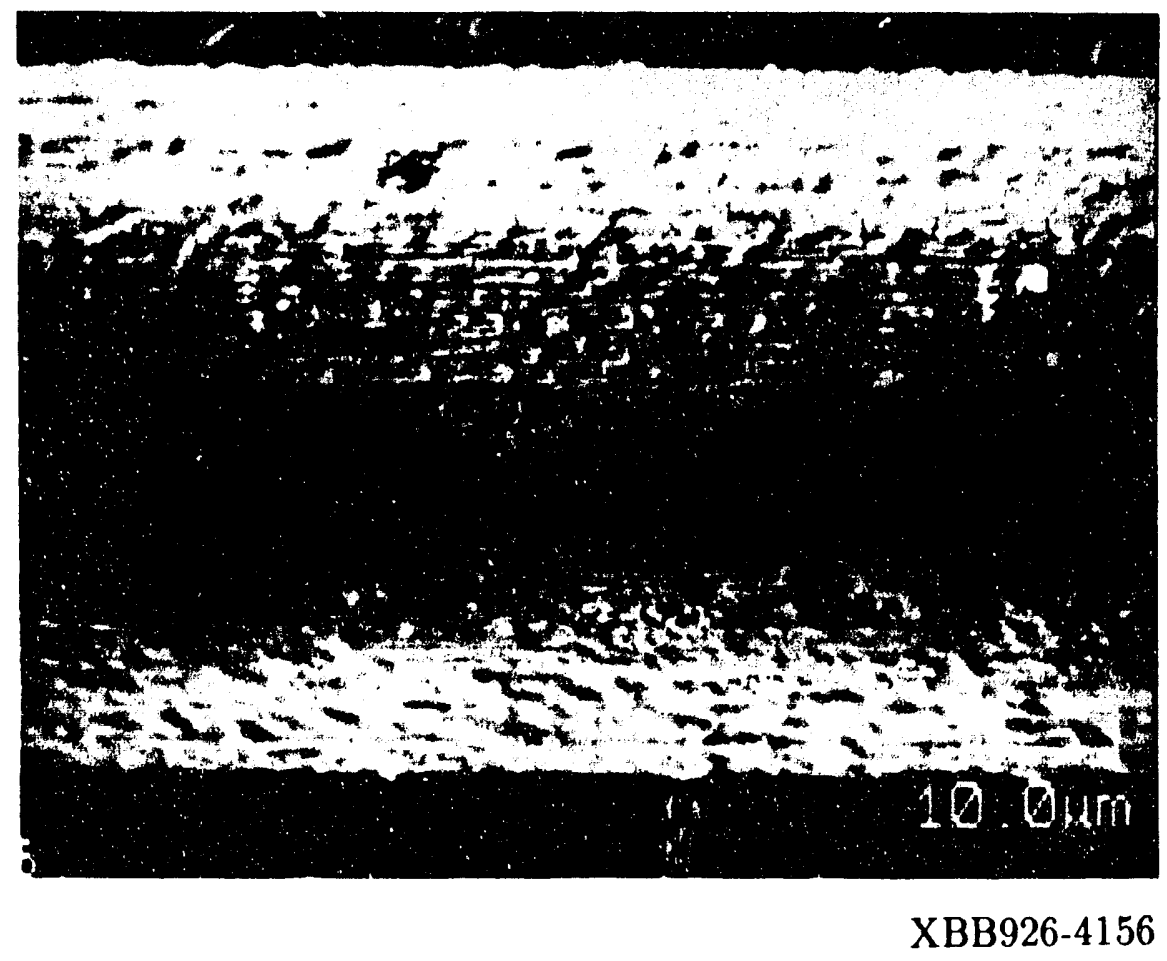

Figure 2.12: Photos of non-gold wires aged in $\mathrm{CF}_{4} / \mathrm{iC}_{4} \mathrm{H}_{10}$ mixtures: (a) $\mathrm{Al}$ wire, $95 / 5$, (b) Ni wire, $80 / 20$. 
revealed a stratified deposit structure, with a carbonaceous layer on top and a metal fluoride underneath (Fig. 2.13). This figure shows a relatively thin carbonaceous

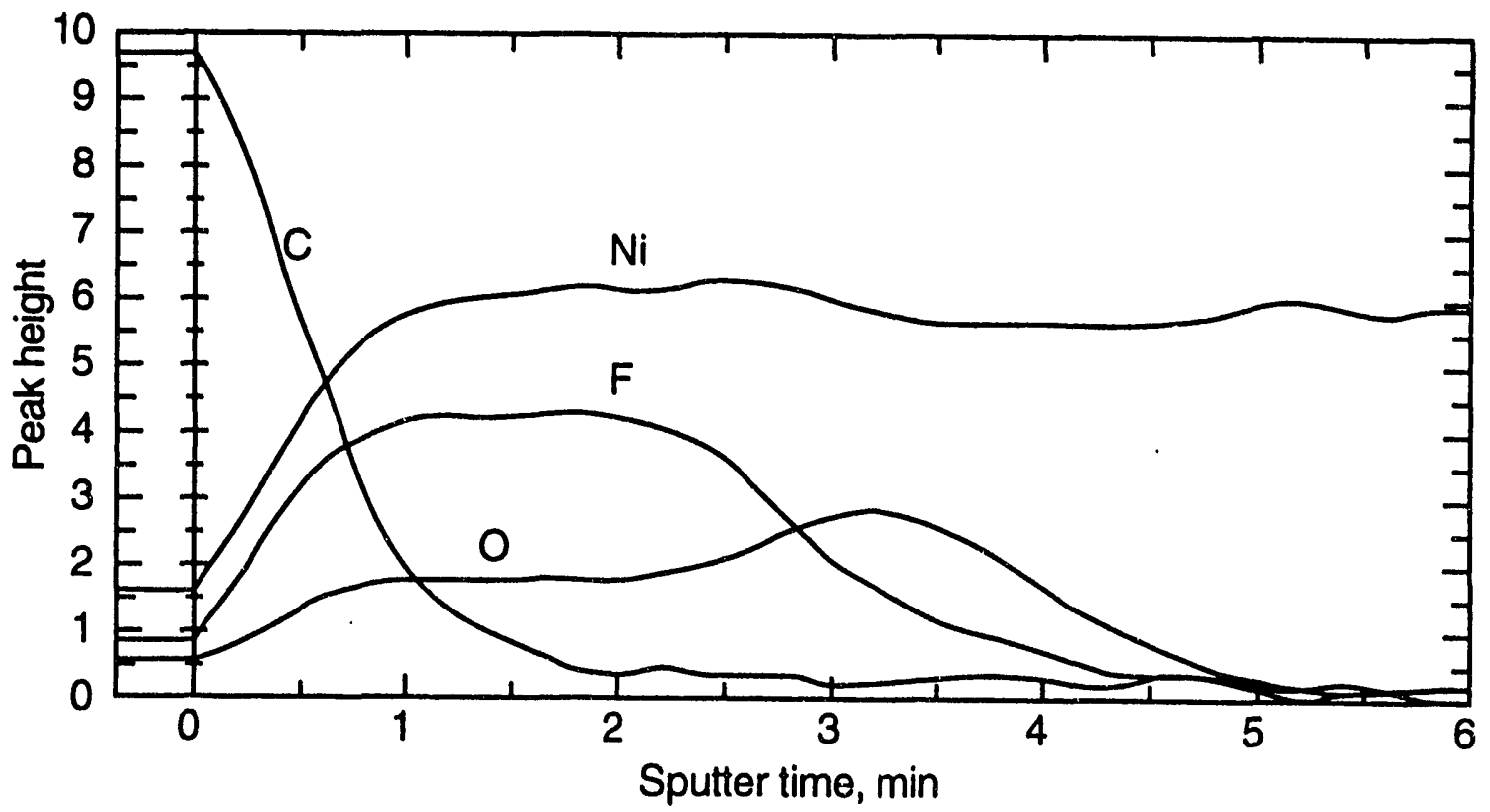

XBL $927-5279$

Figure 2.13: AES depth profile of $\mathrm{Ni}$ wire aged in $\mathrm{CF}_{4} / \mathrm{iC}_{4} \mathrm{H}_{10}(95 / 5)$. A stratified deposit structure with a carbonaceous layer on top of a metal fluoride is evident.

layer. The visibly heavy deposits have thicknesses in excess of $10 \mathrm{~min}$ of sputter time; only carbon is observed in depth profiles in such regions.

$\mathrm{CF}_{4} / \mathrm{iC}_{4} \mathrm{H}_{10}(90 / 10)$ : The deposits formed on $\mathrm{Au} / \mathrm{W}$ wires by the $90 / 10$ mixture are similar, both visually and chemically, to those formed by the $95 / 5$ mixture, although they are not as thick or as extensive. There is also a sharper division in the azimuthal distribution of the deposits, with both coated and uncoated regions distinctly visible (Fig. 2.10b). Aging of non-gold wires was not investigated in this gas mixture.

$\mathrm{CF}_{4} / \mathrm{iC}_{4} \mathrm{H}_{10}(80 / 20)$ : The appearance of $\mathrm{Au} / \mathrm{W}$ wires aged in the $80 / 20$ mixture (Fig. 2.10c) is virtually indistinguishable from that of new wires (Fig. 2.5a). AES analysis revealed only trace deposits (atmospheric contamination) on these aged wires, consistent with a previous analysis of wires whose deposits were etched in this gas mixture [15] and with the lack of aging observed in our aging tests. 
Non-gold wires aged in this gas mixture have heavy deposits (Fig. 2.12b). These deposits also have a layered structure with carbonaceous material on top of a metal fluoride. In one case, on an aluminum wire, the deposits were predominantly fluorocarbon.

$\mathrm{CF}_{4} / \mathrm{iC}_{4} \mathrm{H}_{10}(50 / 50): \mathrm{Au} / \mathrm{W}$ wires aged in this gas mixture have only trace carbonaceous deposits, similar to those observed on wires aged in the 80/20 mixture. The aging rate measured for $\mathrm{Au} / \mathrm{W}$ wires in the $50 / 50$ mixture was $0 \pm 1 \% / \mathrm{C} / \mathrm{cm}$ with total collected charge of $0.4 \mathrm{C} / \mathrm{cm}$. The lack of apparent aging and of deposits suggested that this gas mixture might etch anode deposits. Indeed, recovery of a wire aged in $\mathrm{CF}_{4} / \mathrm{iC}_{4} \mathrm{H}_{10}(95 / 5)$ was at a rate of about $300 \% / \mathrm{C} / \mathrm{cm}$. Both current and pulse height recovered to within $4 \%$ of their initial values after $0.17 \mathrm{C} / \mathrm{cm}$ of collected charge. Only trace deposits were observed on a recovered wire.

Non-gold wires aged in the 50/50 mixture have heavy deposits that are similar both chemically and visually to those observed on non-gold wires aged in other $\mathrm{CF}_{4} / \mathrm{iC}_{4} \mathrm{H}_{10}$ mixtures.

$\mathrm{CF}_{4} / \mathrm{iC}_{4} \mathrm{H}_{10}(15 / 85)$ (mixed from two independently regulated flow streams): Recovery was attempted in this gas, but was largely unsuccessful. After an initial increase in the current of about $20 \%$, the current began dropping at a rate approaching $2000 \% / \mathrm{C} / \mathrm{cm}$. This behavior is very different than that observed in the recovery tests described above, in which the current increased and then remained constant. There was an increase of $10-15 \%$ in the pulse height, but the energy resolution was essentially unchanged from its severely degraded initial condition, suggesting that little or no recovery had occurred. The tendency of $\mathrm{CF}_{4} / \mathrm{iC}_{4} \mathrm{H}_{10}(15 / 85)$ to age is consistent with aging rates of $30-250 \% / \mathrm{C} / \mathrm{cm}$ observed in $\mathrm{CF}_{4} / \mathrm{iC}_{4} \mathrm{H}_{10}(20 / 80)$.

$\mathrm{iC}_{4} \mathrm{H}_{10}$ : We observed aging rates in this gas in the range 0-60\%/C/cm. Aging rates of about zero indicate that little deposition occurs on the anode, consistent with the tendency of $\mathrm{iC}_{4} \mathrm{H}_{10}$ to form cathode deposits [27]. A recovery attempt with $\mathrm{iC}_{4} \mathrm{H}_{10}$ resulted in rapid aging observed in both current and pulse height. In this case it is possible that deposition was enhanced by the presence of deposits on the wire.

Aging and recovery rates for $\mathrm{CF}_{4} / \mathrm{iC}_{4} \mathrm{H}_{10}$ gas mixtures are shown in Fig. 2.14. Recovery results are listed in detail in Table 2.3. The data clearly show a region of 


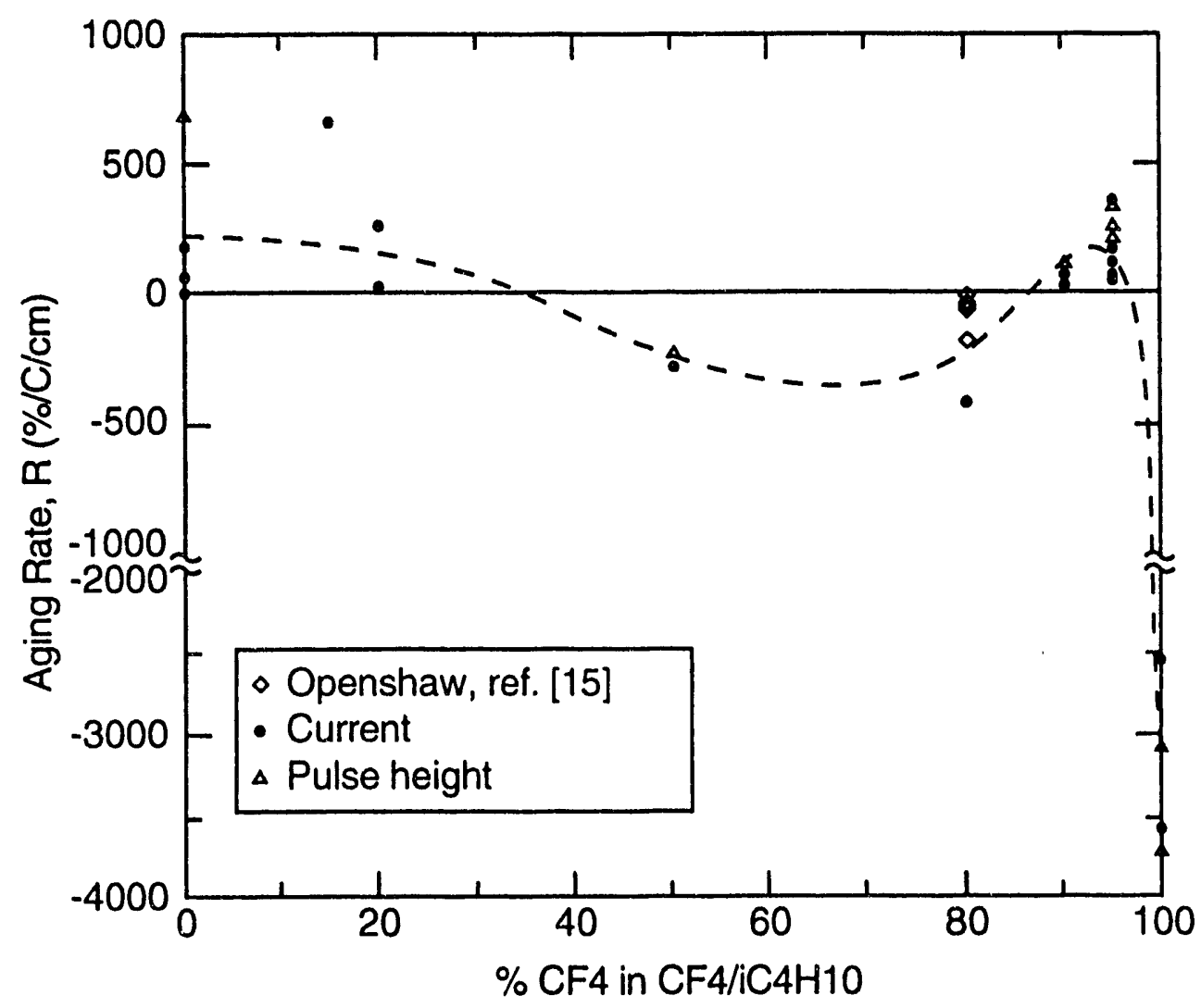

XBL 927-5277

Figure 2.14: Aging (recovery) rates for $\mathrm{Au} / \mathrm{W}$ wires as a function of gas composition in $\mathrm{CF}_{4} / \mathrm{iC}_{4} \mathrm{H}_{10}$ mixtures.

Table 2.3: Summary of recovery results for $\mathrm{Au} / \mathrm{W}$ wires in $\mathrm{CF}_{4} / \mathrm{iC}_{4} \mathrm{H}_{10}$ gases.

\begin{tabular}{|c|c|c|c|c|c|c|}
\hline $\begin{array}{c}\text { Recovery } \\
\text { gas mixture } \\
\mathrm{CF}_{4} / \mathrm{iC}_{4} \mathrm{H}_{10}\end{array}$ & $\begin{array}{c}\text { Aged } \\
\mathrm{PH} \\
{[\%]}\end{array}$ & $\begin{array}{c}\text { Recovered } \\
\mathrm{PH} \\
{[\%]}\end{array}$ & $\begin{array}{c}\text { Recovery } \\
\text { rate, } \mathrm{PH} \\
{[\% / \mathrm{C} / \mathrm{cm}]}\end{array}$ & $\begin{array}{c}\text { Recovery } \\
\text { rate, } I \\
{[\% / \mathrm{C} / \mathrm{cm}]}\end{array}$ & $\begin{array}{c}\text { Total } \\
\text { charge } \\
{[\mathrm{C} / \mathrm{cm}]}\end{array}$ & $\begin{array}{c}\text { Current } \\
\text { density } \\
{[\mu \mathrm{A} / \mathrm{cm}]}\end{array}$ \\
\hline $100 / 0$ & 76 & 103 & 3700 & 3570 & 0.01 & 0.28 \\
$100 / 0$ & 74 & 95 & 3100 & 2535 & 0.01 & 0.27 \\
$80 / 20$ & - & - & - & 410 & 0.36 & 0.50 \\
$50 / 50$ & 72 & 96 & 325 & 265 & 0.17 & 0.34 \\
\hline
\end{tabular}


aging between $0 \%$ and $\sim>20 \% \mathrm{CF}_{4}$, a region of etching between $\sim<50 \%$ and $\sim>80 \%$ $\mathrm{CF}_{4}$, a region of aging between $\sim>80 \%$ and $\sim<100 \% \mathrm{CF}_{4}$, and a small region of etching in the vicinity of $100 \% \mathrm{CF}_{4}$. Because aging transients similar to those shown in Fig. 2.1 occur in $\mathrm{CF}_{4}$-rich gases, aging rates determined from the current in these gases were measured in the asymptotic region of the curve, which can reasonably be assumed to reflect the true anode aging rate. The signs and relative magnitudes of the aging rates are of more relevance than their absolute magnitudes. The magnitudes of recovery rates, in particular, should not be viewed as definitive because etching rates may depend on the composition of the deposits being etched.

\subsection{Chemistry of Wire Aging}

The rf glow discharges (plasmas) used in plasma processing are partially ionized gases containing ions, electrons, and neutral species in both ground and excited states. The degree of ionization is small, typically about $10^{-5}$ of all species, but the degree of dissociation can be quite large, sometimes exceeding $10^{-1}$ of all species. Due to their higher concentration, the neutrals (radicals) are the primary chemical species responsible for deposition and etching processes.

Due to the difference in mobility between ions and electrons, surfaces in contact with an rf plasma generally assume a negative potential with respect to the plasma. As a result, positive ions are accelerated into surfaces, and can have a synergistic effect on etching chemistries [28]. This process is distinctly different in an atmosphericpressure wire chamber, where moderate energy electrons (5-10 eV) and low energy negative ions $(<1 \mathrm{eV})$ bombard the anode and near-thermal positive ions strike the cathode.

Energetic particles of a few $\mathrm{eV}$ can break chemical bonds in a surface, thereby creating adsorptive or reactive sites that may enhance reaction rates. Particles with energies $\sim>30 \mathrm{eV}$ may cause ablation (mechanical removal of material) as a result of momentum transfer. Energetic electrons are capable of breaking chemical bonds, but due to their low mass, electron bombardment does not lead to ablation. 
The chemistry in a plasma is very complex, involving a large number of reactions between many types of species and occurring both in the gas phase and at the gas/surface interface. The chemistry is further complicated by the sometimes sensitive dependence of plasmas to such variables as pressure, electrode temperature, power density, gas flow rate, gas composition, including presence of ppm- or ppb-level impurities, and reactor geometry. It was beyond the scope of this work to investigate the effects of all of these parameters. For application to wire chambers, however, knowledge of the dependence on many of these parameters is not critical because of their small dynamic range in normal operation.

\subsubsection{Chemical Model for Aging in $\mathrm{CF}_{4} / \mathrm{iC}_{4} \mathrm{H}_{10}$ Gases}

One model for fluorine- and carbon-containing etch gases used in plasma processing is the F/C Ratio model [29]. Rather than attempting to describe in detail the chemistry of the discharge, this model views the plasma as a ratio of fluorine species to carbon species. That is, the $\mathrm{F} / \mathrm{C}$ ratio is used as a qualitative parameter to account for the fact that etching and polymerization occur simultaneously in plasmas containing both fluorine and carbon. Anode aging in $\mathrm{CF}_{4} /$ hydrocarbon gases can be understood in terms of a four-part model based, in part, on the F/C ratio. Because of the difficuity in accurately modeling the multitude of chemical reactions in an avalanche, the advantage of using this sort of qualitative model is obvious.

\section{A. Polymerization.}

Plasma polymerization refers to the formation and deposition of polymeric material under the influence of a plasma. Plasma polymerization is believed to occur via a freeradical mechanism, which consists of three basic types of reactions: 1) Initiation, in which reactive species (radicals) are formed by dissociation, 2) Propagation, in which monomers are added to a growing polymer chain, and 3) Termination, in which two radicals combine, thereby destroying the reactivity of both. Propagation reactions in plasma polymerization are believed to proceed primarily with unsaturated monomers, and there is a strong positive correlation between deposition rate and the degree of unsaturation of the monomer [30]. Deposition occurs when the polymer chain becomes 
sufficiently large to be involatile. There is an extensive literature on this subject [31], and plasma polymerization has been discussed as a model for wire aging processes $[1,2,14]$.

With regard to small alkanes, one study of plasma polymerization has shown that the polymerization rate is $\mathrm{CH}_{4}>\mathrm{C}_{2} \mathrm{H}_{6}>\mathrm{C}_{3} \mathrm{H}_{8}$ [30], from which it may reasonably be concluded that $\mathrm{iC}_{4} \mathrm{H}_{10}$ polymerizes less-readily still.

\section{B. Etching.}

Etching refers to a chemical process in which gas-phase species react with a substrate to form volatile products. Etching chemistry is extremely complex. Qualitatively, $\mathrm{CF}_{4}$ dissociates to form highly reactive $\mathrm{F}$ and $\mathrm{CF}_{\mathrm{x}}$ radicals at the same time that electrons are released by the avalanche. These electrons have sufficient energy (5$10 \mathrm{eV}$ ) to break the chernical bonds (typically $4-5 \mathrm{eV}$ ) in a polymeric wire deposit. Upon recombination, some fluorine may be incorporated into the polymer matrix. Under repeated avalanches, the polymer can be reduced to stable, volatile products (e.g., $\mathrm{CF}_{4}, \mathrm{CHF}_{3}, \mathrm{C}_{2} \mathrm{~F}_{6}$ ), which are removed from the wire.

Fluorocarbon deposition in $\mathrm{CF}_{4}$ plasmas is also known [32,33] but, as discussed in sections 2.3.1 and 2.3.2, such deposition was rarely observed in this work. The distinction as to whether etching or deposition will occur in $\mathrm{CF}_{4}$ depends on the plasma characteristics. In wire chambers, it appears that etching is the favored process.

\section{Scavenging-induced deposition.}

Due to the large bond energy of $\mathrm{HF}(5.9 \mathrm{eV})$, fluorine radicals in a plasma react readily with hydrogen in a process known as radical scavenging. $\mathrm{HF}$ is a stable molecule and it does not contribute to etching. Thus, addition of hydrogen to a fluorine-containing plasma reduces the effective concentration of $\mathrm{eorine}$ radicals available for etching.

Radical scavenging can also occur with the hydrogen in hydrocarbons. But in this case, production of $\mathrm{HF}$ is accompanied by production of carbon-enriched residues which, due to their high degree of unsaturation, will have a high tendency to polymerize and will be comparatively involatile. The greater the carbon-enrichment, the greater the likelihood that the residues will deposit onto a wire. The degree of carbon 
enrichment is related to the likelihood that hydrogen is scavenged (i.e., is related to the $\mathrm{CF}_{4} /$ hydrocarbon, or $\mathrm{F} / \mathrm{H}$, ratio). The combined effects of reduced etching (reduced fluorine radical concentration) and increased deposition may lead to serious aging in gases with a high $\mathrm{CF}_{4} /$ hydrocarbon ratio (i.e., in gases with low hydrocarbon content).

\section{Wire surface reactivity.}

Many metals commonly used in wire-chamber wires react with fluorine-containing plasmas, some $(\mathrm{Al}, \mathrm{Cu}, \mathrm{Ni})$ to form nonvolatile fluorides; others $(\mathrm{Cr}, \mathrm{W})$ to form volatile fluorides. Clear evidence of reaction of such wires with $\mathrm{CF}_{4}$ avalanches was presented in section 2.3.2 of this work. No evidence of such reaction was observed for $\mathrm{Au} / \mathrm{W}$ wires. For practical purposes, $\mathrm{Au}$ is considered inert to $\mathrm{CF}_{4}$-based plasmas, although formation of a gold fluoride in such plasmas has been reported $[34,35]$.

By combining the first three parts of this model, the qualitative dependence of aging on gas composition can be determined. The plasma polymerization rate of $\mathrm{iC}_{4} \mathrm{H}_{10}$ is expected to increase with the $\mathrm{iC}_{4} \mathrm{H}_{10}$ content of the gas, in the hypothetical case that the diluent gas, $\mathrm{CF}_{4}$ in this case, is totally inert. Similarly, the etching rate by $\mathrm{CF}_{4}$ is expected to increase with the $\mathrm{CF}_{4}$ content of the gas, again hypothesizing that the diluent gas, $\mathrm{iC}_{4} \mathrm{H}_{10}$ in this case, is totally inert. Although these two dependences are probably nonlinear, their limiting behavior may be considered to be linear and they are shown as linear in Fig. 2.15. Scavenging-induced deposition is proportional to the $\mathrm{CF}_{4} / \mathrm{iC}_{4} \mathrm{H}_{10}$ ratio. Although this ratio becomes infinite as the $\mathrm{iC}_{4} \mathrm{H}_{10}$ content approaches zero, it is clear that the hydrocarbon-related deposition must vanish in the limit of no hydrocarbon. Scavenging-induced deposition must therefore reach a maximum at some $\mathrm{CF}_{4}$ concentration below $100 \%$; it is shown in Fig. 2.15 as reaching a maximum at about $95 \% \mathrm{CF}_{4}$. The general trend of the data for aging behavior as a function of gas composition (Fig. 2.14) can be well explained by the sum of these three effects, shown in Fig. 2.15 as the dashed line. This model explains the divisions between deposition and etching regimes, and shows that a window in which etching will occur is expected for mid-range $\mathrm{CF}_{4}$ concentrations. 


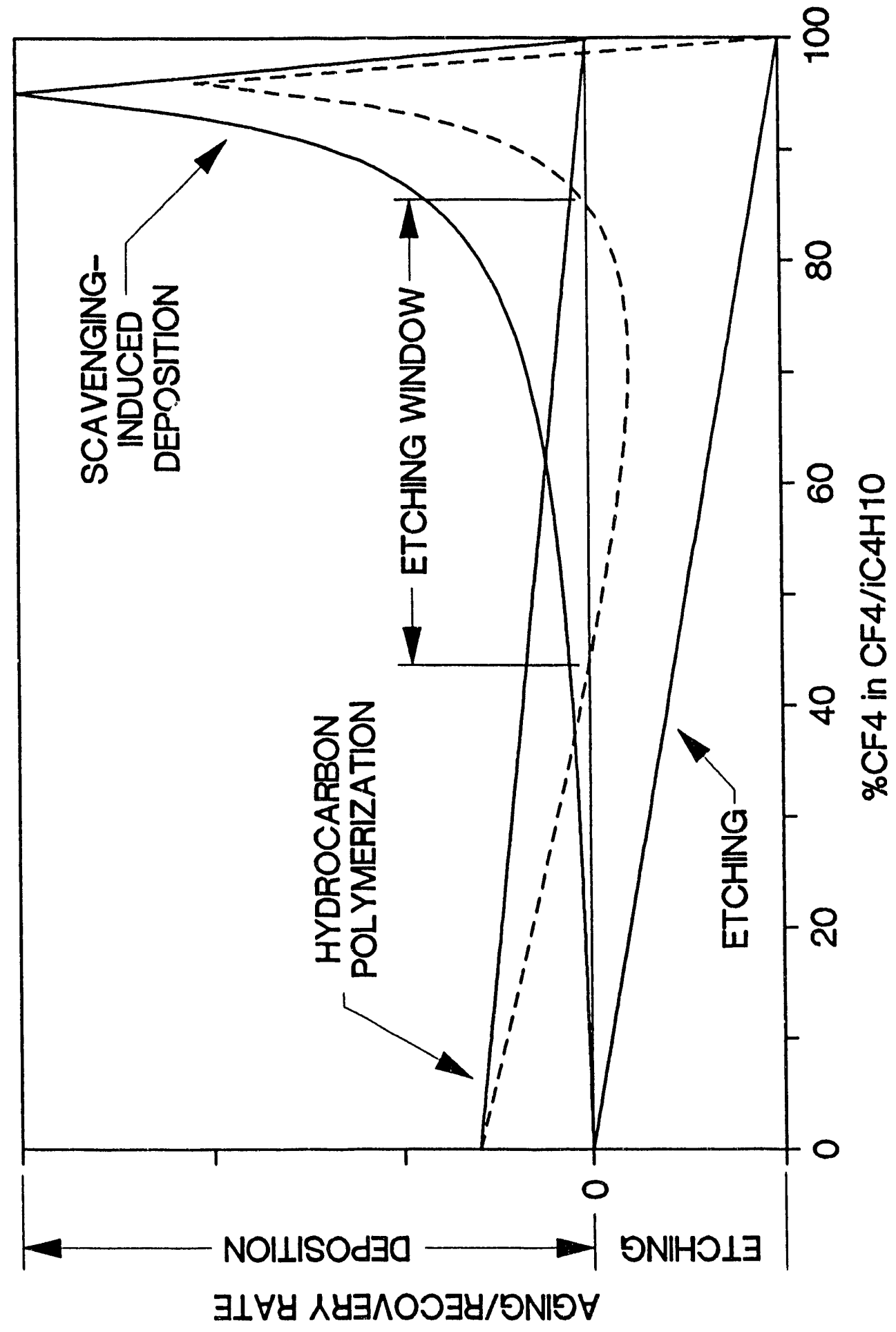

Figure 2.15: Model of anode aging in $\mathrm{CF}_{4} /$ hydrocarbon gases showing relation between polymerization, etching, and scavenging-induced deposition and overall result. 
Note that the relative magnitudes of the polymerization, etching, and scavenginginduced deposition effects shown in Fig. 2.15 are not intended to illustrate the chemistry of any particular $\mathrm{CF}_{4} /$ hydrocarbon mixture, but rather to provide a clear visual indication of the relation between the three effects. Note also that this model is only intended to explain why aging or recovery occurs in a particular gas mixture; it is not intended to predict magnitudes of aging or recovery rates. Finally, note that this model does not include all possible chemical effects and interactions. Not included, for example, is the catalysis of plasma polymerization by halogens [36]. This effect is expected to be small, however, since conventional plasma polymerization is only slightly accelerated by $\mathrm{CF}_{4}$.

Extensive deposition was observed on non-gold wires aged in $\mathrm{CF}_{4} / \mathrm{iC}_{4} \mathrm{H}_{10}$ gas mixtures in cases when similar deposition was not observed on gold-plated wires. This difference indicates that the wire material influences the etching/deposition mechanisms. One possible means of interaction is a loading effect, resulting from the additional reaction pathway provided by fluorination of the wire material, which reduces the effective fluorine radical concentration for all $\mathrm{CF}_{4} / \mathrm{iC}_{4} \mathrm{H}_{10}$ mixtures. With the relative strength of etching reduced, there is a greater tendency to deposit at all $\mathrm{CF}_{4}$ concentrations. However, any loading effect would likely be subject to diffusionlimitation, and would therefore play little role after surface fluorides or deposits had been formed. Another possibility is that the metal fluoride interfacial layer between the metal and the carbonaceous deposit becomes blurred, causing the deposits to be more strongly bonded to the wire. It is also possible that there is enhanced adhesion between gas-phase carbonaceous species and metal fluorides relative to gold.

\subsubsection{Other $\mathrm{CF}_{4}$-Based Gases}

In analogy to $\mathrm{CF}_{4} / \mathrm{iC}_{4} \mathrm{H}_{10}(95 / 5), \mathrm{CF}_{4} / \mathrm{C}_{2} \mathrm{H}_{4}(95 / 5)$ (mixed from two independently regulated flow streams) was observed to form heavy carbonaceous anode deposits. Although $\mathrm{C}_{2} \mathrm{H}_{4}$ is a smaller molecule than $\mathrm{iC}_{4} \mathrm{H}_{10}$, it is more carbon-enriched and is unsaturated. In addition, the $\mathrm{F} / \mathrm{H}$ ratio is larger in the $\mathrm{CF}_{4} / \mathrm{C}_{2} \mathrm{H}_{4}$ mixture (19.6) than in the $\mathrm{CF}_{4} / \mathrm{iC}_{4} \mathrm{H}_{10}$ mixture (7.6), suggesting that more scavenging-induced deposition will occur in the former. 
Previous results showing that $\mathrm{CF}_{4} /$ dimethyl ether (95/5) exhibits very little aging [37] indicate that the magnitude of the scavenging-induced deposition effect is related to the chemical nature and possibly to the size of the hydrocarbon molecule. Dimethyl ether is expected to underco relatively little scavenging-induced deposition because of its oxygen content: oxygen is expected to combine with carbon to form $\mathrm{CO}$ or $\mathrm{CO}_{2}$, both of which are volatile.

We have previously reported that rapid aging $(R \sim 120,000 \% / \mathrm{C} / \mathrm{cm})$ occurs in $\mathrm{Ar} / \mathrm{CF}_{4} / \mathrm{O}_{2}(50 / 40 / 10)$ [38]. This was an unexpected result because this gas mixture was expected to be strongly etching and therefore unlikely to cause deposition on anode wires. It is likely that the phenomenon that causes $\mathrm{CF}_{4}$ to appear to age rapidly also causes the $\mathrm{Ar} / \mathrm{CF}_{4} / \mathrm{O}_{2}$ to appear to age rapidly. Indeed, this gas mixture was observed to etch anode deposits (Table 2.4). SEM showed that an Au/W wire aged

Table 2.4: Summary of recovery results for $\mathrm{Au} / \mathrm{W}$ wires in fluorine-containing gases.

\begin{tabular}{|c|l|c|c|c|c|c|c|}
\hline $\begin{array}{c}\text { Recovery } \\
\text { gas } \\
\text { mixture }\end{array}$ & $\begin{array}{c}\text { Mixture } \\
\text { ratio }\end{array}$ & $\begin{array}{c}\text { Aged } \\
\mathrm{PH} \\
{[\%]}\end{array}$ & $\begin{array}{c}\text { Recov'd } \\
\mathrm{PH} \\
{[\%]}\end{array}$ & $\begin{array}{c}\text { Recovery } \\
\text { rate, } \mathrm{PH} \\
{[\% / \mathrm{C} / \mathrm{cm}]}\end{array}$ & $\begin{array}{c}\text { Recovery } \\
\text { rate, } I \\
{[\% / \mathrm{C} / \mathrm{cm}]}\end{array}$ & $\begin{array}{c}\text { Total } \\
\text { charge } \\
{[\mathrm{C} / \mathrm{cm}]}\end{array}$ & $\begin{array}{c}\text { Charge } \\
\text { density } \\
{[\mu \mathrm{A} / \mathrm{cm}]}\end{array}$ \\
\hline $\mathrm{Ar} / \mathrm{CF}_{4} / \mathrm{O}_{2}$ & $50 / 40 / 10$ & 63 & 94 & 8400 & 16000 & 0.03 & 0.48 \\
$\mathrm{CHF}_{3}$ & 100 & 71 & 98 & 1000 & 990 & 0.09 & 0.43 \\
$\mathrm{CHF}_{3} / \mathrm{CH}_{4}$ & $82 / 18$ & 82 & 99 & 400 & 3830 & 0.05 & 0.43 \\
\hline
\end{tabular}

in this gas was visually clean, but. AES revealed that $\mathrm{C}$ and $\mathrm{O}$ (probably atmospheric contamination), and $\mathrm{F}$ were present on the surface. It should be noted that gold fluorides can be formed in $\mathrm{CF}_{4} / \mathrm{O}_{2}$ plasmas [35], and that such a process could cause some anode aging in the $\mathrm{Ar} / \mathrm{CF}_{4} / \mathrm{O}_{2}$.

As a diagnostic probe of the etching chemistry, it was of interest to determine whether recovery of aged wires would occur in fluorine-containing gases other than $\mathrm{CF}_{4}$. Two such gases tested were $\mathrm{CHF}_{3}$ and $\mathrm{CHF}_{3} / \mathrm{CH}_{4}(82 / 18)$. These gases were chosen without regard to their potential utility in wire chambers. Recovery beginning with a rapid decrease in the current followed by an increase in the current was observed in both of these gases (Table 2.4). The fact that etching was observed in these gases indicates that atomic composition rather than specific molecular configurations govern 
the chemistry. This is generally true for plasma etching and serves as the basis for the F/C Ratio model. We expect that the molecular configuration of the hydrocarbon may be relevant to the extent of scavenging-induced deposition, however.

A general guideline used in the F/C Ratio model is that etching occurs for F/C $>2$. It is possible that similar general guidelines may be established to predict the deposition or etching behavior of potential wire chamber gas mixtures. Table 2.5 lists

Table 2.5: Atomic composition ratios for gas mixtures that either etch or form deposits.

\begin{tabular}{|l|l|l|r|r|r|r|}
\hline Gas mixture & Composition & $\begin{array}{c}\text { Aging } \\
\text { behavior }\end{array}$ & $\mathrm{F} / \mathrm{C}$ & $(\mathrm{F}-\mathrm{H}) / \mathrm{C}$ & $\mathrm{F} / \mathrm{H}$ & $\mathrm{C} / \mathrm{H}$ \\
\hline $\mathrm{CF}_{4}$ & 100 & ETCH & 4.00 & 4.00 & - & - \\
$\mathrm{Ar} / \mathrm{CF}_{4} / \mathrm{O}_{2}$ & $50 / 40 / 10$ & ETCH & 4.00 & 4.00 & - & - \\
$\mathrm{CF}_{4} / \mathrm{C}_{2} \mathrm{H}_{4}$ & $95 / 5$ & DEPOSIT & 3.62 & 3.43 & 19.00 & 5.24 \\
$\mathrm{CF}_{4} / \mathrm{iC}_{4} \mathrm{H}_{10}$ & $95 / 5$ & DEPOSIT & 3.30 & 2.87 & 7.60 & 2.30 \\
$\mathrm{CF}_{4} / \mathrm{iC}_{4} \mathrm{H}_{10}$ & $90 / 10$ & DEPOSIT & 2.77 & 2.00 & 3.60 & 1.30 \\
$\mathrm{CHF}_{3}$ & 100 & ETCH & 3.00 & 2.00 & 3.00 & 1.00 \\
$\mathrm{CHF}_{3} / \mathrm{CH}_{4}$ & $82 / 18$ & ETCH & 2.46 & 0.92 & 1.60 & 0.65 \\
$\mathrm{CF}_{4} / \mathrm{iC}_{4} \mathrm{H}_{10}$ & $80 / 20$ & ETCH & 2.00 & 0.75 & 1.60 & 0.80 \\
$\mathrm{CF}_{4} / \mathrm{iC}_{4} \mathrm{H}_{10}$ & $50 / 50$ & ETCH & 0.80 & -1.20 & 0.40 & 0.50 \\
\hline
\end{tabular}

several atomic ratios of gases investigated in this work that either deposit or etch. For these gases, scavenging-induced deposition dominates for $\mathrm{F} / \mathrm{H}>3$ and no threshold for etching is observed in the range $0.8<\mathrm{F} / \mathrm{C}<4.0$. Using $\mathrm{F} / \mathrm{C}$ as an indication of etching and $\mathrm{F} / \mathrm{H}$ as an indication of scavenging-induced deposition, $\mathrm{C} / \mathrm{H}$ is an indication of the deposition/etching ratio. For the gases studied, deposition occurs for $\mathrm{C} / \mathrm{H}>1$; etching for $\mathrm{C} / \mathrm{H}<1$. Without more data for $\mathrm{CF}_{4}$ in mixtures with hydrocarbons other than $\mathrm{iC}_{4} \mathrm{H}_{10}$, however, the general validity of these guidelines cannot be ascertained. 


\subsubsection{Other Models for Aging in $\mathrm{CF}_{4} / \mathrm{iC}_{4} \mathrm{H}_{10}$}

It has been suggested that the relatively large dissociation energy of the C-F bond $(5.2 \mathrm{eV})$ may make it less prone to disscciate in an avalanche. With less dissociation, fewer radicals would be produced, there would be less polymerization of the radicals, less deposition and, consequently, less aging [2].

It has also been suggested that the beneficial effect of $\mathrm{iC}_{4} \mathrm{H}_{10}$ in $\mathrm{CF}_{4} / \mathrm{iC}_{4} \mathrm{H}_{10}$ gases is to reduce formation of fluorine radicals by cooling electrons in the avalanche to temperatures below that required for dissociative electron attachment to $\mathrm{CF}_{4}$ [17]. With less dissociative attachment, fewer fluorine radicals would be formed, and aging effects resulting from fluorine radicals would be reduced.

But prevention, or even reduction, of fluorine radical formation cannot be the dominant effect in $\mathrm{CF}_{4} / \mathrm{iC}_{4} \mathrm{H}_{10}$ gases. Although we have not directly observed fluorine radicals, there is ample evidence to suggest that they play a central role in determining the properties of these gas mixtures. In particular, the removal of anode deposits by some $\mathrm{CF}_{4} / \mathrm{iC}_{4} \mathrm{H}_{10}$ mixtures can be explained by an etching process requiring fluorine radicals. This is especially true for removal of silicon-based deposits, which may react with fluorine radicals to form volatile $\mathrm{SiF}_{4}$. Finally, fluorine radicals are the primary reactive species in the model presented in this work.

\subsubsection{Practical Guidelines}

With a model for the observed aging, we are in a position to discuss some practical aspects of wire chamber operation with $\mathrm{CF}_{4} / \mathrm{iC}_{4} \mathrm{H}_{10}$ gases.

Because of possible cathode aging effects, use of pure $\mathrm{CF}_{4}$ in a wire chamber may be detrimental. In addition, the deposition/etching balance in pure $\mathrm{CF}_{4}$ is very sensitive to gas composition, with extensive deposition possibly resulting from trace hydrocarbon additives or contaminants. Accordingly, it is safer to operate at a gas composition within the etching window than with pure $\mathrm{CF}_{4}$.

Non-gold wires react with fluorine radicals produced in an avalanche to form metal fluorides, which may promote further deposition. Such wires are therefore 
unacceptable for use in $\mathrm{CF}_{4}$-based gases. Gold wires are essentially inert to fluorinebased plasmas, and can therefore have good aging properties in $\mathrm{CF}_{4}$-based gases. Use of gold-plated wires does not necessarily ensure good aging properties in $\mathrm{CF}_{4}$-based gases, however, as deposition may occur on wires of any material. It should be noted that gold can be etched in plasmas of $\mathrm{C}_{2} \mathrm{Cl}_{2} \mathrm{~F}_{4}$ [35] or $\mathrm{CClF}_{3}$ [39]. Accordingly, these, and possibly other, chlorofluorocarbons should be avoided in wire chambers.

Two issues of relevance to the choice of wire chamber gases are flammability, for the obvious safety reasons, and minimized hydrogen content, to reduce the background noise from recoil protons in neutron radiation environments. The range of the etching window places a lower limit on the hydrocarbon concentration. Applied to $\mathrm{CF}_{4} / \mathrm{iC}_{4} \mathrm{H}_{10}$, the guidelines proposed in section 2.5.2 (that deposition occurs for $\mathrm{F} / \mathrm{H}>3$ or for $\mathrm{C} / \mathrm{H}>1$ ) require minimum $\mathrm{iC}_{4} \mathrm{H}_{10}$ concentrations of $11.8 \%$ or $14.3 \%$, respectively.

We expect that the magnitude of the scavenging-induced deposition effect is directly related to the size of the hydrocarbon molecule. For example, we expect that a carbon-enriched isobutane molecule is more likely to deposit onto the wire than a carbon-enriched methane. (In addition to being less volatile, larger alkanes are also more carbon-enriched than smaller alkanes.) If so, the etching window may extend to lower hydrocarbon concentrations when $\mathrm{CF}_{4}$ is mixed with hydrocarbons smaller than $\mathrm{iC}_{4} \mathrm{H}_{10}$. It may therefore be possible to make $\mathrm{CF}_{4} / \mathrm{CH}_{4}$ or $\mathrm{CF}_{4} / \mathrm{C}_{2} \mathrm{H}_{6}$ mixtures that are nonflammable, have low hydrogen content, and also etch wire deposits.

\subsection{Metal Fluoride Film Growth on $\mathrm{Cu}$ Wires}

Growth of metal fluorides on non-gold wires aged in $\mathrm{CF}_{4}$ (section 2.3.2) may be expected to be diffusion-limited. Indeed, diffusion-limited processes are well-known in plasma processing occurring, for example, in etching of $\mathrm{Si}$ in $\mathrm{SF}_{6}$ plasmas [40] and in growth of $\mathrm{SiO}_{2}$ on $\mathrm{Si}$ in $\mathrm{O}_{2}$ plasmas [41]. If it is assumed that growth of the metal fluoride film is purely diffusion limited, the growth rate can be expressed as

$$
\frac{d z}{d t}=-D_{i} k_{1} \frac{d C_{i}}{d z},
$$




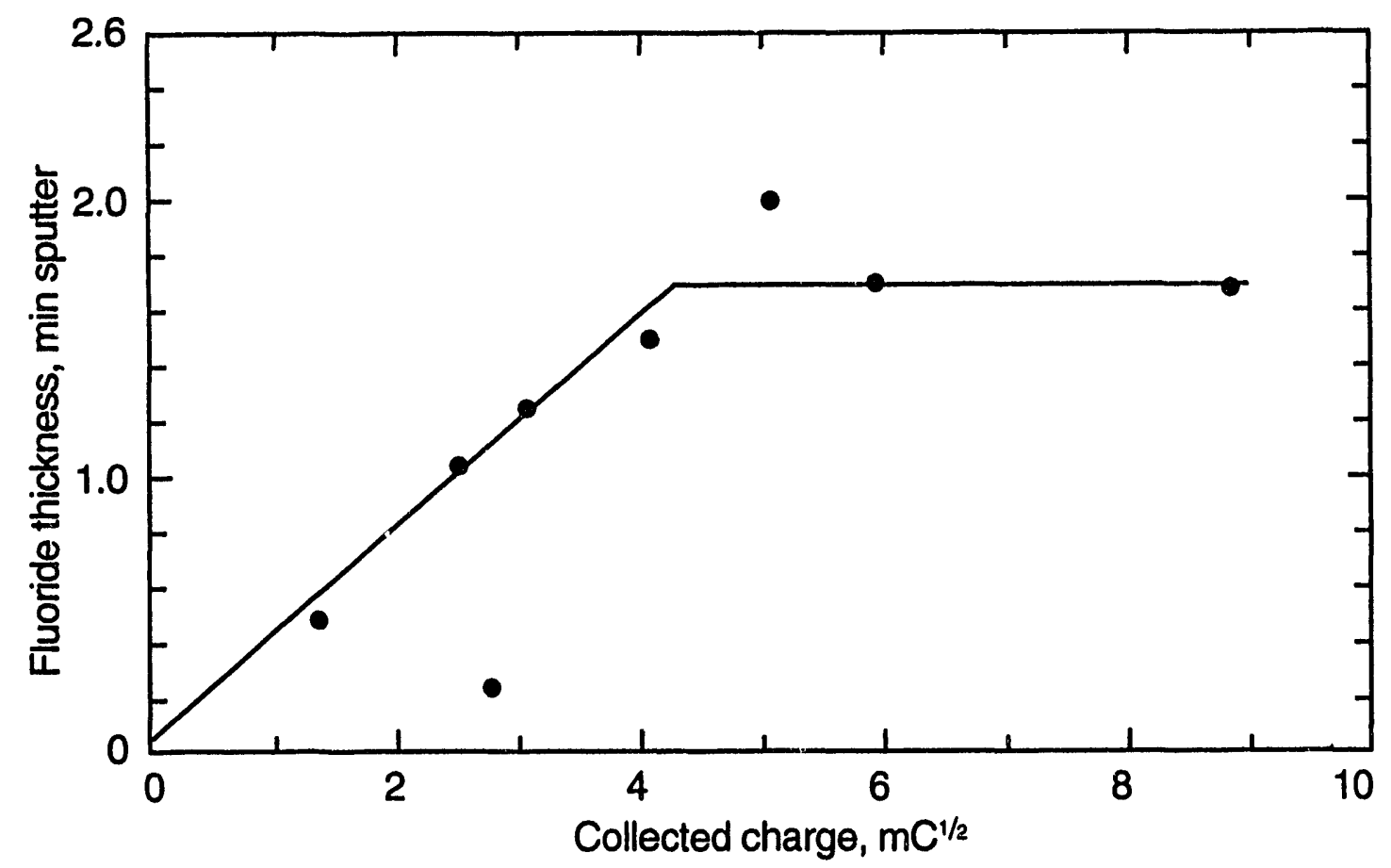

XBL $927-5278$

Figure 2.16: Thickness of the copper fluoride film, measured by AES depth profiling, as a function of the square root of collected charge.

where $D_{i}$ is the solid-state diffusivity of the fluorinating species, $C_{i}$ is the near-surface gas-phase concentration of the fluorinating species, $z$ is the thickness of the fluoride film, and $k_{1}$ is a constant that corrects for stoichiometry and fluoride density. It is permissible to use planar geometry because $z_{\max } \ll r_{\text {anode }}$. Making the assumptions that the concentration gradient is linear and that $C_{i}$ is linearly related to the current,

$$
\frac{d z}{d t}=-D_{i} k_{1} \frac{C_{i}}{z}=-D_{i} k_{1} k_{2} \frac{I}{z} \text {. }
$$

Using the relation $\int I d t=Q$, eqn. 2.4 becomes the classical parabolic rate equation with solution

$$
z(t)=\left[k_{3} Q+\left(z_{0}\right)^{2}\right]^{1 / 2} .
$$

Fig. 2.16 shows the thickness of the copper fluoride layer (measured by the time required to sputter through it) as a function of the square root of the total charge collected during exposure to the $\mathrm{CF}_{4}$ plasma. Two distinct regions are evident: a linear region of nonzero slope, indicating diffusion-limited growth, and a region of 
near-zero slope, in which essentially no further growth occurs. Taking a liberty to assume that the sputter rate of the copper fluoride is similar to that of $\mathrm{Ta}_{2} \mathrm{O}_{5}$ (known to be $\sim 60 \mathrm{~nm} / \mathrm{min}$ under the sputter conditions used), $k_{3}=5.6 \times 10^{2} \mathrm{~nm}^{2} / \mathrm{mC}$ and the maximum film thickness is $\sim 110 \mathrm{~nm}$. Because the thickness measurement was a destructive test, each point shown in Fig. 2.16 was measured on a different wire. Errors associated with the thickness measurements therefore include the variations in aging of the different wires as well as the uncertainty in the azimuthal location of the thickest part of the deposit. For these reasons, the error in the thickness measurements is estimated to be at least $\pm 15 \%$.

The reason for the limiting film thickness is not understood at present. One possibility is that the primary diffusing species are ions and that diffusion is driven by an electric field. If there is a constant potential across the film, the field strength drops as the film grows so that at some film thickness, the field strength is reduced sufficiently that diffusion no longer occurs. The limiting film thickness may explain why non-gold wires aged in $\mathrm{CF}_{4}$ reach an asymptote and do not continue to age.

\subsection{Summary and Conclusions}

There are three important results in this work. First, an apparent cathode aging that results in loss of gain and not in a self-sustained (Malter) breakdown occurs in $\mathrm{CF}_{4}$. Second, a chemical model of aging in $\mathrm{CF}_{4} /$ hydrocarbon gases is developed and predictions of the model are used to suggest practical guidelines for use of $\mathrm{CF}_{4}$-based gases. Third, principles of low-pressure, rf plasma chemistry are used to develop this model, and the correlations to observed phenomena are good.

A. Aging curves in $\mathrm{CF}_{4}$ exhibit a nonlinear transient behavior in which the decrease in current is initially rapid, but then approaches a non-zero asymptote. This aging appears to occur on the cathode.

B. We use the functional form $I=A+B \exp \left(-Q^{1 / 2} / D\right)$ to describe the aging transient in $\mathrm{CF}_{4}$. The parameterization of $I$ is approximately independent of anode material $\left(D \sim 1.2 \mathrm{mC}^{1 / 2} ; I / I_{0} \sim 0.6\right)$.

C. Aging in $\mathrm{CF}_{4} / \mathrm{iC}_{4} \mathrm{H}_{10}$ gases is best characterized by pulse height measurements 
and by analysis of deposits on the wire. Because of apparent cathode effects, the current drawn in accelerated aging tests is not a reliable indicator of anode aging for $\mathrm{CF}_{4}$-rich gases.

D. Gold-plated wires do not age in $\mathrm{CF}_{4}$. Other metals $(\mathrm{Al}, \mathrm{Cu}, \mathrm{Ni})$ react with fluorine radicals in the $\mathrm{CF}_{4}$ discharge to form metal fluorides, which appear to grow by a diffusion-limited process. For $\mathrm{Cu}$ wires, the effective diffusion constant $k_{3} \simeq$ $5.6 \times 10^{2} \mathrm{~nm}^{2} / \mathrm{mC}$. Metal fluorides are observed at the interface between a carbonaceous deposit and the wire material of anodes aged in $\mathrm{CF}_{4} / \mathrm{iC}_{4} \mathrm{H}_{10}$ mixtures.

E. A four-part chemical model of the aging processes in $\mathrm{CF}_{4} / \mathrm{iC}_{4} \mathrm{H}_{10}$ is developed to explain why some $\mathrm{CF}_{4} / \mathrm{iC}_{4} \mathrm{H}_{10}$ mixtures form anode deposits and why others etch such deposits. The model considers 1) plasma polymerization of the hydrocarbon, 2) etching of wire deposits by $\left.\mathrm{CF}_{4}, 3\right)$ acceleration of deposition processes in strongly etching environments, and 4) reactivity of the wire surface. This model may be generally applicable to $\mathrm{CF}_{4} /$ hydrocarbon gases.

F. Some practical implications of the model are 1) that mid-range concentrations of hydrocarbons in $\mathrm{CF}_{4}$ are generally expected to etch wire deposits, while low hydrocarbon concentrations may result in considerable aging, and 2) that gold-plated wires are acceptable for use in $\mathrm{CF}_{4}$-based gases while non-gold-plated wires are unacceptable.

G. Etching is observed over a wide range of $\mathrm{CF}_{4} / \mathrm{iC}_{4} \mathrm{H}_{10}$ mixtures and in some $\mathrm{CHF}_{3}$-based gases. The distinction as to whether or not etching occurs appears to be related to the atomic composition of the gas rather than to specific molecular configurations.

H. Principles of traditional plasma chemistry (low-pressure, rf) can be used with good results to predict the plasma chemistry in wire chambers (1 atm, dc). For $\mathrm{CF}_{4}$-based gases, the chemical mechanisms occurring in the two plasma regimes are apparently similar.

\section{References}

[1] D.W. Hess. In Proceedings of the Workshop on Radiation Damage to Wire Chambers, J. Kadyk, ed., LBL-21170 (1986), p. 15. 
[2] J. Va'vra, Nucl. Instr. and Meth., A252 (1986) 547.

[3] (a) J. Wise, J.A. Kadyk, D.W. Hess, and M.C. Williams, IEEE Trans. Nucl. Sci., NS-37 (1990) 470; (b) J. Wise, MS Thesis, LBL-29033 (1990).

[4] M.E. Fraser, D.A. Fee, and R.S. Sheinson, Plasma Chem. Plasma Process, 5 (1985) 163.

[5] D.E. Tevault, Plasma Chem. Plasma Process, 7 (1987) 231.

[6] S. Kanazawa, M. Kogoma, T. Moriwaki, and S. Okazaki, J. Phys. D: Appl. Phys., 21 (1988) 838.

[7] L.G. Christophorou, D.L. McCorkle, D.V. Maxey, and J.G. Carter, Nucl. Instr. and Meth., 163 (1979) 141.

[8] J. Fischer, A. Hrisoho, V. Radeka, and P. Rehak, Nucl. Instr. and Meth., A238 (1985) 249.

[9] T. Yamashita, H. Kobayashi, A. Konaka et al., Nucl. Instr. and Meth., A283 (1989) 709.

[10] B. Schmidt and S. Polenz, Nucl. Instr. and Meth., A273 (1988) 488.

[11] R. Henderson, R. Openshaw, W. Faszer, M. Salomon, G. Salomons, and G. Sheffer, IEEE Trans. Nucl. Sci., NS-35 (1988) 477.

[12] R. Openshaw, R. Henderson, W. Faszer, D. Murphy, M. Salomon, and G. Sheffer, IEEE Trans. Nucl. Sci., NS-36 (1989) 567.

[13] J. Kadyk, J. Wise, D. Hess, and M. Williams, IEEE Trans. Nucl. Sci., NS-37 (1990) 478.

[14] J.A. Kadyk, Nucl. Instr. and Meth., A300 (1991) 436.

[15] R. Openshaw, R.S. Henderson, W. Faszer, and M. Salomon, Nucl. Instr. and Meth., A307 (1991) 298.

[16] J. Wise, J.A. Kadyk, and D.W. Hess. In The Vancouver Meeting-Particles and Fields '91, D. Axen, D. Bryman, and M. Comyn, eds. (World Scientific, Singapore, 1992), p. 1155.

[17] J. Va'vra, P. Coyle, J. Kadyk, and J. Wise, "Measurement of Electron Drift Parameters for Helium and $\mathrm{CF}_{4}$-based Gases," SLAC-PUB-5728 (1992). Submitted to Nucl. Instr. and Meth., A.

[18] R. Henderson, W. Faszer, R. Openshaw, G. Sheffer, M. Salomon, S. Dew, J. Marans, and P. Wilson, IEEE Trans. Nucl. Sci., NS-34 (1987) 528. 
[19] A.J.F. den Boggende, A.C. Brinkman, and W. de Graaff, J. Sci. Instr. (J. Phys. E), 2 (1969) 701.

[20] (a) K. Kwong, J.G. Layter, C.S. Lindsey, S.O. Melnikoff, B.C. Shen, G.J. Vandalen, and M.C. Williams, Nucl. Instr. and Meth., A238 (1985) 265; (b) M.C. Williams, ref. [1], p. 25; (c) R. Kotthaus, ref. [1], p. 161.

[21] W. Bambynek, Nucl. Instr. and Meth., 112 (1973) 103.

[22] D.W. Hess and D.B. Graves. In Microelectronics Processing, D.W. Hess and K.F. Jensen, eds., Adv. Chem. Series 221 (American Chemical Society, Washington, DC, 1989), p. 392.

[23] D.S. Denisov, Nucl. Instr. and Meth., A306 (1991) 200.

[24] S.S. Friedland and H.S. Katzenstein, Rev. Sci. Instr., 24 (1953) 109.

[25] I. Juricic and J. Kadyk, IEEE Trans. Nucl. Sci., NS-34 (1987) 481.

[26] L. Malter, Phys. Rev., 50 (1936) 48.

[27] Aging in $\mathrm{iC}_{4} \mathrm{H}_{10}$ : S. Majewski, ref. [1], p. 239.

Aging in $\mathrm{Ar} / \mathrm{iC}_{4} \mathrm{H}_{10}$ : G. Charpak, H.G. Fisher, C.R. Gruhn, A. Minten, F. Sauli, G. Plch, and G. Flugge, Nucl. Instr. and Meth., 99 (1972) 279.

Aging in $\mathrm{CO}_{2} / \mathrm{iC}_{4} \mathrm{H}_{10}$ : (a) I. Juricic and J. Kadyk, ref. [25]; (b) P. Drell, ref. [1], pp. 314,315 .

[28] J.W. Coburn and H.F. Winters, J. Appl. Phys., 50 (1979) 3189.

[29] J.W. Coburn and E. Kay, IBM J. Res. Develop., 23 (1979) 33. See also: E. Kay, J. Coburn, and A. Dilks, Top. Curr. Chem., 94 (1980) 1.

[30] H. Kobayashi, A.T. Bell, and M. Shen, Macromolecules, 7 (1974) 277.

[31] See, for example: (a) A.T. Bell, J. Macromol. Sci.-Chem., A10 (1976) 369; (b) H. Yasuda, Plasma Polymerization (Academic Press, New York, 1985).

[32] T. Arikado and Y. Horiike, Jpn. J. Appl. Phys., 22 (1983) 799.

[33] J.C. Martz, D.W. Hess, and W.E. Anderson, J. Appl. Phys., 67 (1990) 3609.

[34] J.H. Linn and W.E. Swartz, Jr., Appl. Spectrosc., 39 (1985) 755.

[35] C.J. Mogab and T.A. Shankoff, J. Electrochem. Soc., 124 (1977) 1766.

[36] H. Kobayashi, M. Shen, and A.T. Bell, J. Macromol. Sci.-Chem., A8 (1974) 1345.

[37] J.A. Kadyk, J. Va'vra, and J. Wise, Nucl. Instr. and Meth., A300 (1991) 511. 
[38] J. Va'vra, SLAC-PUB-5207 (1990).

[39] R.G. Poulsen, J. Vac. Sci. Technol., 14 (1977) 266.

[40] B.E. Thompson and H.H. Sawin, J. Electrochem. Soc., 133 (1986) 1887.

[41] D.A. Carl, D.W. Hess, M.A. Lieberman, T.D. Nguyen, and R. Gronsky, J. Appl. Phys., 70 (1991) 3301. 


\section{Chapter 3}

\section{Effects of Freons on}

\section{Wire Chamber Aging}

Abstract

Data are presented to suggest that trace amounts of Freons do not affect the rate of loss of gain in wire chambers filled with either dimethyl ether or $\mathrm{Ar} / \mathrm{C}_{2} \mathrm{H}_{6}$. Apparent loss of gain in dimethyl ether is explained by attachment of primary electrons to a continuously increasing concentration of Freon 11 in the counter gas. An increase in the concentration of Freon 11 in dimethyl ether is caused by a distillation process in the gas supply bottle and is a natural consequence of the unequal volatilities of the two compounds. Some degradation of ${ }^{55} \mathrm{Fe}$ pulse height spectra obtained at the irradiated region of the anode wire is observed, however.

\subsection{Introduction}

There are at least two reasons why Freons might be expected to cause aging in wire chambers. 1) Freons contain halogens, which are known to catalyze plasma polymerization of hydrocarbons in the low-pressure, rf-discharge regime [1]. This is of relevance because it has been suggested that there may be similarities between the low-pressure, rf-discharge plasma regime and that of wire chambers [2]. 2) Some Freons are very electronegative and are therefore expected to attach electrons and be drawn to the anode where, if they do catalyze polymerization, they could most easily 
affect the aging rate. Since the primary electrons lost by attachment to electronegative species are not available to initiate avalanches, however, the observed wire current can change if the concentration of electronegative species in the gas changes. It is possible that an increase in the concentration of a highly electronegative species such as Freon 11 may cause the wire current to drop, a result which may be interpreted as aging [3]. In this report we discuss a mechanism by which trace species that are less volatile than the main gas may be concentrated in a gas bottle.

\subsection{Experimental}

The aging tests in this study were all performed using copper proportional tubes $(0.95 \mathrm{~cm} \mathrm{ID)}$ with $50-\mu \mathrm{m}$-diameter gold-plated tungsten wires (Luma Metall, Kalmar, Sweden). The design of the proportional tube and the techniques used to collect aging data have already been described [3]. The $5.9 \mathrm{keV}$ photons emitted by an ${ }^{55} \mathrm{Fe}$ source were used to simulate particle radiation. Initial current densities were $\sim 1.3 \mu \mathrm{A} / \mathrm{cm}$, corresponding to wire currents of $\sim 400 \mathrm{nA}$ for an irradiated region $3 \mathrm{~mm}$ long. The gas gains were known only approximately, and were in the 20,000-50,000 range. The gas flow rate in all tests was approximately $20 \mathrm{~cm}^{3} / \mathrm{min}$, corresponding to 1.25 chamber volumes $/ \mathrm{min}$, or an average linear velocity of $0.47 \mathrm{~cm} / \mathrm{sec}$.

We express the aging rate, $R$, as the normalized rate of loss of gain:

$$
R=-\frac{1}{G_{0}} \frac{d G}{d Q}
$$

where $G_{0}$ is the initial gas gain, $G$ is the gas gain at a subsequent time, and $Q$ is the collected charge per length of wire. If the ionization initiating the avalanche does not change, the current on the wire is linearly proportional to the gas gain, and $R$ can be measured as the normalized rate of current decrease:

$$
R=-\frac{1}{I_{0}} \frac{d I}{d Q}
$$

where $I_{0}$ is the initial wire current, $I$ is the wire current at a subsequent time, and $R$ and $Q$ are as defined above. We express $R$ in units of $\% / \mathrm{C} / \mathrm{cm}$. 
Table 3.1: Summary of aging results in which halogenated additives were deliberately added to $\mathrm{Ar} / \mathrm{C}_{2} \mathrm{H}_{6}(50 / 50)$. These tests and their respective control tests were run simultaneously and under otherwise identical conditions, except that the controls were without additives. No significant differences in the aging rates were observed.

\begin{tabular}{|l|l|c|c|c|c|}
\hline Additive & $\begin{array}{c}\text { Additive } \\
\text { name }\end{array}$ & $\begin{array}{c}\text { Additive } \\
\text { concentration } \\
\text { [ppm] }\end{array}$ & $\begin{array}{c}\text { Collected } \\
\text { charge } \\
{[\mathrm{C} / \mathrm{cm}]}\end{array}$ & $\begin{array}{c}R \\
{[\% / \mathrm{C} / \mathrm{cm}]}\end{array}$ & $\begin{array}{c}R \\
\text { control test } \\
{[\% / \mathrm{C} / \mathrm{cm}]}\end{array}$ \\
\hline $\mathrm{CHClF}_{2}$ & Freon 22 & 8 & 0.15 & 5 & 3 \\
$\mathrm{CCl}_{2} \mathrm{~F}_{2}$ & Freon 12 & 680 & 0.18 & -1 & 5 \\
$\mathrm{CH}_{3} \mathrm{Cl}$ & methyl chloride & 680 & 0.38 & 3 & 4 \\
$\mathrm{CH}_{3} \mathrm{Cl}$ & methyl chloride & 550 & 0.36 & 3 & no test \\
\hline
\end{tabular}

\subsection{Aging Tests with Freons in $\mathrm{Ar} / \mathrm{C}_{2} \mathrm{H}_{6}$}

In an attempt to find contaminants that would induce aging in $\mathrm{Ar} / \mathrm{C}_{2} \mathrm{H}_{6}(50 / 50)$ (Matheson grade argon, CP grade ethane, Matheson Gas Co., Newark, CA), a series of aging tests was performed in which gas permeation [4] was used to add halogenated (Freon) contaminants to the $\mathrm{Ar} / \mathrm{C}_{2} \mathrm{H}_{6}$. Permeation was effected with a model $570 \mathrm{C}$ Precision Gas Standards Generator (Kin-Tek Laboratories, Texas City, TX). These aging tests were run only for relatively short periods in an exploratory mode, looking for easily-observed increases in aging rates. In no case was there evidence that Freon addition resulted in significant aging rates. These results are summarized in Table 3.1. A test in which $\mathrm{CCl}_{3} \mathrm{~F}$ (Freon 11) was added to $\mathrm{Ar} / \mathrm{C}_{2} \mathrm{H}_{6}$ is shown in Fig. 3.1. In this test, the concentration of Freon 11 was set at several different levels; at each level the current was stable. The test was initially run without Freon 11 added to the gas (segment A of Fig. 3.1 ); $0.2 \mathrm{C} / \mathrm{cm}$ of charge was collected during this period and the measured aging rate was $R \sim 7 \% / \mathrm{C} / \mathrm{cm}$. When Freon 11 was added to the gas at varying levels (segments B-F), the current dropped from its initial value due to attachment of primary electrons, but then stabilized. Meaningful values of $R$ could not be calculated for these segments because only small amounts of charge were collected at the reduced currents. The transient spikes between levels are due to the thermal inertia of the permeation device. The cause of the small 


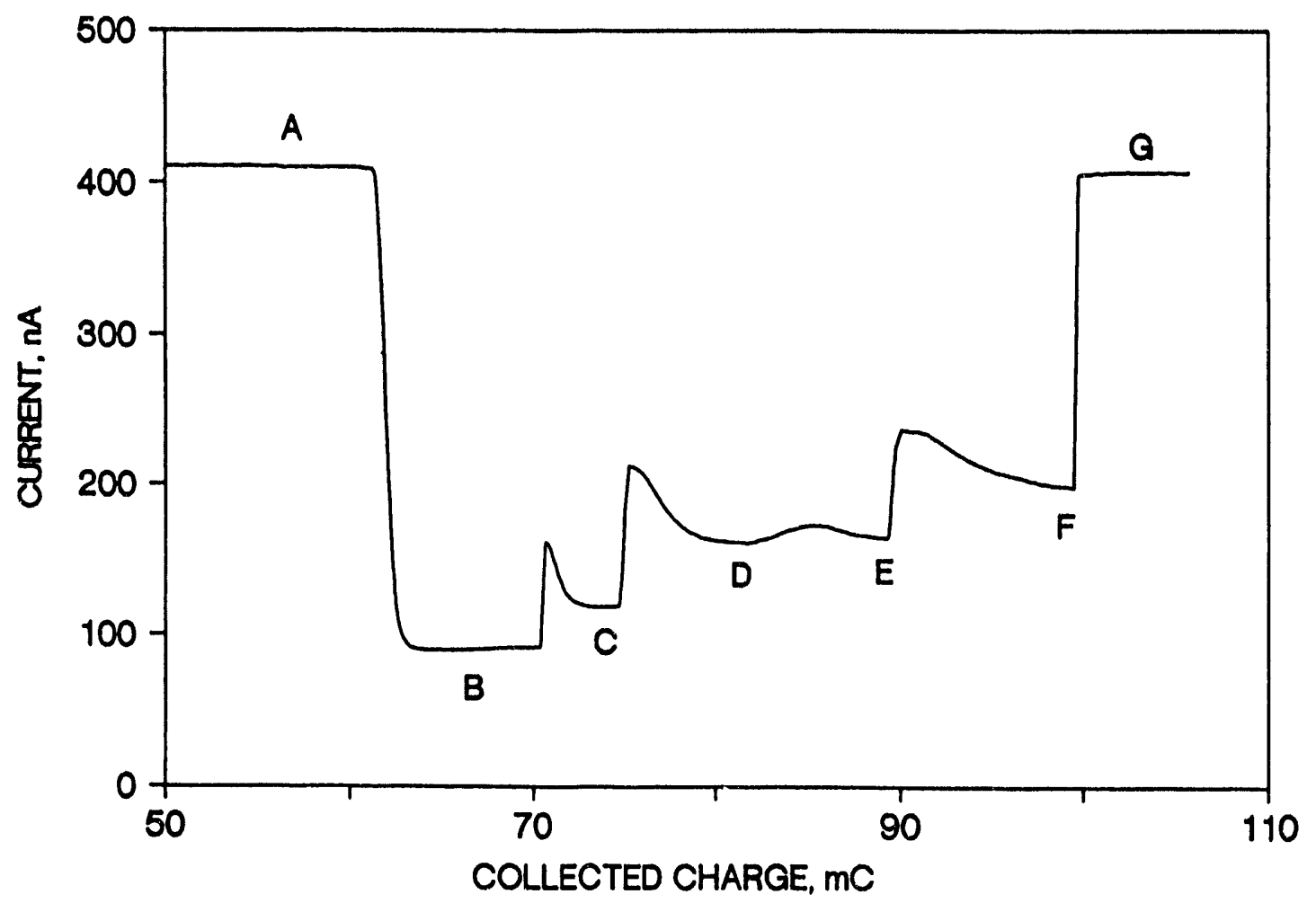

Figure 3.1: Aging test in which Freon 11 at varying levels was added to $\mathrm{Ar} / \mathrm{C}_{2} \mathrm{H}_{6}$ $(50 / 50)$. The irradiated region of the wire was $0.3 \mathrm{~cm}$. Freon concentrations (ppm) wcre: A, 0; B, 100; C, 70; D, 45; E, 45; F, 34; G, 0 .

bump between segments $\mathrm{D}$ and $\mathrm{E}$ is not understood at present. Segment F was apparently approaching a stable level, but the Freon source was removed prior to the establishment of that level. After the Freon source was removed from the system, the current returned to its initial level (segment $G$ ), indicating that little or no deposit had been formed on the wire. A tota! of about $0.12 \mathrm{C} / \mathrm{cm}$ of charge was collected during the exposure to Freon 11 . These results were reproduced in subsequent tests.

\subsection{Dimethyl Ether}

Dimethyl ether (DME) is an attractive gas with good quenching, a high linear ionization density, a low drift velocity, and a low electron diffusion constant [5], properties which make it a good choice for use in high-resolution drift chambers (e.g., vertex 
detectors). There are, however, several reports $[6,7]$ suggesting that Freon 11 contamination in DME causes rapid aging. Since Freon 11 is a commonly observed $[6,7]$ contaminant in DME, the viability of DME as a useful wire chamber gas has been questioned.

A possible alternative explanation of the above-mentioned observations is that the "aging" is due to a loss of primary electrons by attachment to the very electronegative Freon 11 [3]. If Freon 11 is present in the DME supply, it will be concentrated as the DME, which is more volatile (i.e., has a lower boiling point), evaporates preferentially. This process is known as Rayleigh distillation, or batch distillation with no plates [8]. Results that support this explanation are discussed below.

\subsection{Rayleigh Distillation}

Rayleigh distillation describes the equilibrium vaporization process of an initial mass of a binary liquid mixture to which heat is added continuously. It is assumed that the liquid is well mixed (i.e., is of uniform composition throughout) and that vapor in equilibrium with the liquid is generated and removed continuously from the vessel. Clearly, the continuous generation and removal of vapor is a valid description of the vaporization of DME in a gas supply bottle. Further, we believe it reasonable to assume that the liquid is well mixed since liquid diffusivities are high.

To describe a Rayleigh distillation, it is necessary to relate the amount of liquid remaining to its composition. This is done by means of a mass balance relating changes in the amount and composition of the liquid to the amount and composition of the vapor removed. In its most general form, the Rayleigh equation (for component $i$ ) is

$$
\ln \frac{L}{L_{0}}=\int_{x_{i_{0}}}^{x_{i}} \frac{d x_{i}}{y_{i}-x_{i}}
$$

where $L_{0}$ and $x_{i_{0}}$ are the initial number of moles of liquid and liquid mole fraction, and $L, x_{i}$, and $y_{i}$ are the number of moles of liquid, liquid mole fraction, and vapor mole fraction at any subsequent time. Integration of eqn. 3.3 requires a relation between $y_{i}$ and $x_{i}$; the equilibrium relation, as defined by the relative volatility, is used.

The relative volatility, or separation factor, $\alpha$, between two phases in equilibrium 
is defined as

$$
\alpha=\frac{\left(x_{A} / x_{B}\right)_{\text {phasel }}}{\left(x_{A} / x_{B}\right)_{\text {phase2 }}} .
$$

It is conventional to choose the phases so that $\alpha>1$. For the case at hand, this means that phase 1 is the gas, phase 2 is the liquid, the subscript $A$ refers to the light component (DME), and the subscript $B$ refers to the heavy component (Freon 11). Following the common usage that $x_{i}$ refers to a liquid-phase mole fraction and $y_{i}$ to a gas-phase mole fraction,

$$
\alpha=\frac{\left(y_{A} / y_{B}\right)}{\left(x_{A} / x_{B}\right)} .
$$

Because we are interested in very dilute solutions (Freon mole fractions less than $\left.10^{-4}\right)$, we can assume ideal behavior. This means that the solution obeys Raoult's law, which states that the vapor pressure exerted by a component in the solution is equal to the vapor pressure of the pure component weighted by the mole fraction of that component in the solution, and that the vapor phase obeys Dalton's law, which states that the partial pressure of a component in a gas mixture is equal to the total pressure of the gas weighted by the mole fraction of that component in the gas. Combining Raoult's and Dalton's laws,

$$
y_{i} P=p_{i}=x_{i} P_{i}^{0}
$$

where $P$ is the total pressure of the vapor phase, $p_{i}$ is the partial pressure of component $i$, and $P_{i}^{0}$ is the vapor pressure of pure component $i$.

A consequence of Raoult's and Dalton's laws is that $\alpha$ is simply the ratio of the vapor pressures of the two pure components at a given temperature:

$$
\alpha=\frac{P_{A}^{0}}{P_{B}^{0}} .
$$

It can be seen that $\alpha$ is independent of pressure and composition. For this situation, it is further argued that $\alpha$ is only a weak function of temperature [9]. As the temperature of the gas supply bottle is expected to undergo little or no fluctuation, we are justified in treating $\alpha$ as a constant.

Making use of the fact that $x_{A}+x_{B}=y_{A}+y_{B}=1$ for a binary mixture, eqn. 3.5 can be rewritten as

$$
y_{A}=\frac{\alpha x_{A}}{1+(\alpha-1) x_{A}}
$$


Substituting eqn. 3.8 into eqn. 3.3, using the fact that $\alpha$ is constant, and integrating with respect to component $A$ gives

$$
\ln \frac{L}{L_{0}}=\frac{1}{\alpha-1} \ln \frac{\left(1-x_{B}\right) / x_{B}}{\left(\left(1-x_{B}\right) / x_{B}\right)_{0}}-\ln \frac{x_{B}}{x_{B_{0}}} .
$$

With an appropriate value for $\alpha$ (see section 3.6), this equation can be used to predict the Freon 11 concentration as a function of the amount of liquid DME remaining in the bottle.

\subsection{Simulation of Rayleigh Distillation}

For general applicability, we refer to the simulation results in terms of the enrichment multiple $\left(x_{B} / x_{B_{0}}\right)$, which is the heavy-component mole fraction normalized to its initial value, and the fraction of the initial amount of liquid that has been used $\left(1-\frac{L}{L_{0}}\right)$. Equation 3.8 relates the vapor- and liquid-phase concentrations of the light component, but can be rewritten to relate the concentrations of the heavy component:

$$
y_{B}=\frac{x_{B}}{\alpha+(1-\alpha) x_{B}} .
$$

Noting that we are in a regime in which $x_{B} \ll 1$, and hence $(1-\alpha) x_{B} \ll \alpha$, eqn. 3.10 can be approximated as

$$
y_{B}=\frac{x_{B}}{\alpha} .
$$

The enrichment multiple therefore applies to both the vapor and liquid phases.

The pure-component vapor pressures needed to determine $\alpha$ can be calculated from tabulated data [10]. The predicted relative volatility of DME/Freon 11 near room temperature is shown in Table 3.2 .

In the regime of relative volatility $(5.5<\alpha<5.8)$ and initial Freon concentration $\left(x_{B_{0}}<10^{-4}\right)$ in which we are interested, the solution of eqn. 3.9 is not sensitive to variations in either of these parameters: the Freon 11 concentration doubles each time $57 \%$ of the liquid remaining in the bottle is used. The prediction for $\alpha=5.63$ and $x_{B_{0}}=10^{-7}$ is shown in Table 3.3. 
Table 3.2: Predicted relative volatility $(\alpha)$ of DME/Freon 11 near room temperature [10].

\begin{tabular}{|c|c|}
\hline $\mathrm{T}\left[{ }^{\circ} \mathrm{C}\right]$ & $\alpha$ \\
\hline 18 & 5.78 \\
19 & 5.74 \\
20 & 5.70 \\
21 & 5.66 \\
22 & 5.62 \\
23 & 5.59 \\
\hline
\end{tabular}

\subsection{Aging Tests with Freon 11 in Dimethyl Ether}

We previously reported [3] that very low aging rates can be achieved with DME using gas plumbing that is rigorously free of plastics. The tests described below were run using such a plumbing system.

To investigate the effect of a constant level of Freon 11 in DME, a Kin-Tek SRTtype source was used with the gas permeation system mentioned above to add $\sim 5 \mathrm{ppm}$ of Freon 11 to otherwise pure DME (Dymel A, DuPont, Wilmington, DE). (We measured the Freon 11 concentration in this DME to be $\sim 5 \mathrm{ppb}$.) The SRT source is a $\sim 10$-cm length of Teflon tube that contains liquid Freon 11. Although Teflon has been reported to cause signal loss [7], we believe that it did not affect this test. Indeed, low aging rates have been achieved using DME in systems with certain plastics, including Teflon [11]. To ensure that the Freon 11 concentration in the DME supply would not change appreciably due to a Rayleigh distillation, less than $30 \%$ of the liquid in the DME supply bottle was used over the course of the test. The test was started without any added Freon 11 ; as shown in Fig. 3.2, the current dropped to $\sim 25 \%$ of its initial value upon addition of the Freon. The permeation source was bypassed several times during the test, and the current returned to its initial level each time. A total of $0.45 \mathrm{C} / \mathrm{cm}$ of charge was collected during the exposure to Freon 11 , and the measured aging rate during this period was consistent with a value of zero. ${ }^{55} \mathrm{Fe}$ pulse height spectra taken at the end of the test were somewhat degraded, however 
Table 3.3: Numerical solution to eqn. 3.9 for $\alpha=5.63$ and $x_{B_{0}}=10^{-7}$.

\begin{tabular}{|r|r||r|r|}
\hline $\begin{array}{c}\text { Enrichment } \\
\text { multiple }\end{array}$ & $\begin{array}{r}\text { Fraction of } \\
\text { liquid used }\end{array}$ & $\begin{array}{c}\text { Enrichment } \\
\text { multiple }\end{array}$ & $\begin{array}{r}\text { Fraction of } \\
\text { liquid used }\end{array}$ \\
\hline 1.0 & 0.000 & 2.8 & 0.714 \\
1.1 & 0.109 & 3.0 & 0.737 \\
1.2 & 0.199 & 3.5 & 0.782 \\
1.3 & 0.273 & 4.0 & 0.815 \\
1.4 & 0.336 & 4.5 & 0.839 \\
1.5 & 0.389 & 5.0 & 0.859 \\
1.6 & 0.435 & 6.0 & 0.887 \\
1.7 & 0.475 & 7.0 & 0.906 \\
1.8 & 0.511 & 8.0 & 0.920 \\
1.9 & 0.542 & 10.0 & 0.939 \\
2.0 & 0.570 & 12.0 & 0.951 \\
2.2 & 0.617 & 14.0 & 0.960 \\
2.4 & 0.655 & 16.0 & 0.966 \\
2.6 & 0.687 & 32.0 & 0.985 \\
\hline
\end{tabular}

(Fig. 3.3), while those taken at the end of a comparable test without added Freon 11 were not (Fig. 3.4). The spectra shown in Fig. 3.3 were taken at successive positions along the irradiated region of the wire and display the classic degradation pattern [12]. These data indicate that the presence of Freon 11 in DME does not result in measurable loss of gain, but does cause some degradation of energy resolution.

To investigate the possibility of Freon 11 being concentrated by a Rayleigh distillation, two aging tests were performed in which all of the liquid DME (Semiconductor grade, Matheson Gas Co., Newark, CA) in the bottle was used. It was necessary to use all of the liquid because large changes in the enrichment multiple are predicted to occur as $80-100 \%$ of the liquid is used (Table 3.3). The initial gas-phase Freon 11 concentration was approximately $0.2 \mathrm{ppm}$ in the first test and approximately $0.04 \mathrm{ppm}$ in the second test.

In each of these tests, one of which is shown in Fig. 3.5, the current was initially stable, but dropped rapidly toward the end of the test when most of the (liquid) 


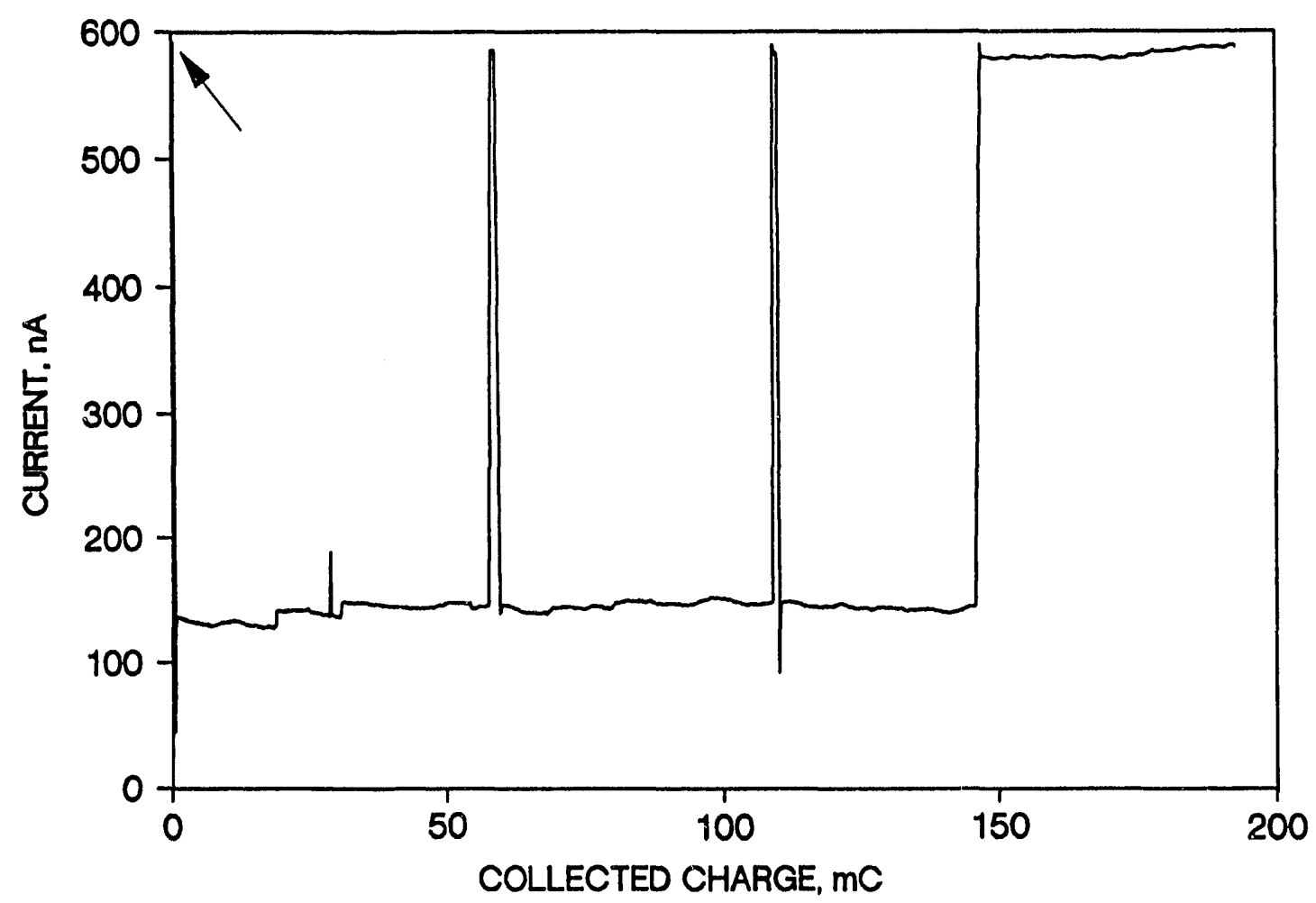

Figure 3.2: Aging test in which $\sim 5 \mathrm{ppm}$ Freon 11 was added to DME. The current dropped $\sim 75 \%$ from its initial value (indicated by the arrow) upon addition of the Freon, but no aging was observed. The irradiated region of the wire was $0.3 \mathrm{~cm}$.

DME had been used. The point at which no liquid DME remained is indicated in the figure. Although no liquid DME remained, the bottle still contained gaseous DME at its room-temperature vapor pressure, $\sim 62$ psig. Subsequent to this point, the distillation process ceased, and the gas composition and the wire current were nearly stable. The gas flow rate, which is a function of the pressure in the bottle, dropped during this period, confirming that no liquid DME remained. When another bottle of DME was connected to the system, the current rose somewhat above its initial level. This was because the Freon 11 concentration in the new bottle was lower than what it had been in the previous bottle at the beginning of the test.

Both of these aging tests were performed using the same proportional tube and the same wire, and a total of $1.4 \mathrm{C} / \mathrm{cm}$ of charge was collected. ${ }^{55} \mathrm{Fe}$ pulse height 


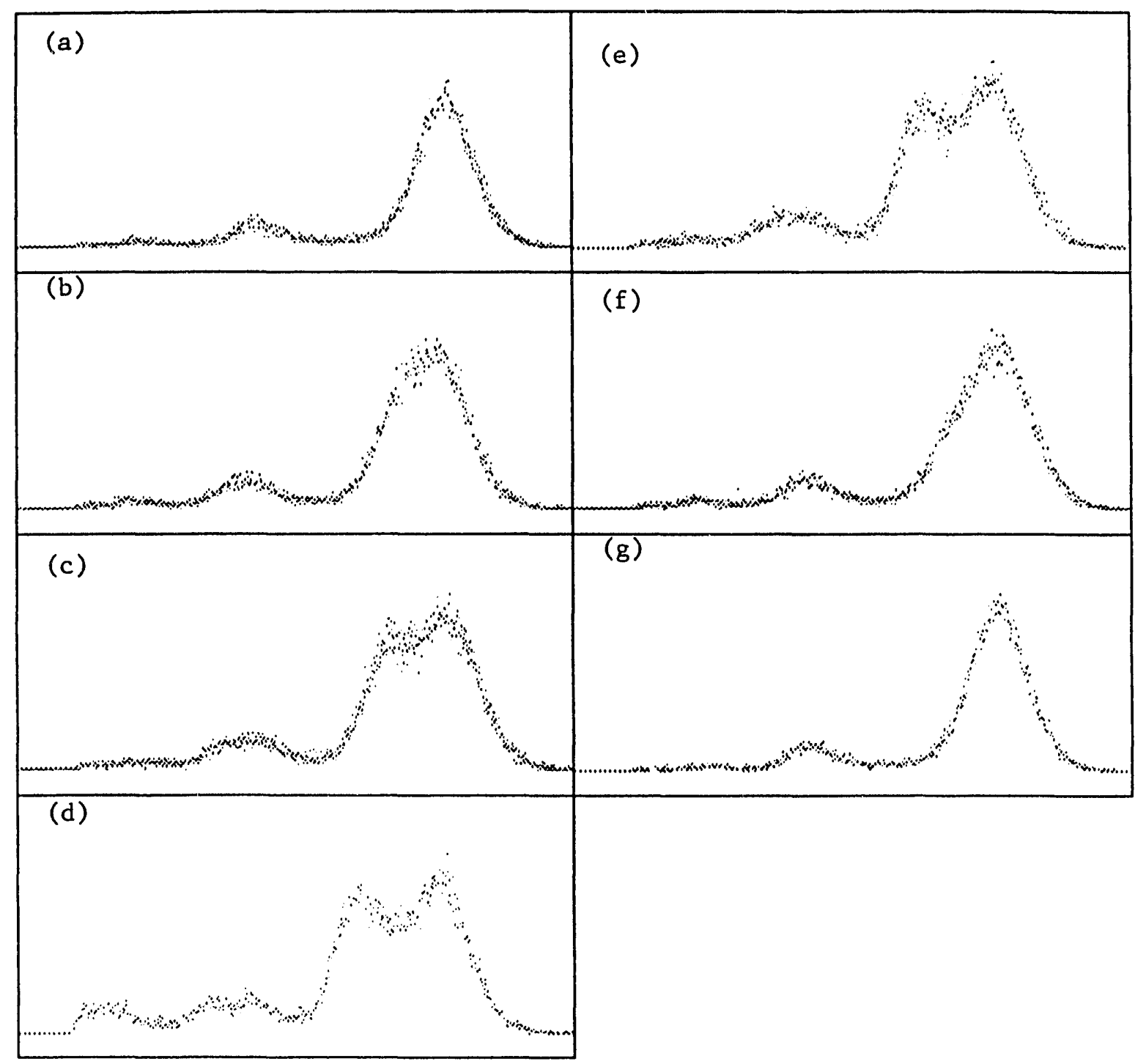

Figure 3.3: ${ }^{55} \mathrm{Fe}$ pulse height spectra taken after DME aging test with $\sim 5 \mathrm{ppm}$ Freon 11 . The ${ }^{55} \mathrm{Fe}$ line source was perpendicular to the wire. The classic pattern of degradation of the spectrum is seen [12]. The positions of the ${ }^{55} \mathrm{Fe}$ source with respect to the approximate center of the irradiated region were: $a,-3 ; b,-2 ; c,-1$; $\mathrm{d}, 0 ; \mathrm{e},+2 ; \mathrm{f},+3 ; \mathrm{g},+4$, where distances are in millimeters, and negative positions are upstream and positive positions are downstream with respect to the direction of gas flow. 


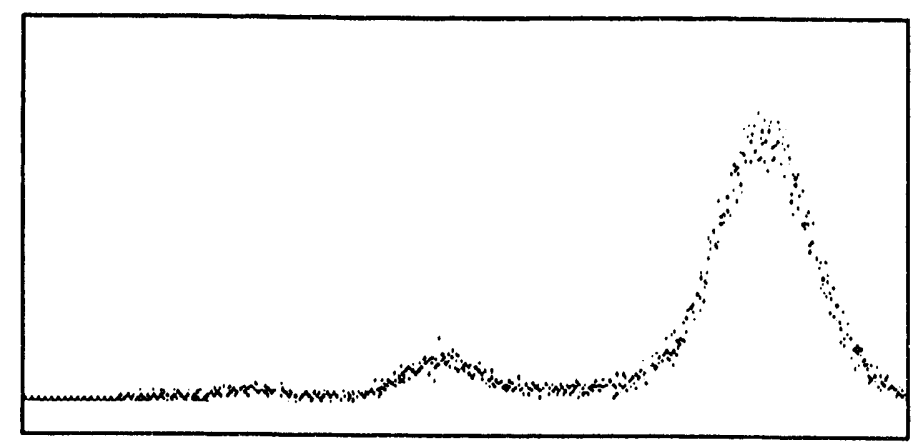

Figure 3.4: ${ }^{55} \mathrm{Fe}$ pulse height spectrum taken at the center of the irradiated region of the wire after DME aging test with no added Freon 11 . The ${ }^{55} \mathrm{Fe}$ line source was perpendicular to the wire. No significant degradation of the spectrum is observed.

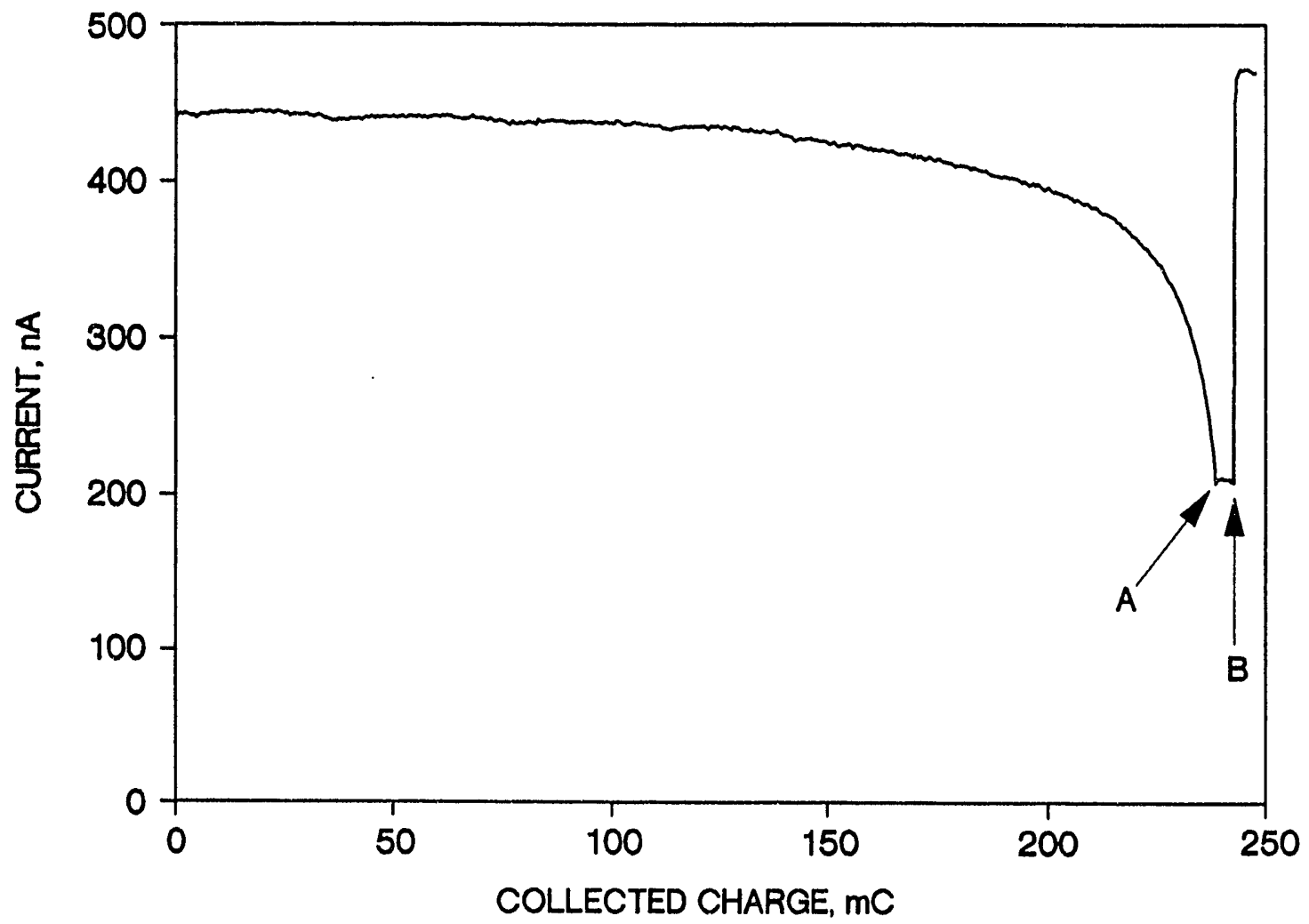

Figure 3.5: Aging test in which all liquid DME was used. No liquid DME remained at point $A$. The liquid-depleted bottle was replaced with a full bottle at point $B$. The enrichment multiple of the Freon 11 in this test is shown in Fig. 3.7b. 
spectra taken at the end of the second test were severely degraded, however (Fig. 3.6), indicating the presence of some deposit on the wire. (See discussion in section 3.8.2.)

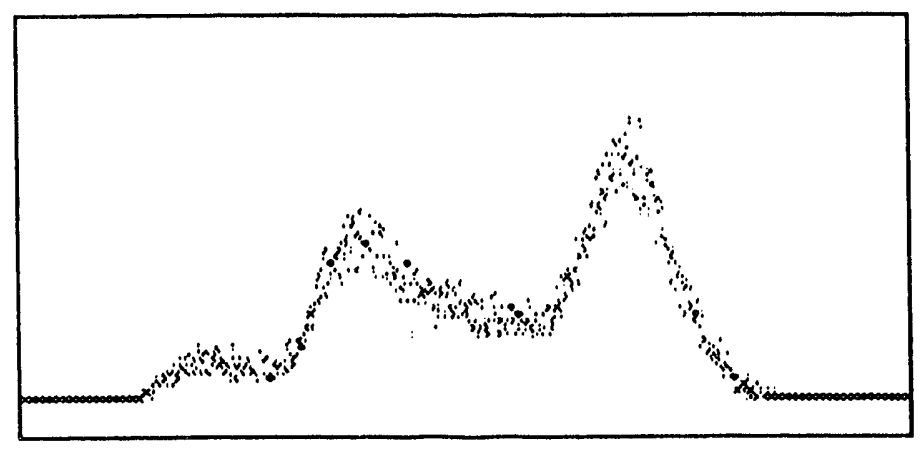

Figure 3.6: ${ }^{55} \mathrm{Fe}$ pulse height spectrum taken after two DME aging tests in which all of the liquid DME was used. The ${ }^{55} \mathrm{Fe}$ line source was perpendicular to the wire. Rather severe degradation of the spectrum is observed.

To evaluate the effect of this deposit on the gain, a bottle of DME that had been used previously and was known not to cause aging was connected to the proportional tube. The ${ }^{55} \mathrm{Fe}$ source that was used for the aging tests was moved along the wire, and the variation in current drawn was observed to be only $1.5 \%$ between the coated and an uncoated region, corresponding to an overall aging rate of $R \sim 1 \% / \mathrm{C} / \mathrm{cm}$. During this test, however, an aging rate of $R \sim 400 \% / \mathrm{C} / \mathrm{cm}$ was observed. A new proportional tube with a new wire was installed: the rapid aging continued. When all the gas plumbing between the DME bottle and the proportional tube was replaced with new components, however, the aging rate returned to a value consistent with zero. These data suggest that some compound remained in the plumbing, but subsequently outgassed and induced rapid aging in DME.

The validity of using the Rayleigh model to describe this system was tested by comparing the predicted and the experimental values of the enrichment multiple as a function of the fraction of the liquid DME used. The enrichment multiple was determined by measuring the concentration of the Freon 11 in the gas throughout the tests. A Varian 3400 gas chromatograph equipped with a Varian model 02-001972-00 electron capture detector (Varian Instrument Group, Walnut Creek, CA) was used for this purpose. The fraction of the liquid used was taken to be equivalent to the 
fractional elapsed time of the test because the gas flow rate, which was monitored, remained constant throughout the test. (Fluctuations in the flow rate were determined to be insignificantly small.)

The GC analysis was performed with a DB-5 capillary column of $30 \mathrm{~m}$ length, $0.25 \mathrm{~mm} \mathrm{ID,} \mathrm{and} 0.25 \mu \mathrm{m}$ phase thickness (J\&W Scientific, Folsom, CA). To effect the desired separation, the GC temperature program consisted of a ramp to $50^{\circ} \mathrm{C}$ at, $10^{\circ} \mathrm{C} /$ min after an initial three-minute hold at $-30^{\circ} \mathrm{C}$. A helium carrier gas pressure of 15 psig was used. The injector and detector were kept isothermal at $100^{\circ} \mathrm{C}$ and $200^{\circ} \mathrm{C}$, respectively. Under these conditions, Freon 11 eluted in $4.7 \pm 0.02 \mathrm{~min}$. The analyzed samples (10 $\mu \mathrm{l}$ each) were withdrawn from the downstream side of the proportional tube.

Some deviation from the Rayleigh prediction can occur as a consequence of the nonzero mass of vapor in the DME bottle, which is not accounted for in the model. Only a small fraction of this vapor (that near the vapor/liquid interface) is in equilibrium with the liquid in the bottle; the remainder is less enriched in Freon 11 because it was produced earlier, from liquid that was less enriched in Freon 11. Therefore, the concentration of Freon 11 in the vapor leaving the bottle, which is what we measured, is always lower than the prediction, and the Rayleigh prediction consequently represents an upper limit on the Freon concentration.

A lower limit on the Freon 11 concentration can be estimated from the time required for vapor-phase concentration changes to propagate from the liquid surface to the point at which samples were withdrawn for analysis. This time is given by the ratio of the corresponding vapor volume to the volumetric gas flow rate. The propagation delay is most conveniently expressed as an offset in the fraction of the liquid used. This limiting offset is numerically equal to the ratio of the propagation time to the total elapsed time of the test, and a line representing the lower limit on the Freon concentration can therefore be plotted by offsetting the Rayleigh prediction by this ratio (Fig. 3.7). This represents a lower limit because any diffusion in or mixing of the vapor will reduce the effective propagation time. In addition, when all of the liquid is used, mixing of the vapor in the bottle dilutes more-highly-enriched vapors, thereby causing the Freon 11 concentration to remain finite, a behavior not predicted 


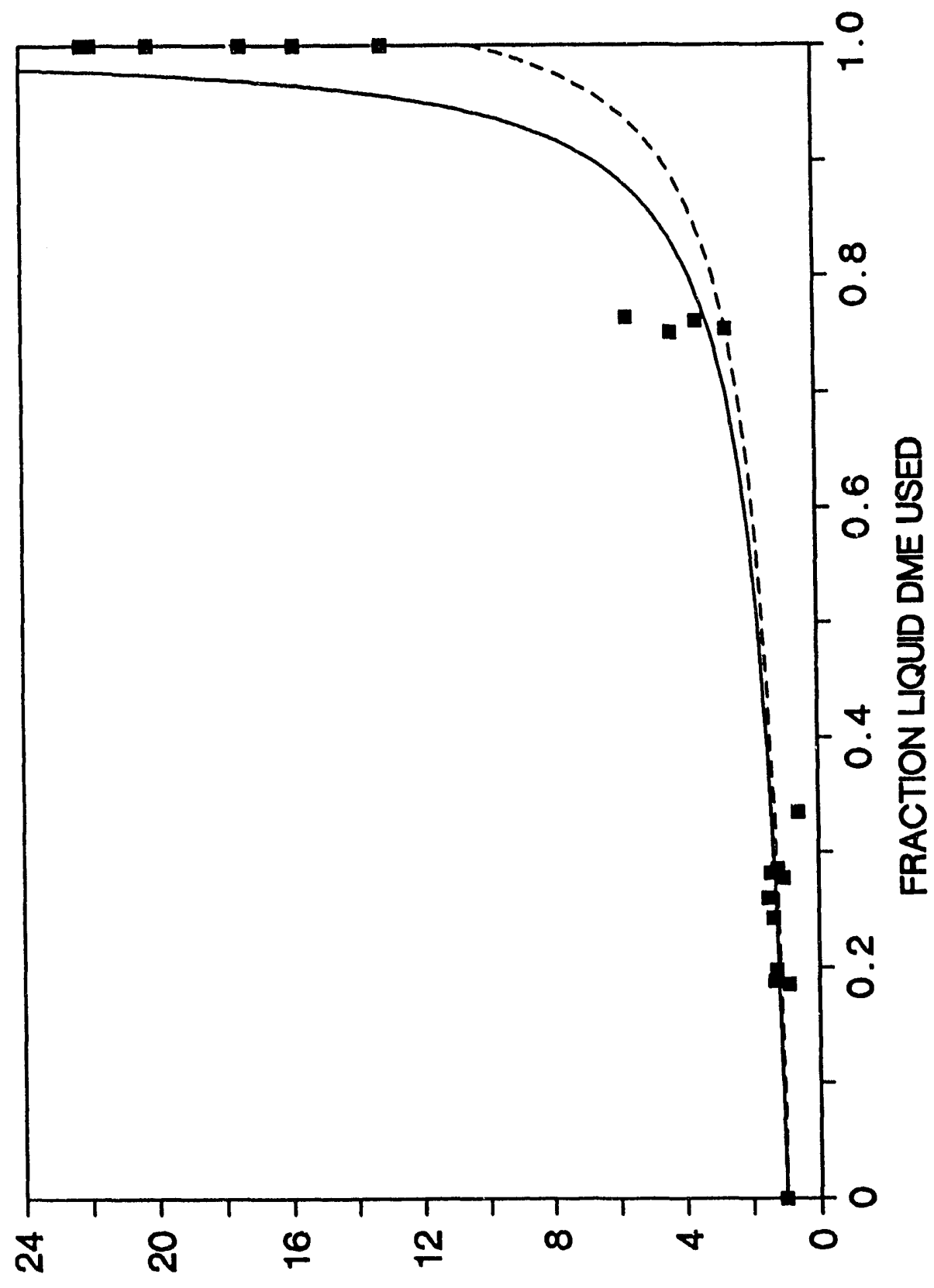

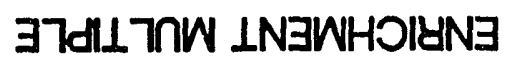

Figure 3.7: Predicted and experimental enrichment multiples of Freon 11 in DME. (a) The solid line represents the Rayleigh prediction; the dashed line represents an offset of 0.058 ( $=5 \mathrm{hr}$ propagation time $/ 86.6 \mathrm{hr}$ total time). The initial amount of DME in this test was $255 \mathrm{~g} ; 60 \mathrm{~g}$ of gas remained after all of the liquid had vaporized. The initial gas-phase Freon 11 concentration was $\sim 0.2 \mathrm{ppm}$. 


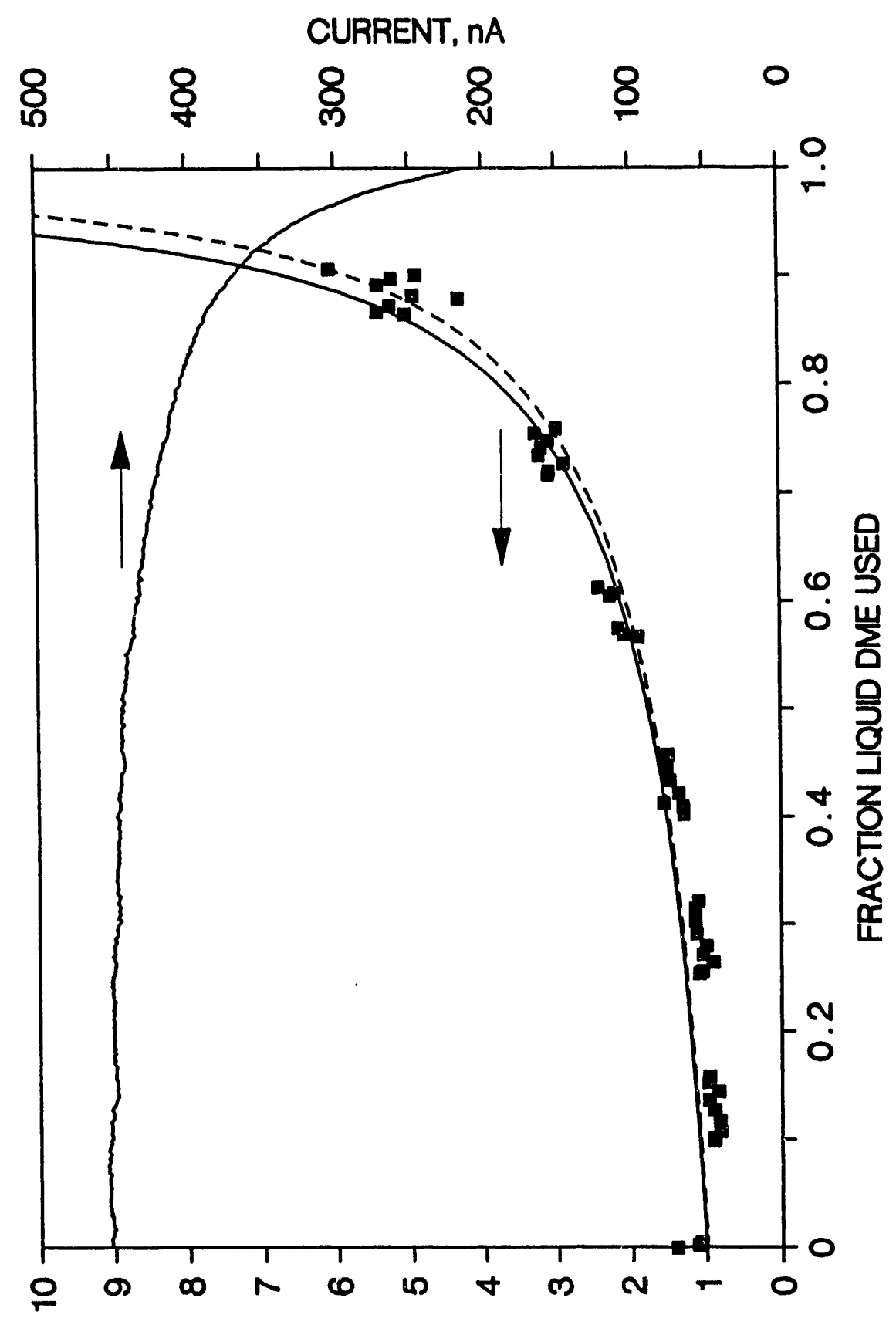

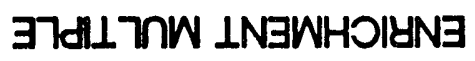

Figure 3.7: Predicted and experimental enrichment multiples of Freon 11 in DME. (b) The solid line represents the Rayleigh prediction; the dashed line represents an offset of 0.018 (=2.9 hr propagation time/159.6 hr total time). The initial amount of DME was $670 \mathrm{~g} ; 60 \mathrm{~g}$ of gas remained after all of the liquid had vaporized. The initial Freon 11 concentration was $\sim 0.04 \mathrm{ppm}$. The wire current as a fraction of the liquid used is also shown. 
by the model.

As shown in Fig. 3.7, there is good agreement between prediction and experiment. Within the experimental uncertainty, the data lie between the limiting cases, indicating that the Rayleigh distillation model accurately describes the vaporization of DME in a gas bottle.

While analyzing the DME for its Freon 11 content during these tests, it was observed in the chromatograms that several species were present in addition to Freon 11, and that the concentrations of all species increased as the liquid DME was used. Further, as the liquid DME was used, progressively larger numbers of distinct species were observed in the chromatograms. These species have not been identified.

\subsection{Discussion}

\subsubsection{Aging Results}

We noted that increases in the concentration of Freon 11 can give the appearance of aging due to electron attachment. Because the concentration of Freon 11 in DME can increase as the result of Rayleigh distillation, it is important to know the initial Freon 11 concentration: the effect of electron attachment may be evident very early (if the initial Freon 11 concentration is large) or it may not be evident until nearly all the liquid has been used (if the initial Freon 11 concentration is small). By using an appropriately small fraction of the DME in the supply bottle, however, the variation in the Freon 11 concentration, and hence the variation in wire currents, can be kept within any desired limit.

We also noted that rapid aging was observed in DME after using all of the liquid in two bottles. It has not yet been possible to identify the compound (or compounds) responsible for this aging, but we believe it to be less volatile than Freon 11, as 1) it did not appear until most, if not all, of the liquid DME had been used, and 2) it appeared to remain in the plumbing, unlike Freon 11, which is quite volatile at room temperature. It is worth noting that both DME bottles used in these tests had been used in previous aging tests in which little aging was observed [3]. Assuming that the compound inducing the aging originated in the bottle, which we believe to be the 
case, it must have been present in the earlier tests, but at too low a concentration to have had an effect. This would be further reason to use only a fraction of the DME in a given supply bottle.

\subsubsection{Degradation of Energy Resolution}

We noted that some degradation of the ${ }^{55}$ Fe pulse height spectrum was observed in the DME aging tests in which Freon 11 was added. Although this degradation indicated the presence of deposits on the wire, we believe it to be of relatively minor significance because the energy resolution is a far more sensitive indicator of wire deposits than is the change in current. Indeed, the severe degradation of the pulse height spectrum shown in Fig. 3.6 corresponded to only a $1.5 \%$ change in current after $1.4 \mathrm{C} / \mathrm{cm}$ of charge was collected.

We expect that the degree to which the pulse height spectrum is degraded may depend on both the concentration of the species inducing the aging and the amount of charge collected. If we take the product of these quantities as a measure of the amount of degradation expected, we find that much more degradation is expected for the wire exposed to the $5 \mathrm{ppm}$ of Freon 11 (Fig. 3.3) than for the wire from the tests in which all of the liquid in two bottles of DME was used (Fig. 3.6):

Tests with direct addition of Freon 11 using gas permeation:

$$
(0.45 \mathrm{C} / \mathrm{cm}) \times(5 \mathrm{ppm} \text { Freon } 11 \text { concentration })=2.25 \text {. }
$$

Tests in which all liquid DME was used:

$$
(1.4 \mathrm{C} / \mathrm{cm}) \times(0.3 \mathrm{ppm} \text { average Freon } 11 \text { coilcentration })=0.42 \text {. }
$$

That the observed degradation of the spectra is actually much less in the case of the direct Freon 11 addition, rather than much more, as the above estimate predicts, can be taken as an indication that some species other than Freon 11 induces aging in DME. As previously noted, many species, any of which could potentially induce aging, were detected in the DME.

We note, however, that energy resolution is of major importance only when using energy-loss $(d E / d x)$ measurements for particle identification, and it is expected that 
this technique will not be very useful at the SSC because the particles of interest will generally have very high energies, outside the range of this technique. For particle tracking only, degradation of energy resolution, as distinct from loss of gain, is not a significant issue or limitation.

\subsubsection{Rayleigh Distillation}

As a result of Rayleigh distillation, concentration changes will occur whenever there is a liquid phase in the gas bottle. Indeed, it was noted in aging tests with propane, which has a liquid phase in the gas bottle, that the gas purity varied not only from bottle to bottle, but also within a bottle as it was used [13]. The concentrations of species less volatile than the main gas will increase while those of species more volatile than the main gas will decrease. This being so, the potential effects of changes in gas purity on wire chamber operation must be considered.

The degree to which the heavier component in a binary mixture will be concentrated as a result of Rayleigh distillation depends primarily on the relative volatility of the two components: the closer this value is to unity, the less noticeable is the concentration effect. For example, the apparent loss of gain caused by Freon 11 will be more severe in propane $\left(\alpha_{\text {propane-Freon } 11} \simeq 9.4[10]\right)$ and less severe in isobutane $\left(\alpha_{\text {isob:tane-Freon } 11} \simeq 3.8[10]\right)$ than in DME $\left(\alpha_{\text {DME-Freon } 11} \simeq 5.6\right)$.

As we have shown, increases in the concentration of highly electronegative species can give the appearance of aging. This work investigated only the effects of Freon 11, but the possibility exists that other electronegative species are of the correct volatility to give the same effect. As suggested above, it is also possible that species that induce wire degradation (as contrasted with the effects of electronegativity) may be concentrated so that their effect is noticeable. A different, but probably less plausible, explanation is that certain species that inhibit aging are depleted because they are more volatile than the main gas. In any case, concentration changes caused by Rayleigh distillation complicate the interpretation of aging results. The concentration changes and their consequences can be minimized, however, by using a suitably small fraction of the liquid in the gas bottle. Alternatively, the concentration changes can be avoided by vaporizing the entire liquid phase in each supply bottle before use. 
Naturally, this approach will not prevent concentration changes due to batch-to-batch variations.

\subsection{Conclusions}

We have found no evidence that Freons in general, and Freon 11 in particular, affect the rate of gain decrease in either $\mathrm{Ar} / \mathrm{C}_{2} \mathrm{H}_{6}$ or dimethyl ether. Aging tests with both gases in which controlled amounts of Freons were added showed no loss of gain in excess of that expected without the Freons. Degradation of energy resolution, as characterized by the ${ }^{55} \mathrm{Fe}$ pulse height spectrum, seems to be accelerated by the presence of Freon 11, however.

The large electronegativity of Freon 11 causes signal loss by attachment of primary electrons and so can give the appearance of loss of gain if its concentration increases. We showed by experiment and simulation that apparent aging observed while using dimethyl ether can be explained by the natural increase in the concentration of Freon 11 that occurs in a Rayleigh distillation process. Large changes in the concentration of Freon 11 in DME and the consequent changes in wire currents can be avoided by not using all of the liquid DME in a given supply bottle.

Concentration changes of trace species are expected to occur whenever there is a liquid phase in a gas bottle. It is therefore prudent not to use all of the liquid phase in such cases regardless of the type of gas. Prevaporization of the liquid phase would mitigate the problems associated with gas-phase concentration changes, however, and would permit virtually complete use of each batch of condensed gas.

\section{Acknowledgements}

We acknowledge Stan Majewski, University of Florida (now at CEBAF), and Mohammed Jibaly, University of Florida (now at University of Northern Iowa), for discussions regarding the effects of Freon 11 and thank them for supplying us with much of the DME used in these tests.

This work was supported by the Director, Office of Energy Research, Office of High 
Energy and Nuclear Physics, Division of High Energy Physics, of the U.S. Department of Energy under Contract No. DE-AC03-76SF00098.

\section{References}

[1] H. Kobayashi, M. Shen, and A.T. Bell, J. Macromol. Sci.-Chem., A8 (1974) 1345 .

[2] D.W. Hess. In Proceedings of the Workshop on Radiation Damage to Wire Chambers, J. Kadyk, ed., LBL-21170 (1986), p. 15.

[3] J. Kadyk, J. Wise, D. Hess, and M. Williams, IEEE Trans. Nucl. Sci., NS-37 (1990) 478.

[4] (a) A.E. O'Keeffe and G.C. Ortman, Anal. Chem., 38 (1966) 760; (b) Correction, Anal. Chem., 41 (1969) 1598.

[5] F. Villa, Nucl. Instr. and Meth., 217 (1983) 273.

[6] I. Juricic and J. Kadyk, IEEE Trans. Nucl. Sci., NS-34 (1987) 481.

[7] (a) M. Jibaly, P. Chrusch, G. Hilgenberg, S. Majewski, R. Wojcik, R. Wein- traub, and F. Sauli, Nucl. Instr. and Meth., A273 (1988) 161; (b) M. Jibaly, P. Chrusch, G. Hilgenberg, S. Majewski, R. Wojcik, F. Sauli, and J. Gaudaen, IEEE Trans. Nucl. Sci., NS-36 (1989) 552; (c) M. Jibaly, S. Majewski, P. Chrusch, R. Wojcik, F. Sauli, and J. Gaudaen, Nucl. Instr. and Meth., A283 (1989) 692.

[8] C.J. King, Neparation Processes (McGraw-Hill, New York, 1980), pp. 115-123.

[9] C.J. King, ref. [8], pp. 30,31.

[10] R.C. Reid, J.M. Prausnitz, and B.E. Poling, The Properties of Gases and Liquids, 4th ed. (McGraw-Hill, New York, 1987).

[11] G. Bari, M. Basile, G. Bonvinvci et al., Nucl. Instr. and Meth., A251 (1986) 292.

[12] A.J.F. den Boggende, A.C. Brinkman, and W. de Graaff, J. Sci. Instr. (J. Phys. E), 2 (1969) 701.

[13] M. Danilov, V. Nagovitsin, V. Shibaev, I. Tichomirov, E. Michel, and W. Schmidt-Parzefall, Nucl. Instr. and Meth., A274 (1989) 189. 


\section{Chapter 4}

\section{Summary and Conclusions}

\subsection{Summary}

The wire chamber aging problem is very complex and the mechanisms of aging phenomena are only partially understood. Previous studies of wire aging have been largely trial-and-error experiments aimed at discovering satisfactory sets of operating conditions. This work attempted to describe wire aging from a more chemical viewpoint by using principles of plasma chemistry. This approach was generally valid. The underlying chemistry of several aspects of wire aging was mo leled with sufficient detail to determine appropriate mitigating actions.

\subsection{Conclusions}

\subsection{1 $\mathrm{CF}_{4} / \mathrm{iC}_{4} \mathrm{H}_{10}$ Gases}

This work showed that there is a nonmonotonic dependence of the aging properties of $\mathrm{CF}_{4} / \mathrm{iC}_{4} \mathrm{H}_{10}$ on gas composition, with extensive deposition occurring in $\mathrm{CF}_{4}$-rich gases. A four-part model considering 1) plasma polymerization of the hydrocarbon, 2) etching of wire deposits by $\mathrm{CF}_{4}, 3$ ) acceleration of deposition processes in strongly etching environments, and 4) reactivity of the wire surface was developed to understand anode aging in $\mathrm{CF}_{4} / \mathrm{iC}_{4} \mathrm{H}_{10}$ gases. This model may we generally applicable to $\mathrm{CF}_{4} /$ hydrocarbon gases. Some practical guidelines suggested by the model are 1) that 
low concentrations of hydrocarbons in $\mathrm{CF}_{4}$ may lead to extensive aging and 2) that gold-plated wires are acceptable and non-gold wires are unacceptable for use in $\mathrm{CF}_{4}$ containing gases. An apparent cathode aging process resulting in a rapid reduction of wire currents was observed in $\mathrm{CF}_{4}$-rich gases. This result was unexpected in view of the traditional explanation of cathode aging, which argues that cathode deposits lead to a self-sustained breakdown.

\subsubsection{Dimethyl Ether}

This work showed that aging in dimethyl ether is not greatly accelerated by Freon 11, as had previously been believed. Rather, the natural distillation in the dimethyl ether supply cylinder provided a mechanism for concentrating Freon 11. Electron attachment to an increasing concentration of Freon 11 or other electronegative species gives the appearance of aging. Knowledge of the rate at which Freon 11 concentrates permits appropriate measures to be taken. Such measures include prevaporizing the liquid dimethyl ether or using only a fraction of the liquid in the supply cylinder.

\subsubsection{Heating Effects}

Heating effects caused by the power dissipated in the avalanches were significantly smaller than previously believed. Rather than being dissipated by the combined effects of the gas flow rate and the gas heat capacity, dissipation of heat occurred primarily by radial conduction through the gas. Gas flow rate is therefore not a critical issue to be considered in the design of straw-tube wire chambers.

\subsection{Future Work}

\subsubsection{Analysis Techniques}

To understand the chemistry of wire aging, direct chemical analysis of the reactive species in the avalanche will be necessary. A regrettable aspect of this work is that no direct in situ analytical techniques were used to elucidate the chemistry. The cryotrap interface to a $\mathrm{GC} / \mathrm{MC}$ constructed during the early phases of this work [1] was useful 
for trace analysis of stable species, but was never intended to be used to analyze reactive species. Although knowledge of the stable species produced in the avalanche is certainly valuable, a detailed chemical model of the avalanche will require a more direct knowledge of the reactive species.

A related issue is that aging tests are a batch process, since each test is normally conducted in a different counter tube with a different wire, and test-to-test variations are expected. An in situ analysis would at least partially alleviate the difficulties involved with analysis of sequential stages of aging on a single wire and also allow relatively simple parametric studies to be made of the effects of such important variables as gas flow rate and gas composition. The value of in situ diagnostics has apparently been recognized, since new wire aging programs are based on such techniques.

Two general types of analysis techniques need to be considered: gas-phase and surface.

For gas-phase analysis, downstream mass spectroscopy has the potential to yield much information about the reactive species in an avalanche. An experiment designed to extract a sample from the avalanche by supersonic expansion is under development [2]. An alternative approach for extracting a sample is to construct a hollow, perforated anode wire. Reactive species might be drawn into a carrier gas within the wire and fed into a mass spectrometer. To the extent that this technique drifts reactive species in an atmospheric-pressure carrier gas, it has much in common with drift tube MS experiments. Although the reactive species may react while in the drift region, thereby requiring a kinetic analysis to determine the initial species, this technique is potentially a rather direct diagnostic probe of the avalanche.

Optical techniques are powerful diagnostic tools that have found extensive application in plasma studies. Optical emission spectroscopy has previously been used to investigate scintillation processes [3]. More recently, a program to study wire aging has begun to use this technique to gain direct evidence of specific carbon radicals and of some trace-level species in the gas [4]. Of the many optical techniques available, laser-induced fluorescence [5] may be particularly suited to probing the chemistry of an avalanche because it combines the benefits of small analysis volume and species specificity. 
All surface analysis in this work was concerned with chemical composition and was destructive, requiring that the wires be removed from the counter tubes. An alternate approach would be to measure the mass of the wire in situ. Such a diagnostic technique would permit direct measurements of deposition or etching rates, and would thus be a valuable tool for evaluating the extent of anode aging and for identifying possible cathode aging. Knowledge of deposition rates would also give mechanistic information, allowing kinetically-limited deposition processes to be distinguished from diffusion-limited growth processes. (Chemical analyses would still be necessary to determine the densities of deposits.) For the point-irradiation in our aging tests, a mass sensitivity of $0.02 \mu \mathrm{g}$ would be necessary; this could be reduced by irradiating longer portions of the wire. A vibratory response technique analogous to the quartzcrystal microbalance might be adaptable for this application.

\subsubsection{Subjects for Further Study}

There are many areas of potential interest for further study of wire aging. One important area suggested by the present work concerns possible cathode aging in $\mathrm{CF}_{4}$-based gases. One way to approach this problem is to use multiwire proportional counters containing both anode and cathode wires. To determine whecher the $\mathrm{CF}_{4}$ aging transient results from cathode aging, the counter would be aged, the cathode wire(s) replaced, and the test continued. If the transient is due to cathode aging, replacement of the cathode(s) should cause it to reoccur. Due to the smaller surfice area of cathode wires relative to a continuous cathode, any (chemical) modifications to the cathode surface would be more concentrated and therefore easier to detect. Effects of cathode material could also be investigated easily in this way.

The model developed in Chapter 2 should be generally applicable to $\mathrm{CF}_{4} /$ hydrocarbon gases. Due to increasing interest in $\mathrm{CF}_{4} / \mathrm{CH}_{4}$ and $\mathrm{CF}_{4} / \mathrm{C}_{2} \mathrm{H}_{6}$ gases, it would be useful to determine the range of the etching window in such mixtures.

There are also a number of more general topics relating to wire aging that remain to be understood. One such topic is the effect on wire aging of oxygen-containing molecules (molecular oxygen, water, alcohols). These species have been observed empirically to have beneficial effects in wire chambers, but their effects on the chemistry 
of the avalanche is not understood. Even less is known about the effects of other oxygenated species (ethers, aldehydes, ketones), although such molecules are occasionally detected in the gaseous effluent from chambers.

A second topic concerns transport effects outside the avalanche. Negative ion transport is a potentially important transport mechanism: negative ions are drawn to the anode, where they may most easily become involved in aging processes. This mechanism may be particularly relevant for halogenated molecules, which tend to be electron-attaching and which may catalyze plasma polymerization.

A third topic concerns the relation between bond dissociation energies, bond unsaturation, and wire aging. If aging occurs primarily by polymerization of radicals, it might be accelerated by the presence of compounds with low dissociation energies, which would fragment readily in an avalanche to form radicals. Aging might also be accelerated by the presence of unsaturated compounds, which may polymerize relatively easily. For example, TMAE, which is both unsaturated and has a low dissociation energy, causes rapid wire aging [6]. The mechanism and driving forces for this aging are not understood, however.

Other topics include the chemistry of $\mathrm{Ar} / \mathrm{C}_{2} \mathrm{H}_{6}$ with $\mathrm{NH}_{3}$ additive, which we have observed to age rapidly and create a readily-visible deposit, the effect of argon on the plasma chemistry of hydrocarbon- and $\mathrm{CF}_{4}$-based gases, and the effect of selfsustained (Malter) breakdowns on anode aging.

Since it is still widely believed that trace-level contamination by certain species can cause aging, a programmatic evaluation of the effects of adding such species to wire chamber gases may be useful. Knowledge of chemical mechanisms that lead to aging would permit judicious choice of the species to be tested.

Finally, the effect of radiation dose rate on the chemistry of the avalanche is an important factor to determine the validity of accelerated aging tests. There is some evidence that aging is more rapid at lower dose rates in Ar/hydrocarbon gases [7]. It may therefore be necessary to study the chemistry of such gases at low dose rates, which might complicate chemical analyses due to the reduced avalanche intensity and/or volume under these conditions. 


\section{References}

[1] J. Wise, MS Thesis, LBL-29033 (1990).

[2] K. Kurvinen (Research Institute for High Energy Physics, Univ. of Helsinki), personal communication (1992).

[3] T.J. Sumner, G.K. Rochester, P.D. Smith, J.P. Cooch, and R.K. Sood, IEEE Trans. Nucl. Sci., NS-29 (1982) 1410.

[4] M.M.F.R. Fraga, E.P. de Lima, R.F. Marques, M. Salete, and S.C.P. Leite, "Fragments and radicals in gaseous detectors," presented at Sixth International Wire Chamber Conference, Vienna, Austria, Feb. 17-21, 1992.

[5] R.A. Gottscho and T.A. Miller, Pure Appl. Chem., 56 (1984) 189.

[6] (a) J. Va'vra, IEEE Trans. Nucl. Sci., NS-34 (1987) 486; (b) C.L. Woody, IEEE Trans. Nucl. Sci., NS-35 (1988) 493.

[7] R. Openshaw, R. Henderson, W. Faszer, D. Murphy, M. Salomon, and G. Sheffer, IEEE Trans. Nucl. Sci., NS-36 (1989) 567. 


\section{Appendix A}

\section{Heating Effects in Straw Tubes}

\section{A.1 Introduction}

Straw tubes have received attention as candidates for use in detectors at the proposed Superconducting Super Collider (SSC), where they would be exposed to highradiation environments. Before straw-tube wire chambers can be implemented, however, a number of issues need to be addressed, including 1) design and construction of the tubes, 2) aging behavior of the tubes, 3) possible gain fluctuations or nonuniformities due to temperature changes caused by the power dissipated in the gas, 4) signal attenuation in long tubes, and 5) optimal operating gain.

This appendix, which discusses the use of straw tubes equipped with carbon wires to study the thermal effects of avalanches, is excerpted from a broader work [1], which also discusses straw tube construction techniques, the effect of water on straw tube operation, and aging in straw tubes.

\section{A.2 Heating Effects}

Possible limitations to the use of straw tubes in high radiation environments are gas temperature changes and the consequent gain changes. Temperature changes as small as $6^{\circ} \mathrm{C}$, corresponding to $\sim 10 \%$ gain variations, may be unacceptable in some applications. The potential difficulty arises in removal of the power dissipated as heat in the tubes. 
To illustrate the potential difficulty caused by heating effects on gain, we consider the following hypothetical case in which heat removal from the straw tube occurs solely by the gas flow. In this case, the temperature rise is determined by the gas heat capacity, gas flow rate, and power input. For the latter, we will assume $2 \mathrm{~mW}$ of power generated over a $1 \mathrm{~m}$ length of wire $(2000 \mathrm{~V} \times 1 \mu \mathrm{A} / \mathrm{m})$. The heat is deposited mainly by drifting positive ions produced in an avalanche, and not by the electrons, since the former charges traverse a much larger potential difference (nearly the full anode-cathode voltage). However, the heating is concentrated near the anode wire because the potential difference, and hence the power deposited, is logarithmic with the radius. For a $4 \mathrm{~mm}$-diameter tube with a $33 \mu \mathrm{m}$-diameter wire, one-half of the power is produced within a radius of about $260 \mu \mathrm{m}$. Since the gas velocity is relatively small (low Reynolds number), we expect laminar flow, and the power deposited within this radius will heat the gas in a corresponding volume. For a $1 \mathrm{~m}$ long tube, we calculate that the heated volume of $0.053 \mathrm{~cm}^{3}$ contains $2.4 \times 10^{-6}$ moles of gas. At an assumed flow velocity of $1 \mathrm{~mm} / \mathrm{sec}$, there would be a volume change every $1000 \mathrm{sec}$. For the case of $\mathrm{Ar} / \mathrm{C}_{2} \mathrm{H}_{6}(50 / 50)$, which has a heat capacity of about $40 \mathrm{~J} / \mathrm{mol}-\mathrm{K}$, this volume will experience a temperature rise of

$$
\frac{(1 \mathrm{~mW})(1000 \mathrm{sec})}{(40 \mathrm{~J} / \mathrm{mol}-\mathrm{K})\left(2.4 \times 10^{-6} \mathrm{~mol}\right)}=10^{4}{ }^{\circ} \mathrm{K} \text {. }
$$

Various heat transport mechanisms will surely limit the temperature rise to a much smaller anount than this. However, from this analysis we recognize the possibility that unacceptably large increases in temperature may occur.

If the heat is removed entirely by a uniform heating of the gas, the gas flow necessary to maintain an acceptable temperature rise is inconveniently large: average linear gas velocities of several centimeters per second are needed to achieve the assumed $6^{\circ} \mathrm{C}$ maximum allowable temperature rise. Even at these velocities, however, the Reynolds number is on the order of ten, far below the values corresponding to turbulent flow [2], suggesting that uniform heat distribution would not be achieved.

There are, however, other mechanisms by which heat can be removed, namely radiation and conduction. At the small temperature increase allowable for acceptable operation, radiant heat transfer is negligible; this is not the case for conduction. 
The heat, $Q$, transferred by conduction between concentric cylinders is given by

$$
Q=\frac{2 \pi L k \Delta T}{\ln \left(r_{2} / r_{1}\right)},
$$

where $L$ is the length of the cylinders, $k$ is the thermal conductivity of the medium between the cylinders, $\Delta T$ is the temperature difference between the cylinders, and $r_{2}$ and $r_{1}$ are the radii of the outer and inner cylinders (cathode and anode), respectively. For the above-mentioned example of the $4 \mathrm{~mm}$-diameter straw tube with the $33 \mu \mathrm{m}$ diameter wire, a temperature difference of only about $0.1^{\circ} \mathrm{C}$ is needed to conduct all of the heat from the wire to the wall through an $\mathrm{Ar} / \mathrm{C}_{2} \mathrm{H}_{6}(50 / 50)$ gas mixture. A smaller temperature difference is needed to conduct the heat from the wall into a surrounding gas environment.

For the purpose of investigating the heat transfer mechanisms in detail, we used a straw tube [1] with a $33 \mu \mathrm{m}$-diameter carbon anode wire through which current was passed to produce ohmic heating and in this fash; to simulate the heat produced in a tube in a high-radiation environment. We believe this method simulates closely the gas heating near the surface of the wire and the associated heat flow through the tube.

A small dc current supplied by a battery was passed through the carbon wire, and the voltage across the wire and the current through the wire were measured simultaneously. These measurements determined directly both the resistance of the wire and the power dissipated. The resistance determination permitted an estimate of the temperature of the carbon wire, since the resistance of carbon is a function of temperature. To estimate the temperature, we used the coefficient for carbon resistivity as a function of temperature, measured by us using a temperature-controlled oven (Varian model 3400 gas chromatograph) to be $-2.0 \times 10^{-4} /{ }^{\circ} \mathrm{C}$ [3]. Fig. A.1 shows the estimate of the anode wire temperature as a function of voltage across the wire. A similar method was previously used to estimate the surface temperature of $7-\mu \mathrm{m}$-diameter carbon wires [4].

A second method of estimating the temperature near the wire surface was measurement of the gain increase observed in the pulse height spectrum of ${ }^{55} \mathrm{Fe}$ when the wire was heated. The dependence of gain on temperature has been well established from ambient pressure and temperature changes during many wire aging tests 


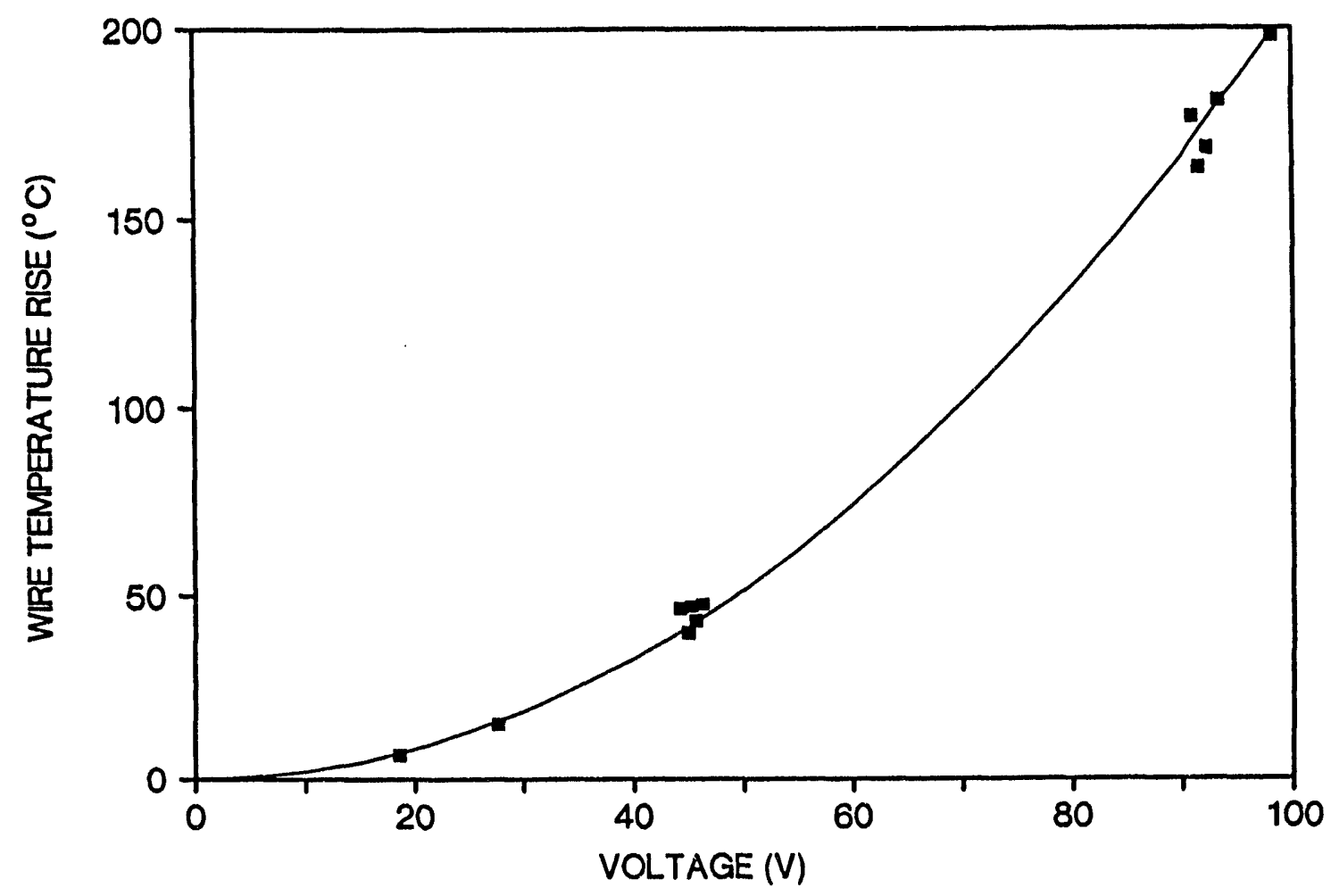

Figure A.1: Estimate of the carbon-wire anode temperature as a function of the applied voltage. The curve is based on a quadratic fit of resistance vs. voltage. The temperature dependence of carbon resistivity was measured to be $-2.0 \times 10^{-4} /{ }^{\circ} \mathrm{C}$ [3]. The resistance of the wire was $9.22 \mathrm{k} \Omega$ at $21^{\circ} \mathrm{C}$. The wire fails near $800^{\circ} \mathrm{C}$ in air. 
performed with this system.

A third method of determining the wire temperature follows from a heat transfer analysis. Estimates show that all except one of the potential channels for heat flow are small enough to be neglected: conduction through the gas along the radial direction between the anode and the cathode dominates the heat flow. With this simplification, an estimate of the temperature change is obtained directly from the conduction equation (eqn. A.1), using the known heat input to the wire.

Measurements of the temperature were made using all three methods, by varying the battery voltage up to about $100 \mathrm{~V}$. Two specific cases, $9 \mathrm{~V}$ and $46 \mathrm{~V}$, are summarized in Table A.1. The agreement between the three methods is good. Estimates of uncertainties in the temperature rise in Table A.1 include those involved in the determination of the resistivity coefficient of the carbon filament and of the temperature dependence of gain. Not included is a potential correction arising from the difference in the geometric relationship of the wire to its surroundings in the feedthrough region compared to the remaining (active) region of the wire (see Fig. A.2). The temperature rise in the feedthrough region could be somewhat less than in the remainder of the wire, leading to an underestimate of the temperature rise. This effect is expected to be small, since the principal heat sinks are at the wedge pins, where the wire is secured, but a gross upper limit of a factor of 1.9 on the temperature increase can be obtained from the ratio of the total and active wire lengths.

The level of agreement between these two cases gives some confidence that this procedure can be extrapolated to the still lower power levels appropriate to an SSC experiment. Although the power corresponding to the $9 \mathrm{~V}$ case is $\sim 60 \mathrm{~mW} / \mathrm{m}$, perhaps 100 times the maximum expected in normal SSC operation, the temperature rise is nevertheless sufficiently small to be acceptable. Since the temperature rise is expected to scale linearly with power, the anticipated temperature rise in an SSC experiment would be very small indeed for an isolated tube.

As an additional verification of the conductive model of heat transfer, the gas flow rate was varied from 1.5 to $150 \mathrm{~cm}^{3} / \mathrm{min}$ while monitoring the gain. No change of gain was observed for flow rates of $1.5-120 \mathrm{~cm}^{3} / \mathrm{min}$, indicating that the gas temperature in the avalanche region is largely unaffected by the gas flow rate, as expected if 
Table A.1: Measurements of heating effects in straw tube with $33 \mu \mathrm{m}$ diameter carbon filament anode: $9 \mathrm{~V}$ and $46 \mathrm{~V}$ cases. Temperature dependence of carbon resistivity: $\left(1 / R_{0}\right) d R / d T=-2.0 \times 10^{-4} /{ }^{\circ} \mathrm{C}$. The resistance of the filament was $9.22 \mathrm{k} \Omega$ at $21^{\circ} \mathrm{C}$. The electrical length of the wire was $22.9 \mathrm{~cm}$; the active length was $12.2 \mathrm{sm}$.

\begin{tabular}{|l|c|c|}
\hline & $9 \mathrm{~V}$ & $46 \mathrm{~V}$ \\
\hline Voltage across filament $(\mathrm{V})$ & 9.0 & 45.8 \\
Current through filament $(\mathrm{mA})$ & 0.98 & 5.0 \\
Resistance of filament $(\mathrm{k} \Omega)$ & 9.22 & 9.13 \\
Power input $(\mathrm{mW})$ & 8.8 & 230 \\
Power input to active region $(\mathrm{mW})$ & 4.7 & 123 \\
& & \\
Gas flow (cm $\left.{ }^{3} / \mathrm{min}\right)$ & 20 & 18 \\
& & \\
${ }^{55}$ Fe: Pulse height of principal peak, pedestal subtracted (channel) & & \\
$\quad$ Base case* $(0 \mathrm{~V})$ & 400 & 376 \\
$\quad$ With voltage applied & 423 & 769 \\
Gain ratio [ $G(\mathrm{~V}) / G(0)$ ] & 1.06 & 2.04 \\
& & \\
Computation of temperature rise $\left({ }^{\circ} \mathrm{C}\right)$ (estimated error) & & \\
$\quad$ From filament resistance $( \pm 20 \%)$ & 1.6 & 43 \\
$\quad$ From fractional gain change $( \pm 10 \%)$ & 2.4 & 45 \\
$\quad$ From power and radial conduction (eqn. A.1)( $\pm 5 \%)$ & 1.6 & 41 \\
\hline
\end{tabular}

*The tests were made on different days, and the differences in the pulse heights of the base cases are due to barometric pressure changes. 


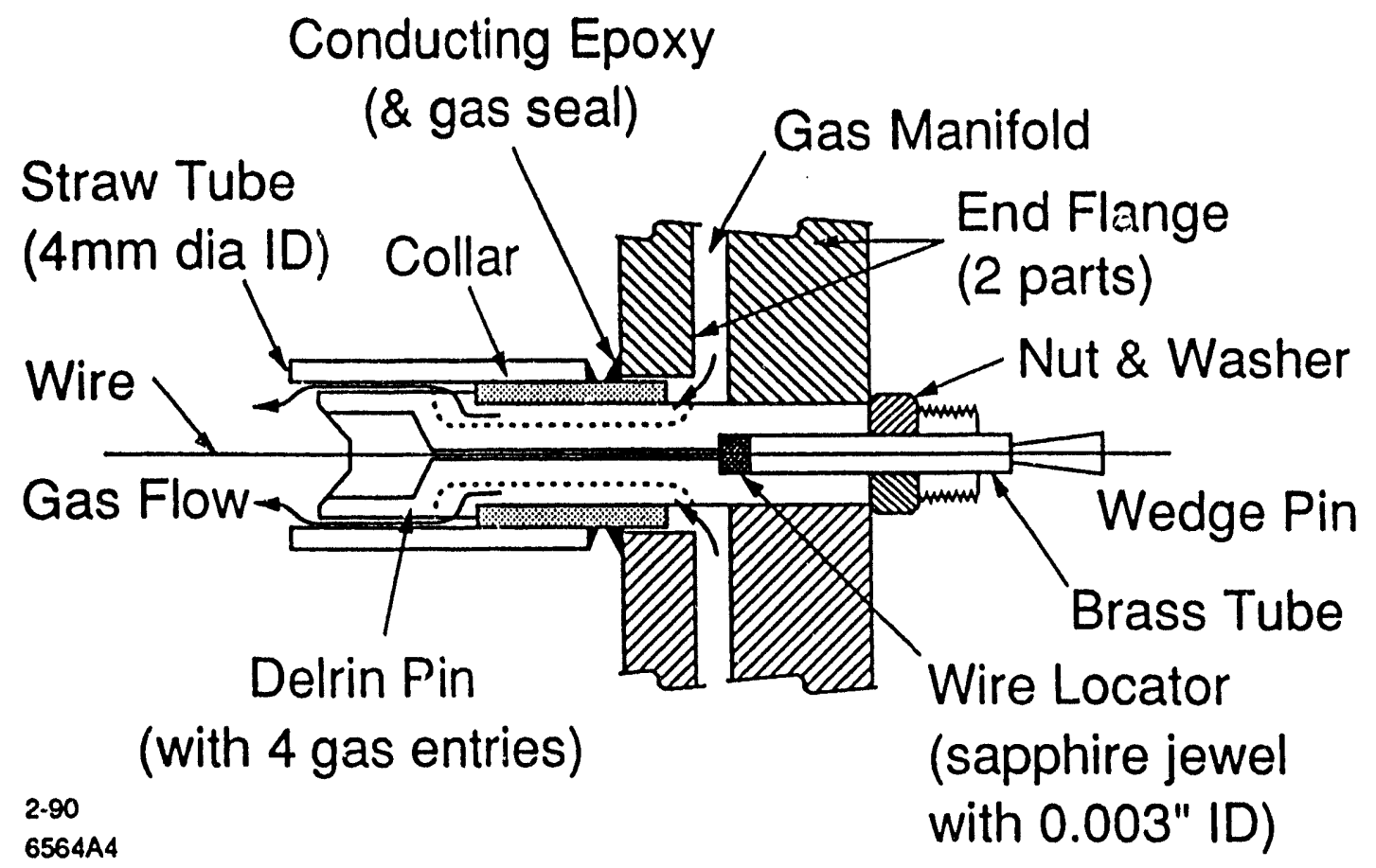

Figure A.2: Cross-sectional view of the feedthrough pin.

radial conduction is the dominant heat transier mechanism. Some change in gain was observed for flow rates in the $120-150 \mathrm{~cm}^{3} / \mathrm{min}$ range, however (Fig. A.3). We believe that this was where the transport of heat by gas flow through the tube at higher flow rates began to compete with removal of heat by conduction radially.

Since conduction is the dominant heat transport mechanism, the gas flow rate is not dictated by heat removal, and can be as low as consistent with acceptable aging. We obtained good aging results with gas flows as low as $\sim 1.0 \mathrm{~cm}^{3} / \mathrm{min}$, corresponding to an average linear gas velocity of only $1.3 \mathrm{~mm} / \mathrm{sec}$ (Table A.2).

For isolated straw tubes, conduction alone is sufficient to remove the heat from the tube wall; some convection is expected to be necessary to remove heat from an array of tubes such as in a full-scale detector. If tubes are arranged in layers with a small number of tubes per layer, as in some current designs [5], there will still be only negligibly small temperature rises within each layer according to our estimate, with the heat being carried away efficiently by the gas between layers. 


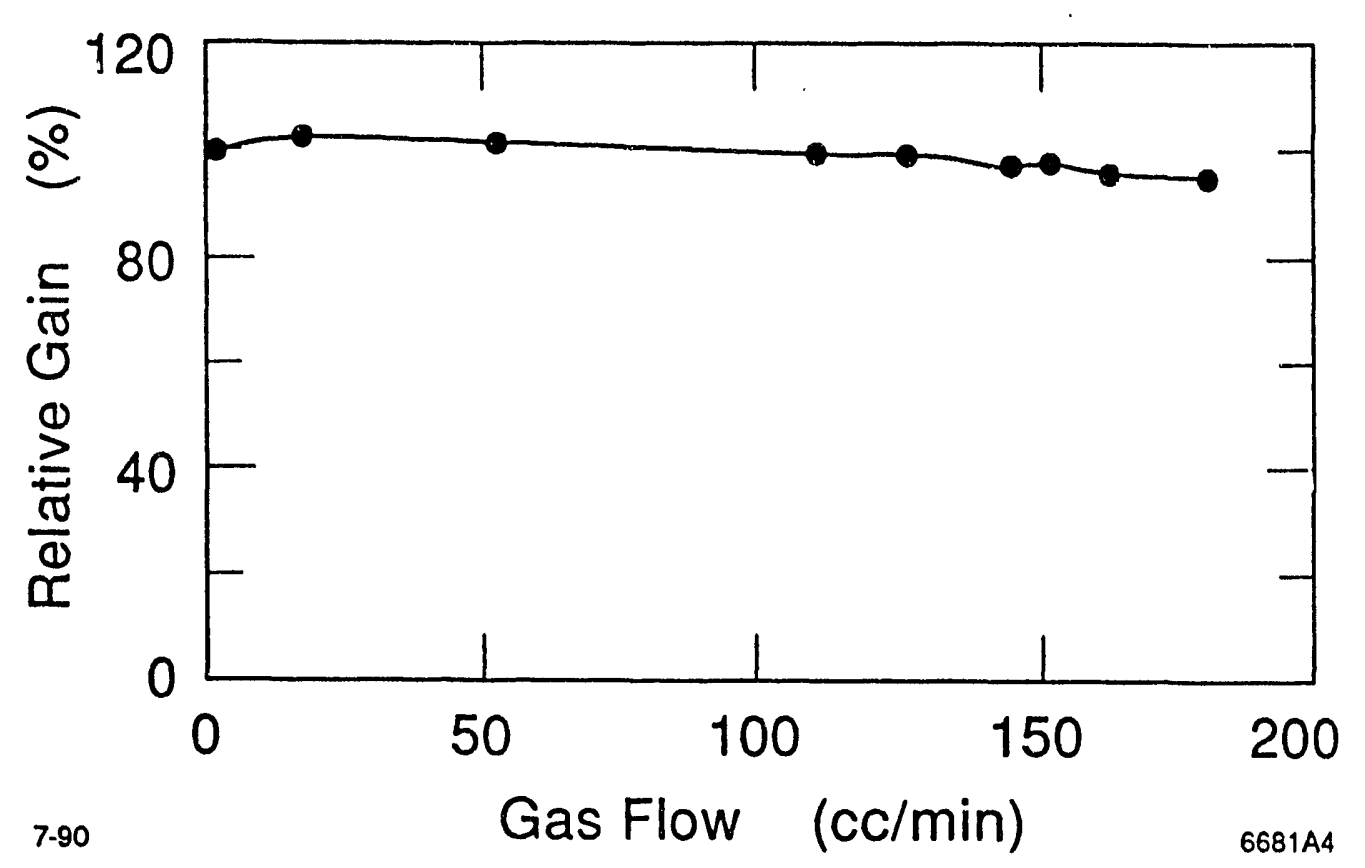

Figure A.3: Observed gain in a straw tube as a function of gas flow rate through the tube.

Table A.2: Summary of aging results in straw tube with a $33 \mu \mathrm{m}$ diameter carbon wire as a function of the gas flow rate. $\mathrm{Ar} / \mathrm{C}_{2} \mathrm{H}_{6}(50 / 50)$ was used for all tests. The anode voltage was $1590 \mathrm{~V}$. All measured values of $R$ are consistent with zero within our estimated systematic uncertainties.

\begin{tabular}{|c|c|c|c|}
\hline $\begin{array}{c}\text { Gas } \\
\text { flow rate } \\
{\left[\mathrm{cm}^{3} / \mathrm{min}\right]}\end{array}$ & $\begin{array}{c}\text { Average gas } \\
\text { velocity } \\
{[\mathrm{mm} / \mathrm{sec}]}\end{array}$ & $\begin{array}{c}R \\
{[\% / \mathrm{C} / \mathrm{cm}]}\end{array}$ & $\begin{array}{c}\text { Collected } \\
\text { charge } \\
{[\mathrm{C} / \mathrm{cm}]}\end{array}$ \\
\hline 20 & 26.5 & -2 & 1.0 \\
2.7 & 3.6 & $\sim 0$ & 0.4 \\
1.0 & 1.3 & -3 & 0.3 \\
1.0 & 1.3 & $\sim 0$ & 0.2 \\
\hline
\end{tabular}




\section{A.3 Conclusions}

A simple prototype straw tube proportional counter was used for studies of proportional gain fluctuations due to avalanche heating under conditions that are expected to be encountered at SSC experiments.

The investigation of heating effects used a $33 \mu \mathrm{m}$-diameter carbon anode wire to model the avalanche gas heating by ohmic heating from small electric currents. Results indicate that heat transfer from the wire is almost completely controlled by conduction through the gas along the radial direction. The recognition that gas flow rate is not dictated by heat removal may simplify considerably the design of large straw-tube detectors.

\section{References}

[1] J.A. Kadyk, J. Va'vra, and J. Wise, Nucl. Instr, and Meth., A300 (1991) 511.

[2] R.B. Bird, W.E. Stewart, and E.N. Lightfoot, Transport Phenomena (Wiley, New York, 1960), p. 54.

[3] This measured value is lower than some tabulated values. See, for example: R.I. Sarbacher, Encyclopedic Dictionary of Electronics \& Nuclear Engineering (Prentice-Hall, Englewood Cliffs, NJ, 1959), p. 1121.

[4] J. Va'vra, SLAC-PUB-4432 (1987), and IEEE Trans. Nucl. Sci., NS-34 (1987) 486.

[5] H. Ogren, Tracking Review for the SDC Collaboration, DPF Meeting, Snowmass, CO (1990). 


\section{Appendix B}

\section{Appearance of the Plasma in}

\section{Aging Tests}

To view the plasma, a proportional counter was equipped with a side port with a $2.5 \mathrm{~cm}$-diameter $\times 6 \mathrm{~mm}$-thick quartz window. Two gas plasmas were viewed in this tube: $\mathrm{CF}_{4} /$ dimethyl ether (DME) $(90 / 10)$ and $\mathrm{Ar} / \mathrm{C}_{2} \mathrm{H}_{6}(50 / 50)$.

In the case of the $\mathrm{CF}_{4} / \mathrm{DME}$, a whitish/blue glow could be seen extending to a radius of $\sim 0.5 \mathrm{~mm}$ around the wire when the counter was drawing $400 \mathrm{nA}$; the current was not varied to determine its effect on the intensity of the glow. In the case of the $\mathrm{Ar} / \mathrm{C}_{2} \mathrm{H}_{6}$, the glow was more greenish, and a higher current ( $\left.700 \mathrm{nA}\right)$ was needed before the glow could be discerned. For both gases, although a point source $(1 \mathrm{mCi}$ ${ }^{55} \mathrm{Fe}, 3 \mathrm{~mm}$ diameter) was used to irradiate the wire, the glow extended along the wire beyond the full viewing region permitted by the window $(\sim 1 \mathrm{~cm}$ along the wire).

Self-sustained (Malter) breakdowns were also observed in the $\mathrm{Ar} / \mathrm{C}_{2} \mathrm{H}_{6}$. In this case, with the ${ }^{55} \mathrm{Fe}$ source removed, the glow did not extend beyond the window region; separate, distinct bright spots, which looked like stars sitting in the wire, were seen instead. There was also a crackling noise, which could be heard when the $\mathrm{Ar} / \mathrm{C}_{2} \mathrm{H}_{6}$ glow was drawing at least $750 \mathrm{nA}$. Repeated tests in which the voltage and/or the source were removed confirmed that the crackling was associated with the Malter breakdown. It is possible that the bright spots were areas of recurrent sparking and that the crackling noise resulted from this sparking.

The intensity of the glows was sufficiently low that it was necessary to completely 
darken the room to see them. This involved darkening all pilot lights, either by turning off the equipment or by taping over the lights, taping over spaces between the door and its frame, etc. The difficulty in doing this, the time required for an observer's eyes to adjust to the darkness, the difficulty in focusing clearly on the glow, and the lack of distinguishing characteristics of the glow visible to the naked eye rendered these observations of little immediately obvious diagnostic utility, and they were not pursued. 


\section{Appendix C}

\section{Wire Pretreatment Processes}

\section{C.1 Introduction}

As an approach towards altering wire surfaces before using them in test proportional counters, some wires were treated by plasma processing in a barrel plasma reactor $[1]^{*}$. Two plasma processes were used. The first, a deposition process, used a $\mathrm{CHF}_{3}$ plasma to deposit a fluorocarbon film. The second, normally used as an etching process, used an $\mathrm{SF}_{6} / \mathrm{O}_{2}(96 / 4)$ plasma to generate fluorine radicals and thus fluorinate wire surfaces. Details of these processes are given below.

\section{C.2 Operational Procedure}

A support device consisting of four Teflon rods (Fig. C.1) was placed in the barrel reactor. The device could hold up to four wires for simultaneous treatment. In all cases, the reactor, with the Teflon supporting device in position, was subjected to a conditioning run $(60 \mathrm{sec})$ before wires were treated.

"The barrel reactor used for this work is located in the Microfabrication laboratory in Cory Hall at the University of California at Berkeley, and is named breact. 

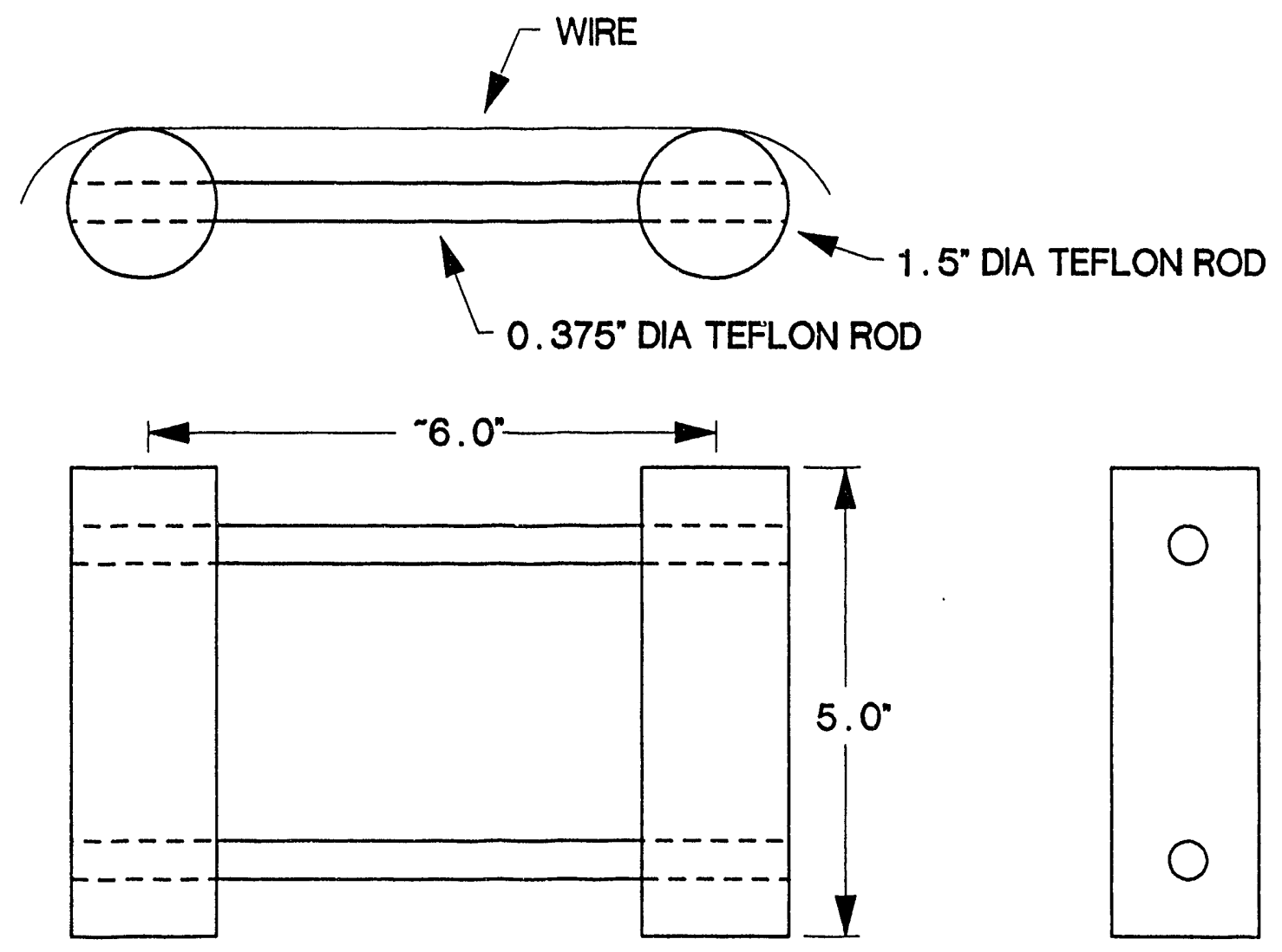

Figure C.1: Three-view drawing of the wire support device. 


\section{C.3 Fluorocarbon Deposition by $\mathrm{CHF}_{3}$}

$\mathrm{A} \mathrm{CHF}_{3}$ (Matheson Gas Co., Newark, CA) plasma was used to deposit a fluorocarbon film. Deposition conditions were $350 \mathrm{mTorr}$ and $200 \mathrm{~W}$, with exposure times of $30 \mathrm{sec}, 60 \mathrm{sec}$, or $120 \mathrm{sec}$, or $700 \mathrm{mTorr}$ and $200 \mathrm{~W}$ with exposure times of $30 \mathrm{sec}$ or $60 \mathrm{sec}$. Pieces of silicon wafers were used as controls; ellipsometry (model L116A, He-Ne $632.8 \mathrm{~nm}$ laser, Gaertner Scientific, Chicago, IL) was used to measure the deposited film thickness on the wafers and it was assumed that because the wires and the wafers were in close proximity to each other that the film thickness on the wire would be similar to that on the wafer. Fig. C.2 shows film thicknesses for the various deposition conditions as a function of position in the reactor. In all cases, the front-to-rear distance is $\sim 10 \mathrm{~cm}$. As expected, deposition rates are generally higher at the center of the reactor, where the plasma is denser, and film thicknesses increase with deposition time.

The composition of the films was investigated by analyzing a treated wire by AES, and was found to be uniform with respect to both position on the wire and depth within the film. The raw data indicate a film composition of approximately $\mathrm{C}_{4} \mathrm{~F}$.

\section{C.4 Fluorination by $\mathrm{SF}_{6} / \mathrm{O}_{2}$}

An $\mathrm{SF}_{6} / \mathrm{O}_{2}(96 / 4)$ (Matheson Gas Co., Newark, $\mathrm{CA}$ ) plasma was used to fluorinate wire surfaces. Processing conditions were $200 \mathrm{mTorr}$ and $30 \mathrm{~W}$, with exposure times of $60 \mathrm{sec}$ or $180 \mathrm{sec}$. Because this plasma stmosphere is utilized for etching purposes, it was expected that the wafer surface would be roughened sufficiently thai ellipsometry would not give a reliable measurement of the deposit thickness. Indeed, when ellipsometry was attempted, the laser spot and its associated scattered light were visible, indicating a rough surface. Although ellipsometric measurements were taken, they were believed to have little significance due to the surface roughness.

Two other methods were used to investigate the condition of the wafer surface. First, optical microscopy $(500 \mathrm{x})$ of silicon wafers treated in the $\mathrm{SF}_{6} / \mathrm{O}_{2}$ plasma revealed that the surface was frosted or spotty. (This was a rather subjective distinction.) Second, the surface roughness of the treated wafers was estimated using stylus 

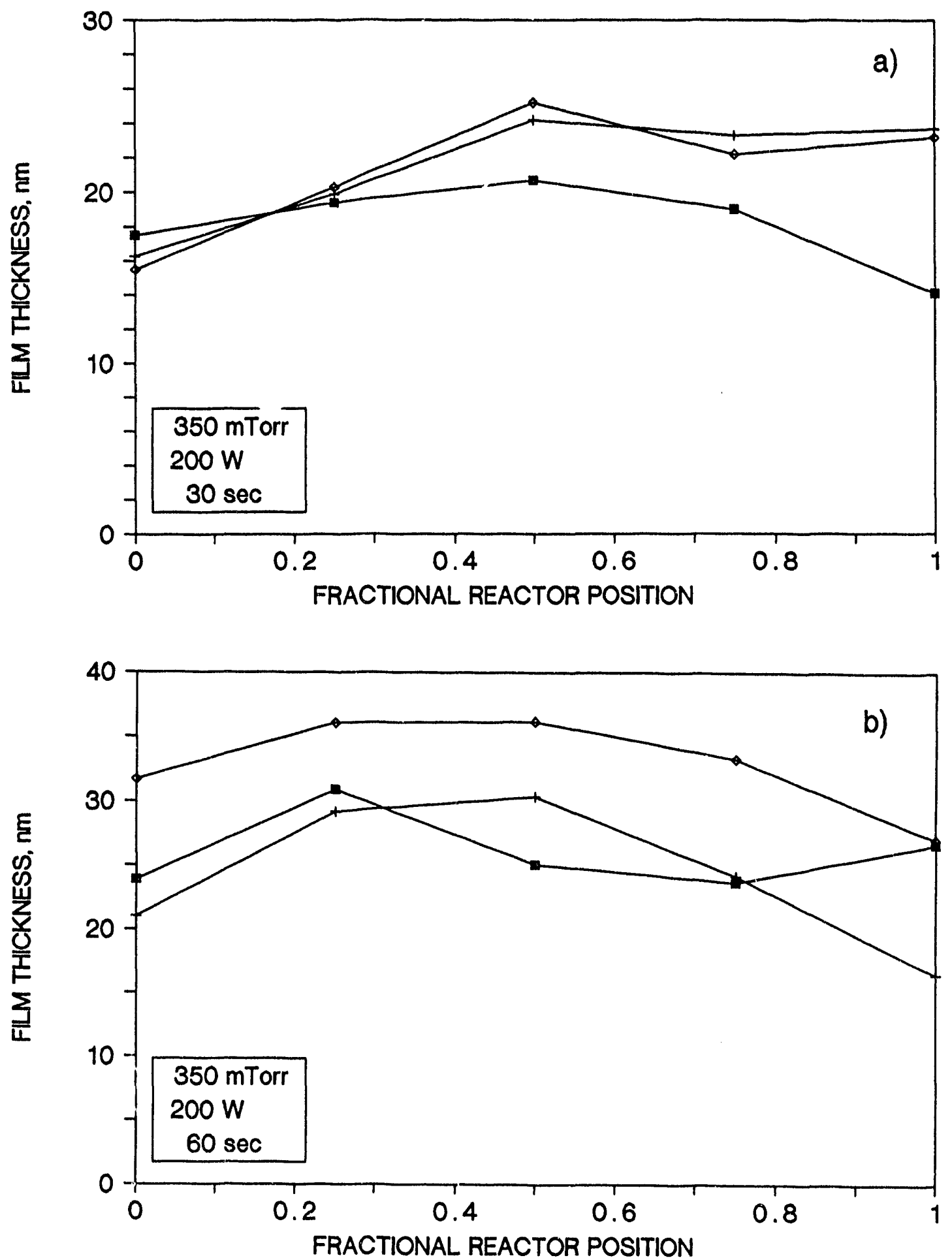

Figure C.2: Film thicknesses deposited from $\mathrm{CHF}_{3}$ as a function of position in the reactor. Reaction conditions were (a) $350 \mathrm{mTorr}, 200 \mathrm{~W}, 30 \mathrm{sec}$; (b) $350 \mathrm{mTorr}$, $200 \mathrm{~W}, 60 \mathrm{sec}$. 

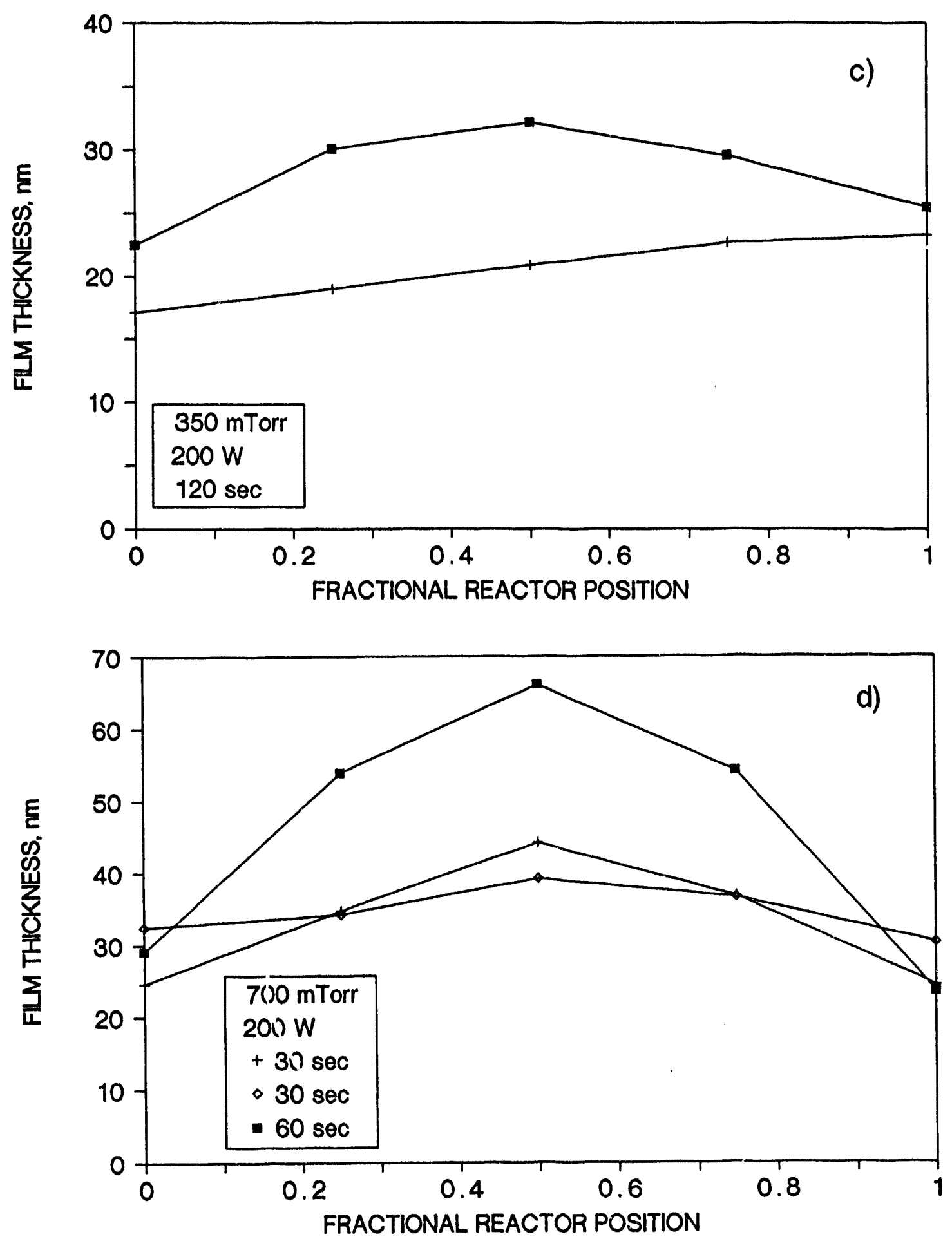

Figure C.2: Film thicknesses deposited from $\mathrm{CHF}_{3}$. Reaction conditions were (c) 350 mTorr, $200 \mathrm{~W}, 120 \mathrm{sec}$; (d) $700 \mathrm{mTorr}, 200 \mathrm{~W}, 30 \mathrm{sec}$ and $60 \mathrm{sec}$. 
profilometry (model AS200, Tencor Instruments, Mountain View, CA). Profiles from this technique are shown in Fig. C.3. Ellipsometric and profilometric measurements of the surface roughness are summarized in Table C.1.

Table C.1: Summary of thickness measurements on silicon wafers treated in $\mathrm{SF}_{6} / \mathrm{O}_{2}$ (96/4). Treatment conditions: $200 \mathrm{mTorr}, 30 \mathrm{~W}$.

\begin{tabular}{|c|c|c|}
\hline $\begin{array}{c}\text { Treatment } \\
\text { time [sec] }\end{array}$ & $\begin{array}{c}\text { Ellipsometry } \\
\text { thickness [nm] }\end{array}$ & $\begin{array}{c}\text { Profilometry } \\
\text { peak-to-peak [nm] }\end{array}$ \\
\hline 0 & 1 & 4 \\
60 & 12 & 15 \\
180 & 20 & 20 \\
\hline
\end{tabular}

AES depth profiling was used to analyze wires treated in the $\mathrm{SF}_{6} / \mathrm{O}_{2}(96 / 4)$ plasma (180 sec exposure). The analyzed wire samples were taken from regions of the wire that had been in the center of the reactor, in the dense region of the plasma. Analysis revealed that the treatment had fluorinated the surface of a $\mathrm{Ni}$ wire such that it resembled a wire aged in $\mathrm{CF}_{4}$ to $\sim 100 \mathrm{mC} / \mathrm{cm}$ collected charge (RUN389) (Fig. C.4). The $\mathrm{Cu}$ wire was oxidized (Fig. C.5), while the $\mathrm{Au} / \mathrm{W}$ wire was unaffected by this treatment.

Note that the fluoride thickness on the $\mathrm{Ni}$ wire after $\sim 100 \mathrm{mC} / \mathrm{cm}$ of collected charge is significantly less than that observed on $\mathrm{Cu}$ wires after comparable charge exposures (see section 2.6).

Samples from the ends of treated wires were also analyzed. Because the ends of the wires had been near the reactor walls during treatment, they had not been exposed to the dense region of the plasma. No fluorination was observed on these samples, confirming that the fluorination depth is a function of reactor position, a situation analogous to that observed for depos it thickness in the $\mathrm{CHF}_{3}$ plasma.

\section{Acknowledgement}

It is a pleasure to thank Bill Flounders for his cheerful assistance in the Microlab. 

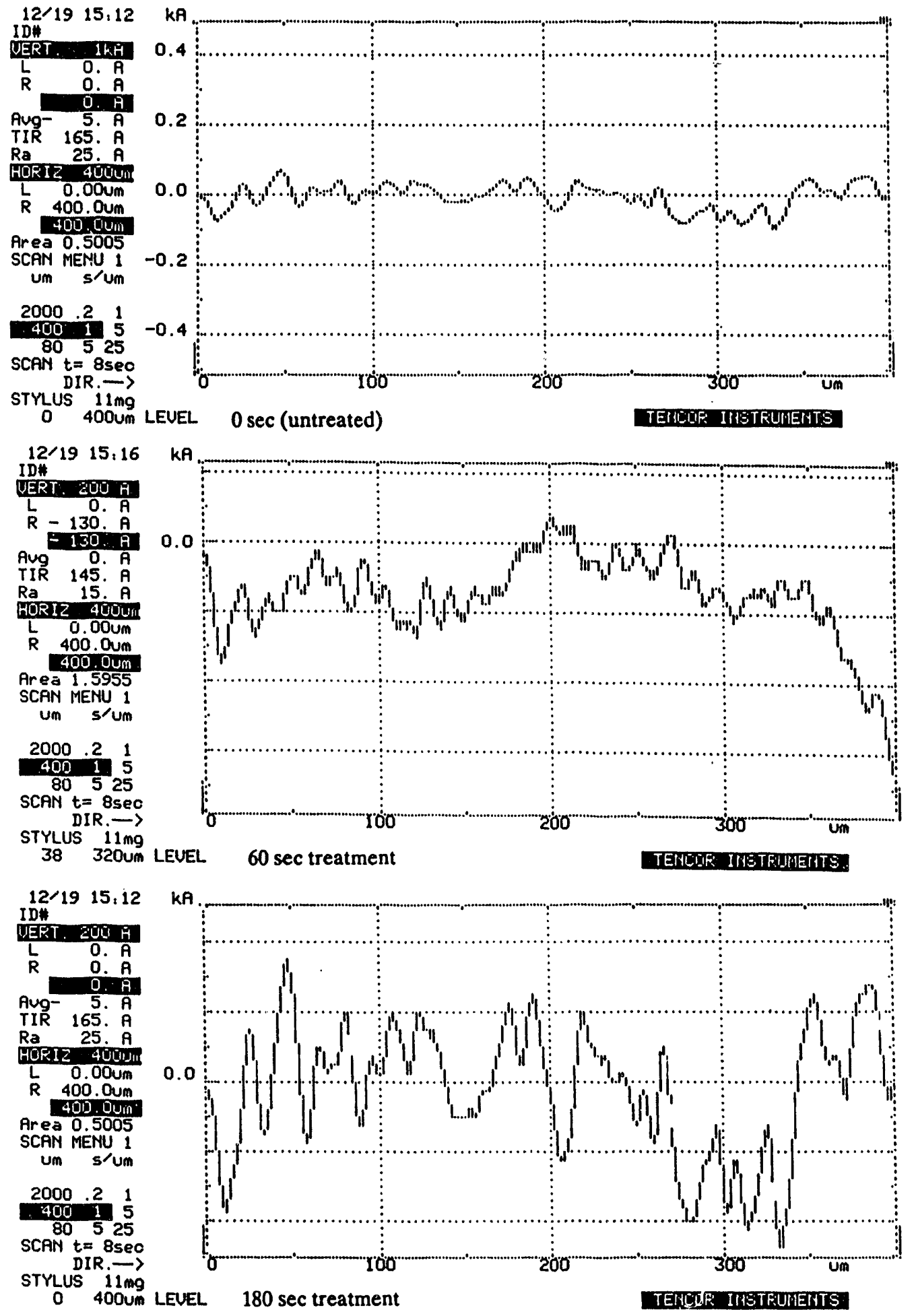

Figure C.3: Surface roughness profiles of silicon wafers treated in $\mathrm{SF}_{6} / \mathrm{O}_{2}(96 / 4)$ at $200 \mathrm{mTorr}$ and $30 \mathrm{~W}$. Treatment times were (top) $0 \mathrm{sec}$ (untreated); (middle) $60 \mathrm{sec}$; (bottom) 180 sec. 

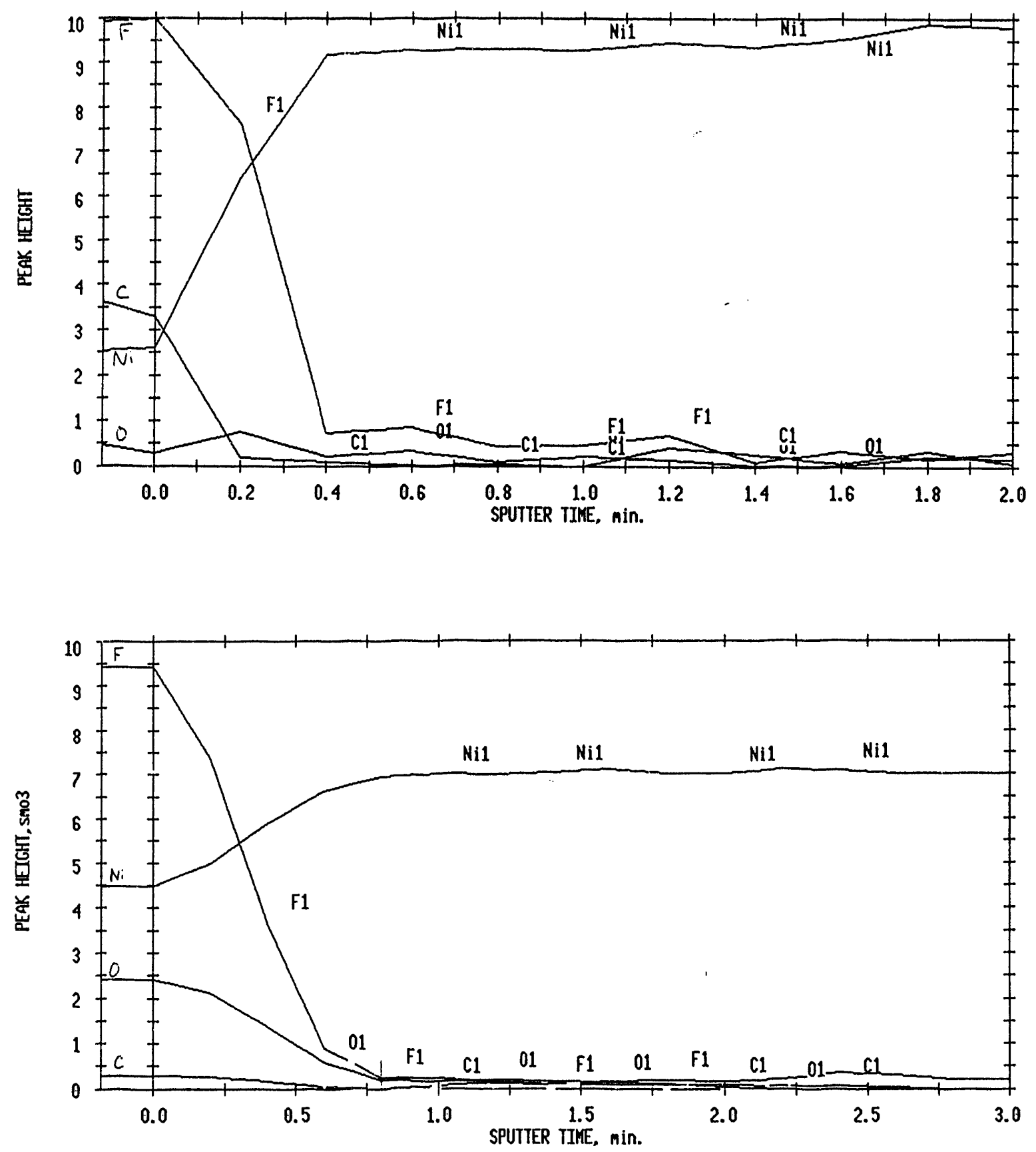

Figure C.4: AES depth profiles of (top) Ni wire treated in $\mathrm{SF}_{6} / \mathrm{O}_{2}$ (180 sec exposure), (bottom) $\mathrm{Ni}$ wire aged in $\mathrm{CF}_{4}(\sim 100 \mathrm{mC} / \mathrm{cm})$. Note the difference in the horizontal scale of the two plots. 

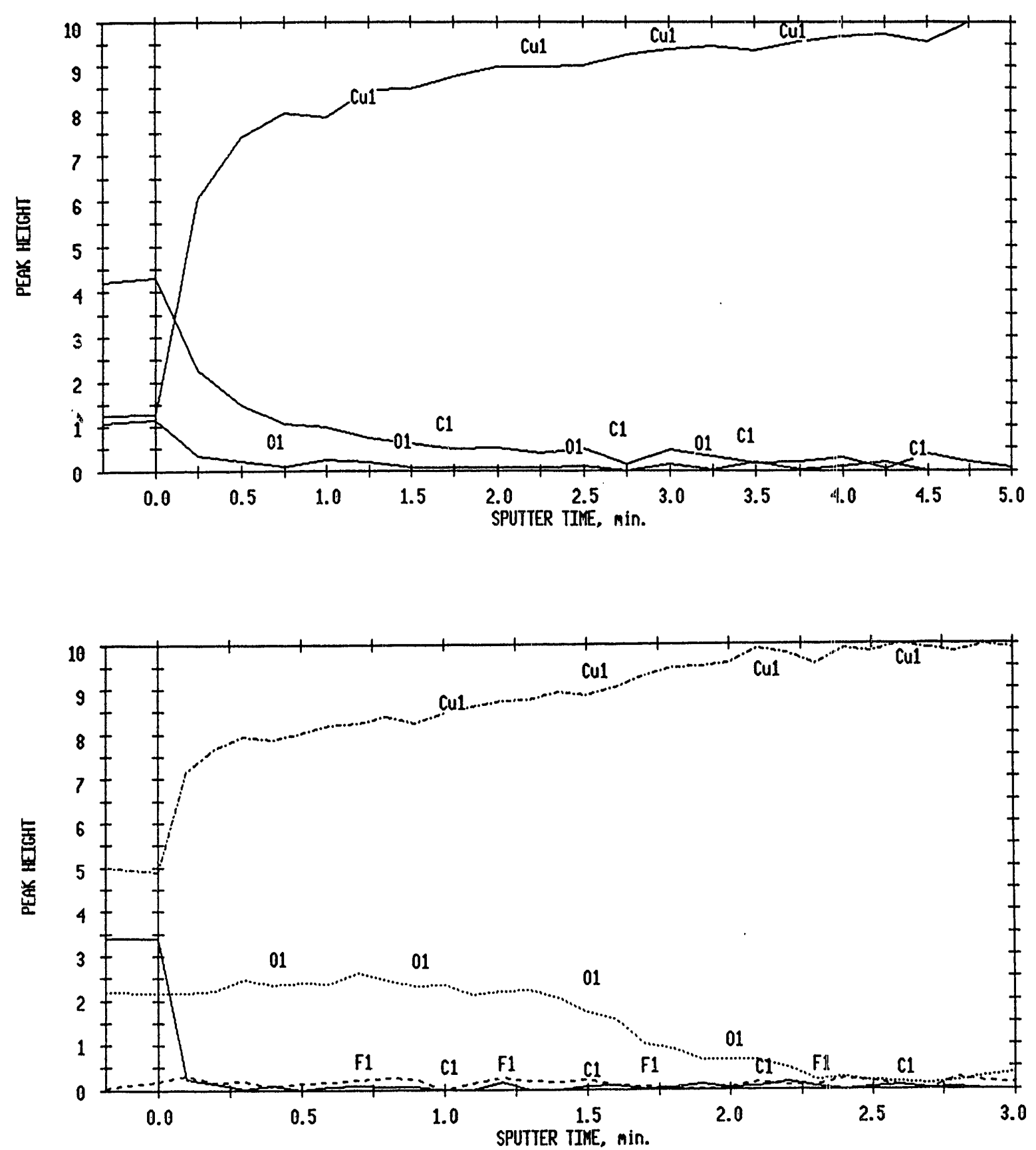

Figure C.5: AES depth profiles of Cu wires: (a) untreated, (b) treated in $\mathrm{SF}_{6} / \mathrm{O}_{2}$ (180 sec exposure). The presence of a copper oxide on the treated wire is evident. 


\section{References}

1. D.W. Hess and D.B. Graves. In Microelectronics Processing, D.W. Hess and K.F. Jensen, eds., Adv. Chem. Series 221 (American Chemical Society, Washington, DC, 1989), p. 392. 


\section{Appendix D}

\section{Procedures for Aging Tests}

\section{D.1 Introduction}

Following is a description of the instrumentation and procedures used in preparation, startup, data collection, and termination of wire aging tests. The instrumentation has been described elsewhere [1].

\section{D.2 Apparatus}

A schematic drawing indicating electrical connections to and gas flow through the apparatus used for wire aging tests is shown in Fig. D.1. Four identical test channels are available, although only two channels are shown in the figure. The functional devices are:

\section{A. Test Wire Chamber (Proportional Counter)}

Two types of proportional counters are available for use in these tests. The first (Fig. D.2a), used infrequently, is made from rectangular aluminum tubing with cross section $9 \times 15 \mathrm{~mm}$. The second (Fig. D.2b), used almost exclusively, is made from copper tubing 0.5 inch OD $\times 0.375$ inch ID. The length of both types of counters is $\sim 20 \mathrm{~cm}$. At the ends of the counters are small rectangular feedthrough insulators sealed into endpieces as shown in Fig. D.2. A small hole is cut into the tubing wall 
(gldפ) Sกg 88t $\exists \exists \exists I$

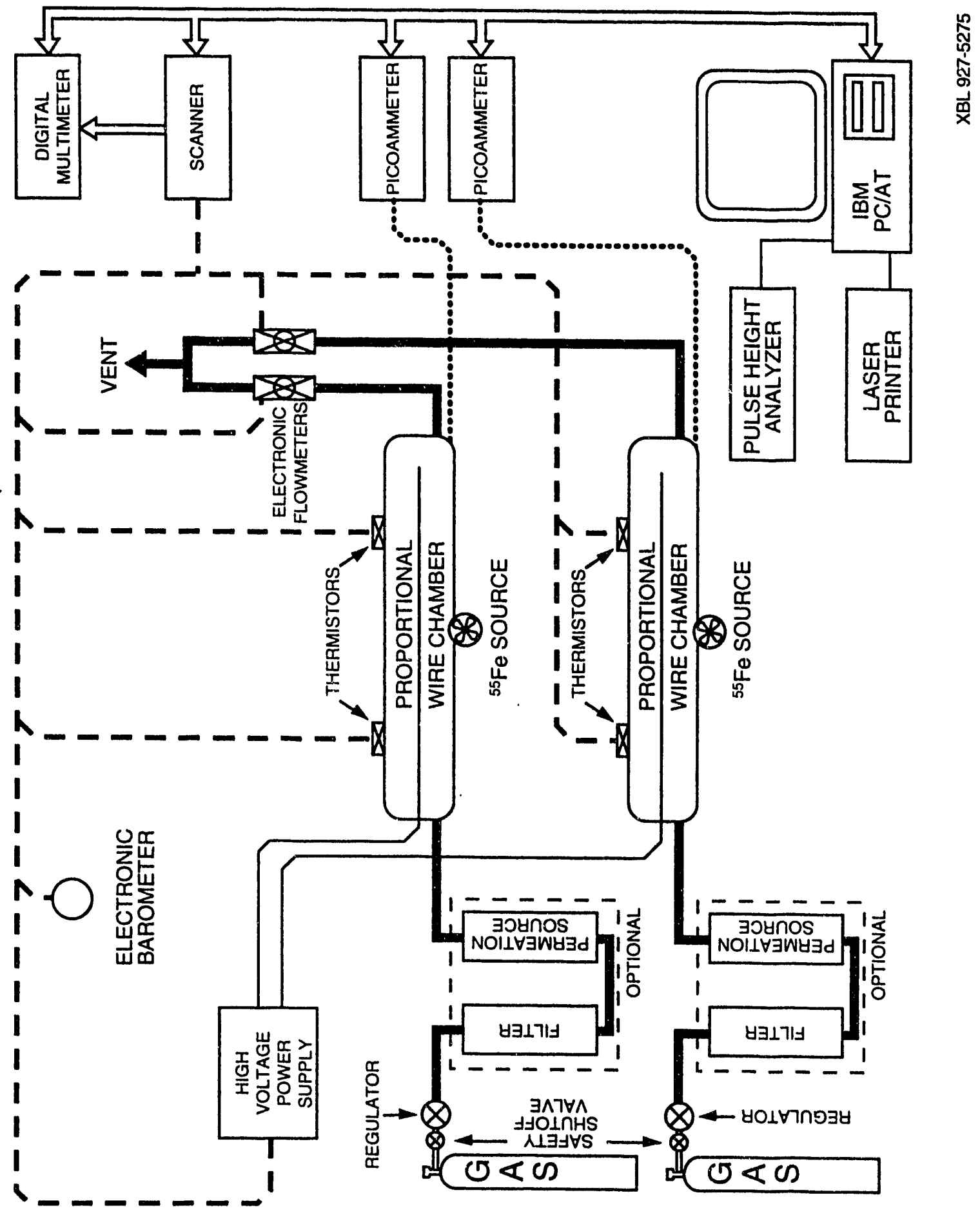

Figure D.1: Schematic of the wire aging test system. Only two of the four independent channels are shown. 


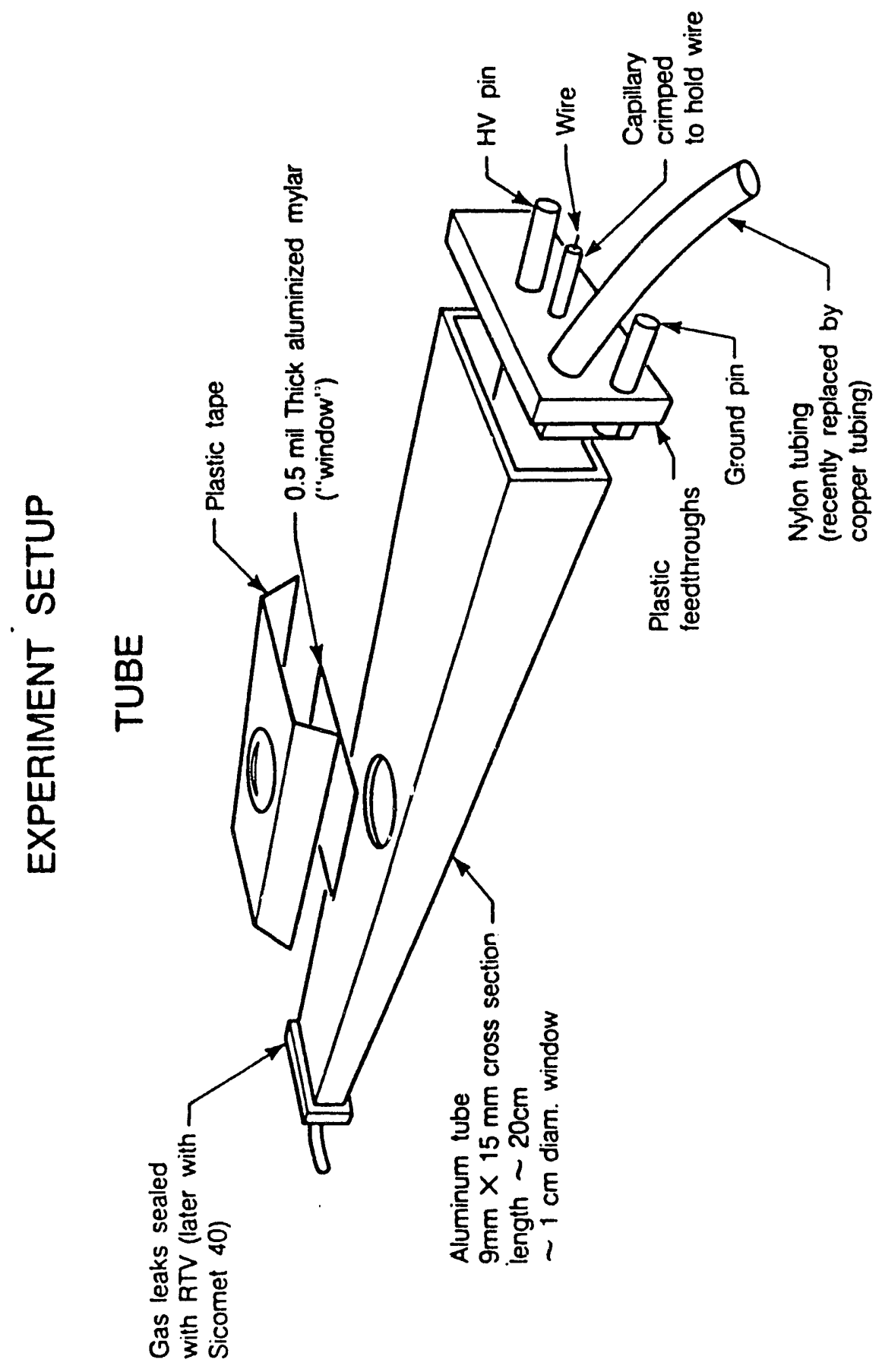

Figure D.2: Proportional counters used for wire aging tests. (a) aluminum counter tube. 


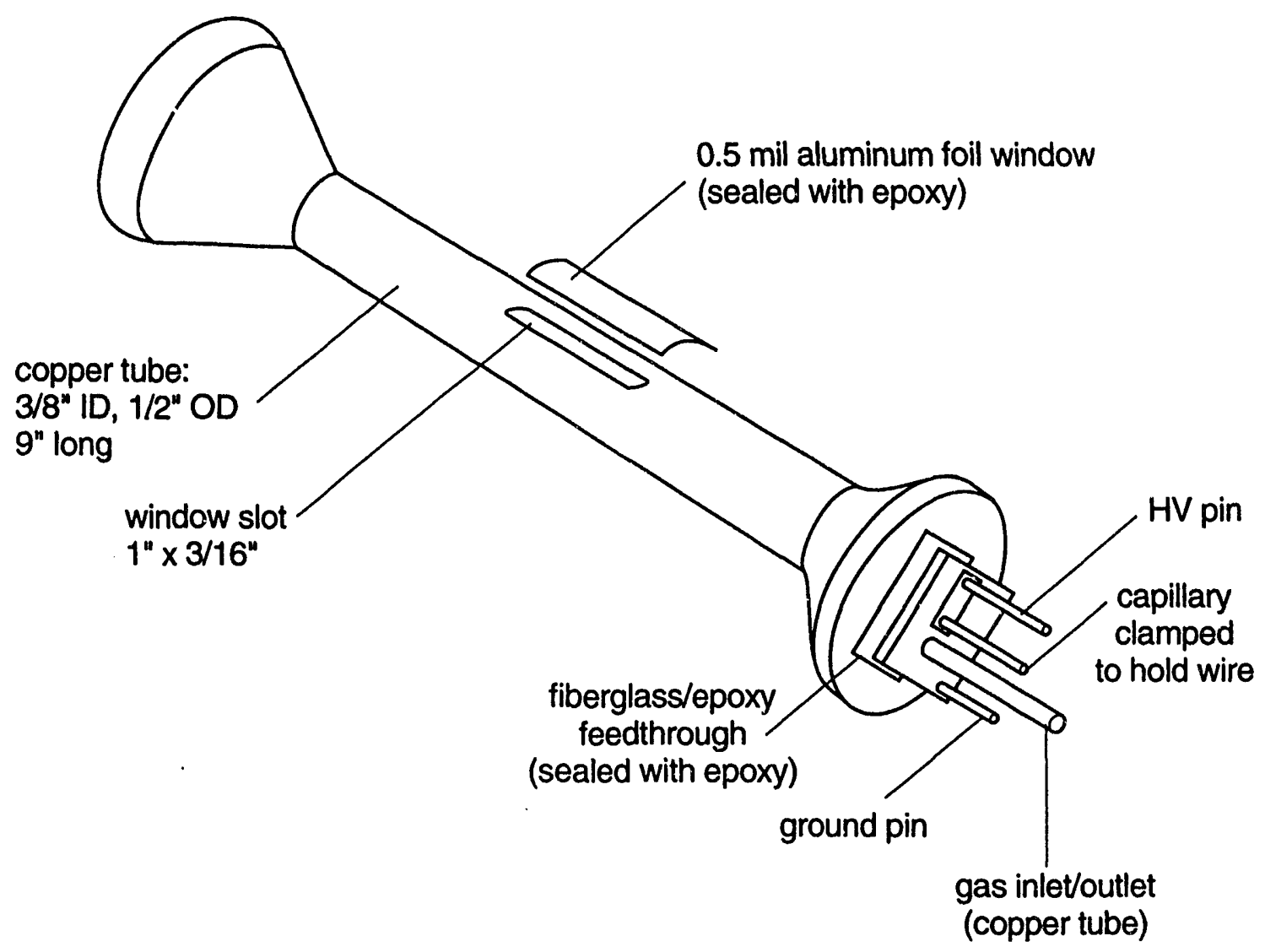

XBL 927-5285

Figure D.2: Proportional counters used for wire aging tests. (b) copper counter tube. 
and covered with 0.0005 inch aluminum foil to serve as a window for radiation, usually that from a ${ }^{55} \mathrm{Fe}$ source. Further details of the construction of the copper counter tubes are given in section D.3.A.

\section{B. Digital Multimeter (Keithley 196)}

Analog signals (the outputs of the electronic gas flowmeters, the thermistors, the barometer, and the high voltage power supplies) are digitized by the digital multimeter (DMM) so that they can be read by the computer. The 6-1/2 digit precision of this meter is more than adequate to read out any device used in the system.

\section{Gas Flow Meters (Matheson 601, Omega FMA-213)}

There is a rotameter flow gauge (Matheson 601, mounted in a Matheson 7441 Tube Cube) and an electronic flowmeter (Omega FMA-213) on the exhaust side of the wire chamber. The flow measurement devices are located downstream of the chamber to minimize contamination due to possible outgassing. A needle valve is an integral part of the rotameter; to minimize the pressure drop, the valve is completely opened. A bubble flow meter is used to calibrate the flow measurement devices to an accuracy of about $\pm 10 \%$. Calibration graphs for the various gases used are in the back of the $\log$ books.

\section{Thermistors (Yellow Springs Instruments YSI-44201)}

The temperature of the proportional counter is measured with two thermistors, one located near the inlet and another located near the outlet of each test chamber. These thermistors have an accuracy of about $\pm 0.1^{\circ} \mathrm{C}$, and their reading are averaged to obtain the temperature needed to correct the gain measurements.

\section{E. Precision Barometer (Setra 270)}

The barometer has a precision of about $\pm 0.2 \mathrm{mmHg}$. It is used to correct the chamber gas gain for ambient atmospheric pressure changes: since the exhaust of the chamber is at atmospheric pressure (the pressure drop across the exhaust lines is insignificant), the pressure needed to correct the gain measurements is obtained directly. 


\section{F. High Voltage Power Supply (Bertan 375P, 1755P)}

These $0-5 \mathrm{kV}$ supplies are stable to about $\pm 0.2 \mathrm{~V}$ when running at a typical voltage of $2-3 \mathrm{kV}$.

\section{G. Analog Scanner (Hewlett-Packard 3495A)}

This unit provides switching ( 40 channels) for ihe DMM to sample the analog instruments described above.

\section{H. Picoammeter (Keithley 485)}

The current flowing through the wire chamber is monitored by a picoammeter connected between the cathode (wire chamber outer shell) and the HV ground. Digitization is done in the picoammeter. (See also section D.3.B and Fig. D.3.)

\section{IBM PC/AT Computer}

This is the principal data retrieval device and analytical instrument for wire aging tests. Digitized measurements from the DMM and picoammeter are collected by the computer at programmed intervals and stored onto a hard disk memory. The computer is also used to plot the current vs. collected charge or time, and to fit this curve to determine the aging rate.

Various other utility programs are available on the computer for analysis and plotting, and for driving the laser printer. These programs are largely menu-driven and should not require explicit instructions.

\section{J. GPIB Interface Bus (National Instruments GPIB-PC2)}

Communication between the instruments (DMM, picoammeters, scanner) and the computer occurs via a general purpose interface bus (GPIB), the IEEE 488 standard. Software to control the GPIB is written in FORTRAN. 


\section{K. Pulse Height Analyzer (Nucleus Personal Computer Analyzer)}

The computer is equipped with a Nucleus Personal Computer Analyzer pulse height analysis card, which is used to probe the gain uniformity along the anode wire as a measure of wire deposits. This is normally done using $\mathrm{Ar} / \mathrm{C}_{2} \mathrm{H}_{6}(50 / 50)$ and a weak, collimated ${ }^{55} \mathrm{Fe}$ source. The ratio of FWHM of the main peak to the pulse height is $16-18 \%$ for a clean wire.

\section{Laser printer (Hewlett-Packard Laserjet II)}

This printer communicates with the IBM PC/AT and with other computers in the room, and prints out in graphics mode or in text mode in a variety of fonts.

\section{D.3 Wire Chamber}

\section{A. Tube Fabrication}

Wire chambers are presently made from copper tubes 0.5 inch OD $\times 0.375$ inch ID. The ends are flared as indicated in Fig. D.2b to accomodate feedthrough insulators, which are made of molded fiberglass and epoxy composite. The feedthroughs are sealed in the ends using Hardman 04001 extra fast setting epoxy. The anode wire (50 $\mu \mathrm{m}$ dia) is crimped into a capillary tube ( $200 \mu \mathrm{m}$ ID) molded into the feedthrough. The wires are under about $150 \mathrm{~g}$ tension (for $\mathrm{Au} / \mathrm{W}$ wire; less tension is used for weaker wire materials). Two electrodes are molded into the feedthroughs. One electrode makes contact with the capillary tube (anode), the other makes contact with the wall of the chamber (cathode). A window for entry of source radiation is cut through the tube wall and covered with 0.0005 inch aluminum foil, using Hardman 04001 epoxy to make the gas seal. The source is rigidly affixed to the tube during tests using a small copper frame that holds the source and clamps onto the tube.

At the conclusion of tests, the wire is removed from the counter. A segment of the wire $\sim 9 \mathrm{~cm}$ long with the irradiated region in its center is secured with Scotch tape (3M No. 810 or equivalent) to a strip cut from a cardboard index card. (Care is taken to ensure that the tape does not touch the irradiated region.) The wire 
and its cardboard mount are stored in a glass culture tube with a screw cap and saved for future surface analysis. The feedthroughs and window are removed and discarded. The tube is then cleaned ultrasonically using isopropanol, a new window and feedthroughs are installed, and the tube is restrung with a new anode wire.

\section{B. HV Distribution Box}

The electrodes are connected to the HV power supply through a small local distribution box having a $1 \mathrm{M} \Omega$ series resistor in the anode lead. A signal suitable for an oscilloscope monitor or the pulse height analyzer is provided through a blocking capacitor. The electrical schematic of the HV distribution box is shown in Fig. D.3.

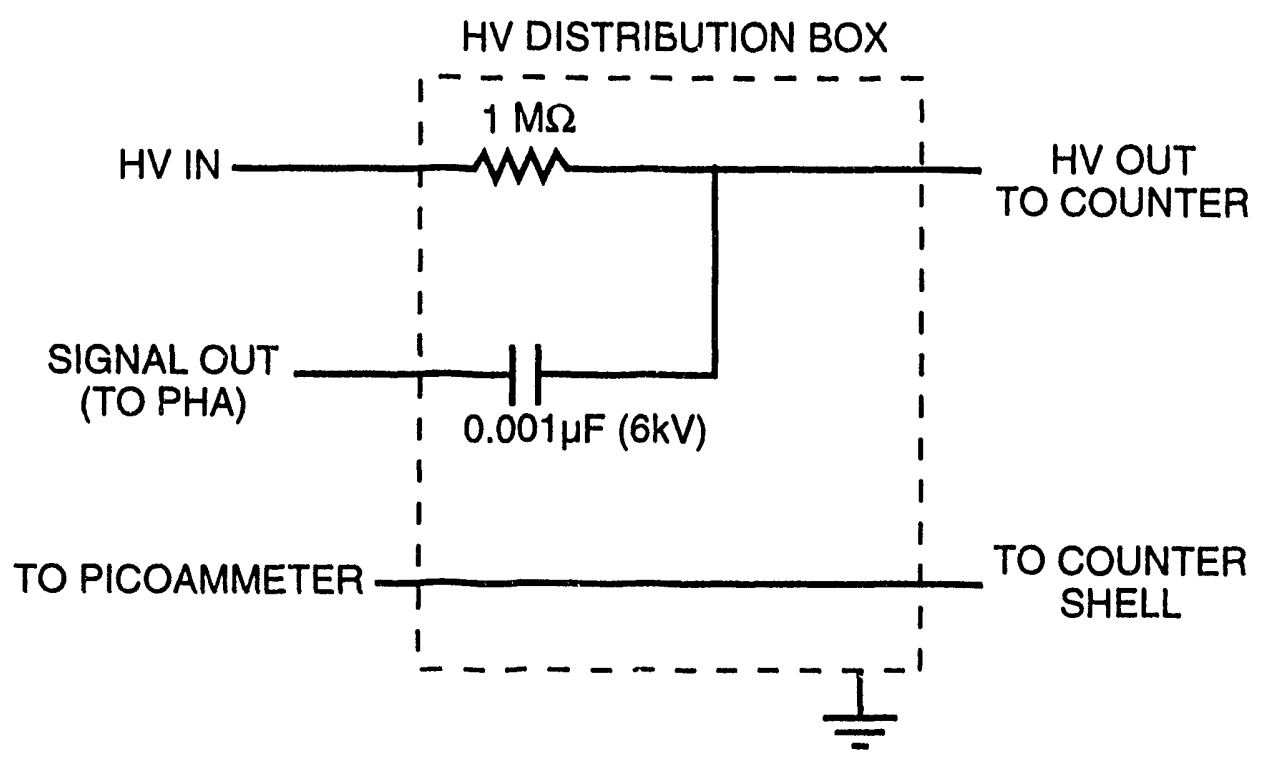

XBL 927.5276

Figure D.3: Electrical schematic of the HV distribution box.

\section{D.4 Gas Plumbing and Safety Shutoff System}

The gas used for wire aging tests is contained in steel cylinders at pressures generally less than 700 psig, although a few gases previously used had pressures as high as 2000 psig. We have found it unnecessary to have pressures much above a few hundred 
psig, as the amount of gas in a $1 \mathrm{~A}$ cylinder at this pressure is sufficient for most aging tests. Metal plumbing components used have pressure capabilities in excess of 2000 psig.

A pneumatically operated gas safety shutoff valve is located a few inches downstream of the gas cylinder outlet port and upstream of the gas regulator, and is operated in the normally-closed mode. The actuation pressure, $\sim 90 \mathrm{psig}$, is obtained from a dedicated nitrogen cylinder, the house air pressure being marginally low. The nitrogen is controlled by a solenoid, which is operated by a flammable gas alarm with a detector head above the gas cylinders. The solenoid also operates in the normallyclosed mode, and vents the pneumatic line to the gas safety shutoff valve at the same time that the nitrogen is cut off, so that the safety valve closes immediately. Thus, the gas for the tests is immediately interrupted at the gas cylinder if any of the following occur: 1) the flammable gas alarm is activated, 2) AC power is lost, or 3) the nitrogen actuation pressure drops too low.

Immediately downstream of the shutoff valve is a two-stage pressure regulator (Matheson 3803 or 3813 ). On the low pressure (5-10 psig) side of the regulator, nylon, copper, or stainless steel tubing is used to carry the test gas a few feet to the test area, where it connects to a pinch valve that further regulates the gas flow. The three types of tubing are used with different purposes in mind, since they have distinctly different effects on the tests due to differences in their outgassing characteristics.

Filtering or other conditioning of the gas, if any, is done between the regulator and the pinch valve. Filtering is done mainly to remove oxygen, water vapor, or halogenated impurities. Supelco OMI-1 indicating filters have been used to purify hydrocarbon and argon/hydrocarbon gases. Semi-Gas Systems L-60 Nanochem filters have been used to purify $\mathrm{CF}_{4}$. To add components to the gas stream, we use a KinTek 570C Precision Gas Standards Generator ("permeation device"). The theory and practice of gas permeation have been described elsewhere [2,3].

The pinch valve is a piece of stainless steel tubing (3/16 inch OD, 0.032 inch wall) which has been flattened to create the flow restriction for the very small flow rates involved in these tests (typically $10 \mathrm{~cm}^{3} / \mathrm{min}$ ). Commercially available valves either were not sufficiently restrictive or contained plastics that outgassed, thereby affecting 
the tests. A wide range of stable gas flow rates could be obtained by compressing the flattened portion of the pinch valve and/or adjusting the gas pressure.

Immediately downstream of the pinch valve is the test chamber, to which is attached a radioactive source, two thermistors, and the electrical supply leads. The exhaust of the test chamber passes through a rotameter and an electronic flowmeter, and then to a vent manifold, which ultimately exhausts to the atmosphere outside the building.

\section{D.5 Test Startup Procedures}

\section{A. Gas Leak Check}

When the test chamber has been installed and ail plumbing has been connected and secured, a leak detector is used on each connection of the plumbing system. For flammable gases, a portable detector (Sierra Monitor Corporation 2000) is used. This instrument is extremely sensitive, and responds unambiguously at less than $10 \mathrm{ppm}$ of flammable gas. Dimethyl ether is known to give a very strong response at a level of $\sim 10^{-3} \mathrm{~cm}^{3} / \mathrm{min}$. For nonflammable gases, a different detector (Matieson Leak Hunter 8065) is used or, alteriatively, a flammable gas such as $\mathrm{Ar} / \mathrm{C}_{2} \mathrm{H}_{6}(50 / 50)$ is allowed to flow through the system for the purpose of leak checking, and then the nonflammable gas intended for testing is restored.

\section{B. Electrical Leak Check}

After the gas leak check, the electrical leads are connected to the chamber, and voltage is applied before the ${ }^{55} \mathrm{Fe}$ source is attached. The steady-state current at the nominal operating voltage (usually $\sim 2000 \mathrm{~V}$ for Ar-based gases or $\sim 3000 \mathrm{~V}$ for $\mathrm{CF}_{4}$-based gases) should be at most a few nanoamperes, and is usually much less: some leakage can be expected on the surface of the insulating feedthrough material, especially on the Hardman 04001 epoxy, which is somewhat hygroscopic. If leakage currents are excessive, the electrical contacts and surrounding regions of the feedthrough must be cleaned by scraping off the excess epoxy. After starting an aging test, leakage currents generally decrease within a day or so. 


\section{Pinch Valve Adjustment and Gas Flow Regulation}

The gas flow is regulated by a combination of the gas pressure at the outlet of the pressure regulator and the orifice aperture $\left(\mathrm{C}_{\mathrm{v}}\right)$ of the pinch valve. The latter adjustment is accomplished by changing the force on a steel pin lying across the flattened portion of the $3 / 16$ inch OD stainless steel tubing; this is done with a machinists parallel clamp. The gas flow rate can be varied over a range of about one order of magnitude with the pinch valve.

\section{Calibration of Gas Flow}

The response of the rotameter and electronic flowmeters depend on the gas mixture, and therefore must be calibrated. This is done, to an accuracy of about $\pm 10 \%$, by using a bubble flow meter. This accuracy is adequate because aging test results have been determined to be relatively insensitive to the gas flow rate.

\section{E. Chamber Bakeout and Equilibration}

Some residual air and moisture exist in the chamber when it is first installed, and the outgassing of these can affect the chamber operation. Accordingly, a period of at least $1 / 2$ day is normally reserved for flowing gas with the full HV present before the ${ }^{55} \mathrm{Fe}$ source is installed and the actual test is begun.

\section{F. Thermistor Attachment}

Two thermistors are attached to the chamber, one near the entrance of the tube and the other near the exit. This is accomplished using a narrow ( $\sim 4 \mathrm{~mm}$ wide) piece of aluminum adhesive tape.

\section{G. Selection and Attachment of Radioactive Source}

Most tests are run with currents of 200-400 $\mathrm{nA}$ and at a gain in the region of 20,00050,000. The source strength and HV are chosen to accomplish this: ${ }^{55} \mathrm{Fe}$ sources are available in the range $\sim 0.2-2.0 \mathrm{mCi}$, and thin aluminum foil shims can be used to attenuate the $\mathrm{x}$-ray intensity (attenuation factor of $\sim 2.5$ per 0.001 inch shim). The 
sources are mounted on a 1 inch diameter disk, which is held by a copper frame that attaches firmly to the chamber tube so as to hold the active region of the source directly over the aluminum foil window of the chamber. By adjusting the source axially and azimuthally, the tube current is maximized to ensure that the source is directly over the window.

\section{H. Setting Initial Parameters and Starting Test Run}

The gas flow is adjusted to the desired value (not critical), and the HV is adjusted to obtain the desired current (also not critical), and the run is commenced. All parameters (HV, current, two thermistor readings, barometer, and electronic gas flowmeter) are recorded for this initial reading, as well as at least once per day during the run. Other information relevant to the run is also recorded: the type of gas, the gas bottle label code, the type and diameter of the wire in the chamber, the cathode material, the type of plumbing used, the source identification label and strength, and the attenuation shims used (if any).

\section{D.6 Mid-Run Activities}

\section{A. Log Book Records}

Once per day, or more often as needed, a record is kept in tabular form of the six values read out by the computer. In addition, the date, time (PST always), computer file record number, and sampling rate are recorded. Other comments relevant to the run are recorded in the text of the log book as necessary.

\section{B. Inspection of Intermediate Results}

The graphing and analytic capabilities of the computer are used frequently to observe the progress of the run. The current vs. collected charge is the most relevant and useful plot, and it can give evidence for anomolous behavior, which could change the objectives and program for the run. Such plots are viewed without affecting the data collection cycle. Occasionally, it is desirable to use a fitting program, a macro written for LOTUS 1-2-3, to obtain a quantitative measure of the aging rate. 


\section{Checking HV}

High voltage is checked directly at the front panel of the DMM since there is significant noise introduced in this channel by the scanner, resulting in loss of the needed accuracy of $\sim 1 \mathrm{~V}$. We have found that the front panel readings typically vary by only 0.1-0.2 V during the course of a run.

\section{Pressure and Temperature Correction}

Gas gain, and therefore the measured anode current, is a function of gas density. Thus, when analyzing $\mathrm{d} i \mathrm{ta}$, it is necessary to correct the measured current for changes in gas temperature and pressure. Temperature changes are mainly diurnal, while pressure changes are driven by prevailing weather patterns.

The current for each record number, $n$, is corrected according to the following formula:

$$
I_{n}^{\prime}=\frac{I_{n}}{\left(c_{n}\right)^{\alpha}} ; \quad c_{n}=\frac{P_{0} T_{n}}{P_{n} T_{0}}
$$

where $\alpha$ is the density dependence of gas gain (typically, $4<\alpha<7$ ). The correction factor, $c$, is calculated assuming ideal gas behavior.

\section{D.7 Termination of Runs}

\section{A. Decision to End Runs}

This decision is normally dictated by the degree of accuracy needed on the aging rate. If there is little aging, a longer run will be needed to determine the aging rate with some reliability; if the aging is rapid, a shorter test run will be sufficient. The criterion for the amount of charge collected during a run may be the amount of charge estimated to be collected in an anticipated experiment (e.g., at the SSC).

\section{B. Gas Leak Check}

An additional check for gas leaks is done to determine whether the test may have been influenced by a leak opening up during the course of the run. 


\section{Pulse Height Analysis}

Deposits on the wire can most sensitively be detected by examining the pulse height spectrum using an argon-based gas mixture $\left(\mathrm{Ar} / \mathrm{C}_{2} \mathrm{H}_{6}(50 / 50)\right.$ is our standard) and a collimated ${ }^{55} \mathrm{Fe}$ source. Pulse height spectra should be acquired at this time if desired. Refer to the Nucleus Personal Computer Analyzer instruction manual, and use the labelling scheme as indicated in the log book to denote PHA files.

\section{Shutdown of Apparatus}

The shutdown consists of shutting off the HV, closing off the gas supply at the gas bottle, removing the source and storing it in the source cabinet, and removing the test chamber. The chamber should be marked with the run number, and either stored or recycled to prepare it for a new run. Plugs or caps are placed on the chamber plumbing connections to minimize contact with atmosphere and dust during the period of nonuse.

\section{D.8 Addresses of Suppliers}

Bertan Associates, 121 New South Rd., Hicksville, NY 11801, ph. 516-433-3110.

Hardman, Inc., 600 Cortlandt Rd., Belleville, NJ 07109, ph. 210-751-3000.

Hewlett-Packard Co., PO Box 303, Loveland, CO 80537.

Keithley Instruments, 28775 Aurora Rd., Cleveland, OH 44139, ph. 216-248-0400.

Kin-Tek Laboratories, PO Drawer J, 2315 Palmer, Texas City, TX 77590, ph. 409-945-4529.

Matheson Gas Co., 6775 Central Ave., Newark, CA 94560, ph. 510-793-2559.

National Instruments, 12109 Technology Blvd., Austin, TX 78727, ph. 512-250-9119.

the Nucleus, Inc., 761 Emory Valley Rd., Oak Ridge, TN 37831, ph. 615-482-4041.

Omega Engineering, One Omega Dr., Box 4047, Stamford, CT 06907, ph. 203-359-1660.

Semi-Gas Systems, Inc., 625 Wool Creek Dr., San Jose, CA 95112, ph. 408-971-6500.

Setra Systems, Inc., 45 Nagog Park, Acton, MA 01720, ph. 508-263-1400.

Sierra Monitor Corp., 1991 Tarob Ct., Milpitas, CA 95035, ph. 408-262-6611.

Supelco, Inc., Supelco Park, Bellefonte, PA 16823, ph. 814-359-3441.

Yellow Springs Instruments, Yellow Springs, OH 45387, ph. 513-767-7241. 


\section{References}

[1] J. Kadyk, J. Wise, D. Hess and M. Williams, IEEE Trans. Nucl. Sci., NS-37 (1990) 478.

[2] (a) A.E. O'Keeffe and G.C. Ortman, Anal. Chem., 38 (1966) 760; (b) Correction, Anal. Chem., 41 (1969) 1598.

[3] F.P. Scaringelli, A.E. O'Keeffe, E. Rosenberg, and J.P. Bell, Anal. Chem., 42 (1970) 871. 

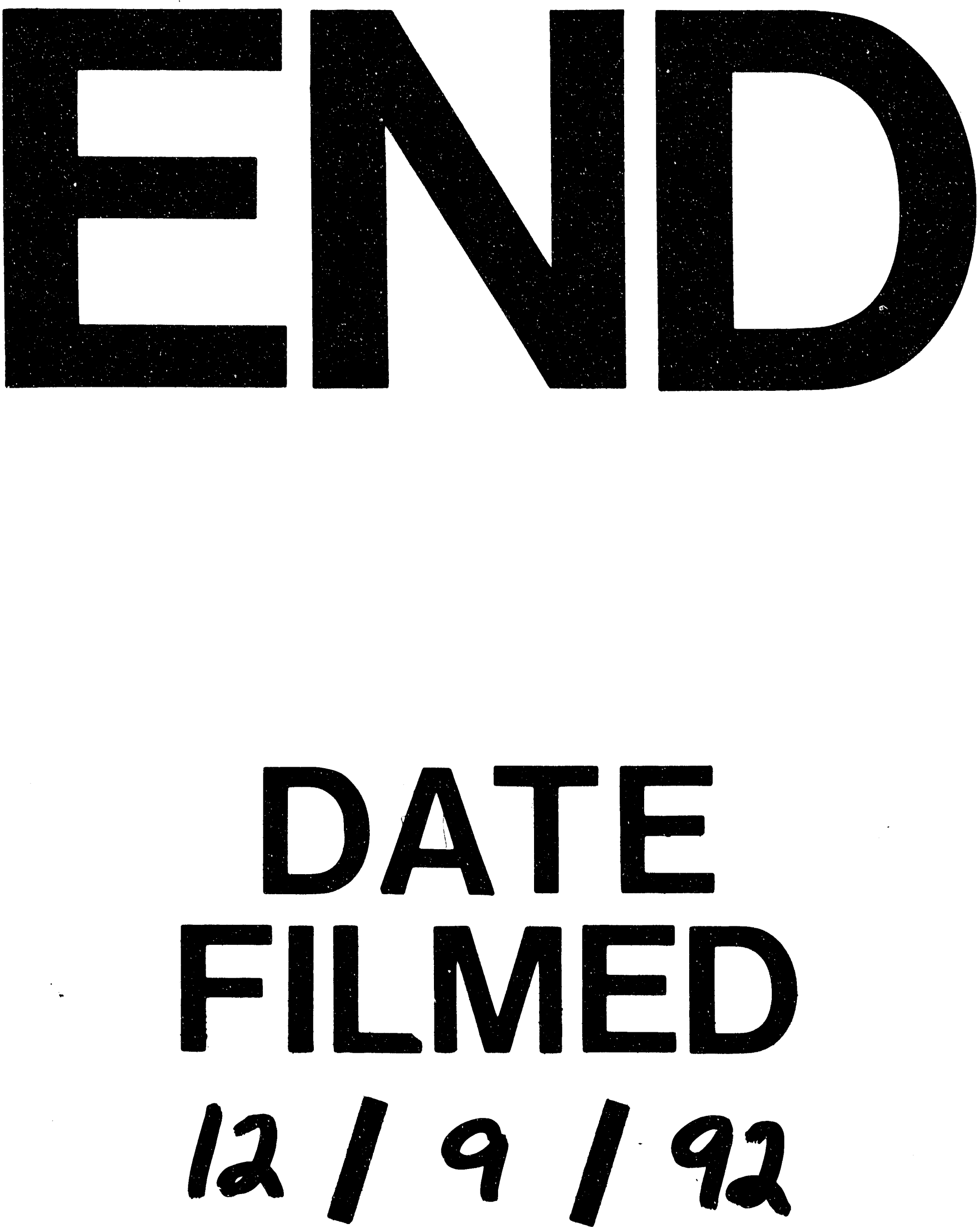
